\title{
Discursos y prácticas de
}

la educación superior intercultural La experiencia de Chiapas
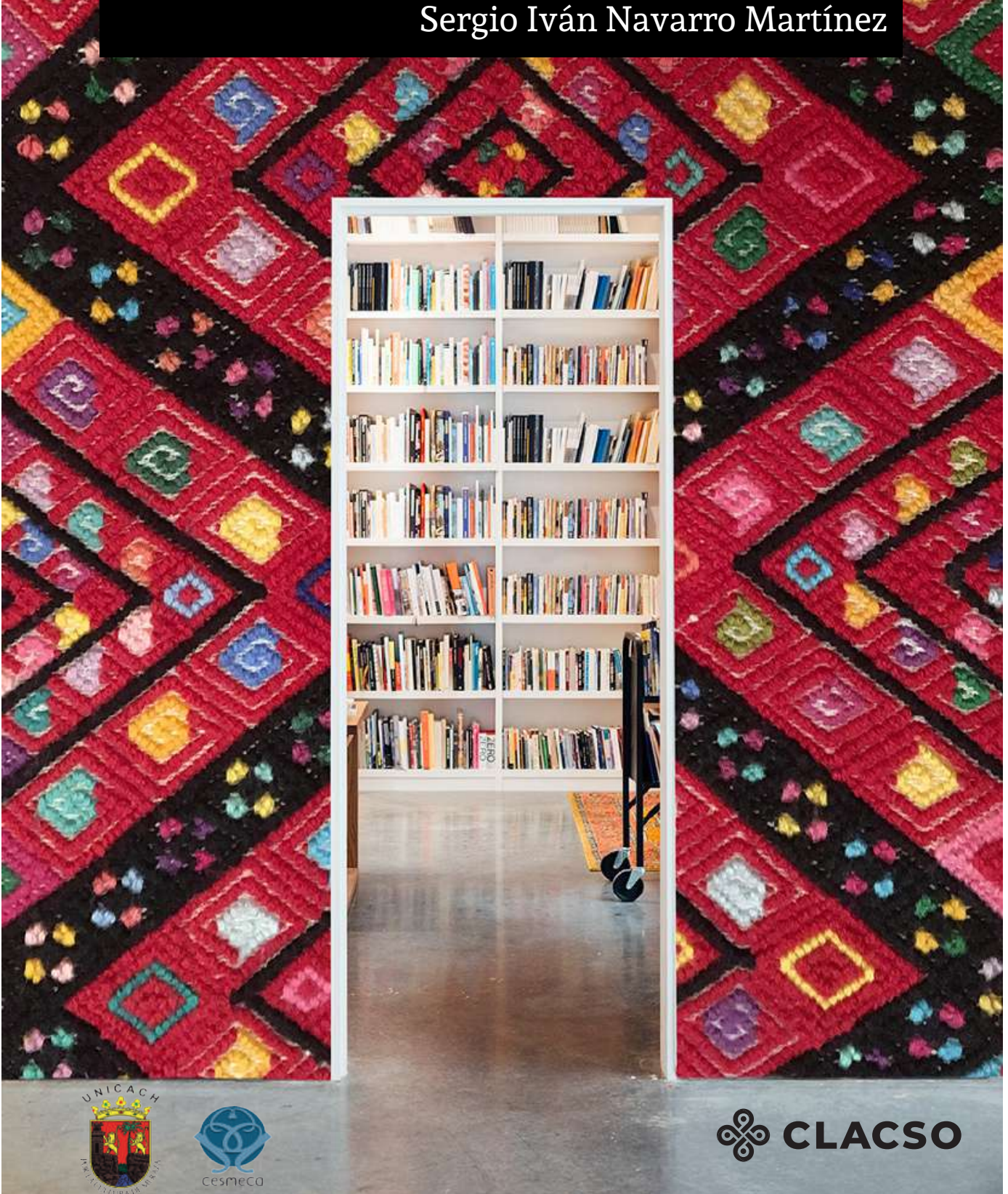


\section{Discursos y prácticas de la educacion superior intercultural}

La experiencia de Chiapas 



\section{Discursos y prácticas de la educacion superior intercultural}

La experiencia de Chiapas

Sergio Iván Navarro Martínez
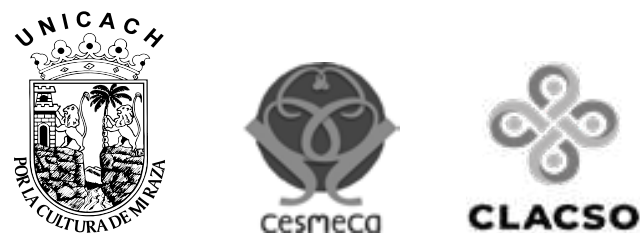

Universidad de Ciencias y Artes de Chiapas Centro de Estudios Superiores de México y Centroamérica Consejo Latinoamericano de Ciencias Sociales (CLACSO) 
Navarro Martínez, Sergio Iván

Discursos y prácticas de la educación superior intercultural: La experiencia de Chiapas /

Sergio Iván Navarro Martínez.-- 1a. ed.-- Tuxtla Gutiérrez, Chiapas: Universidad de Ciencias y Artes de Chiapas, Buenos Aires: CLACSO, 2020.

216 páginas: $14 \times 21$ centímetros.

ISBN 978-607-543-116-1

1. Educación superior (universidad intercultural) - Desarrollo educativo-sociocultural. 2.

Educación superior (universidad intercultural) - Vinculación comunitaria - Población rural. 3. Educación superior (universidad intercultural) - Desarrollo académico - Población rural.

ISBN 978-607-543-116-1

D.R. (c) Universidad de Ciencias y Artes de Chiapas

1a Av. Sur Poniente 1460

29000, Tuxtla Gutiérrez, Chiapas, México

www.unicach.edu.mx

Centro de Estudios Superiores de México y Centroamérica

Calle Bugambilia 30, Fracc. La Buena Esperanza

29243, San Cristóbal de Las Casas, Chiapas, México

Tel.: (0052967) 67869 21, ext. 106

www.cesmeca.unicach.mx

editorial.cesmeca@unicach.mx

D.R. ( ) Consejo Latinoamericano de Ciencias Sociales (CLACSO)

Estados Unidos 1168

C1023AAB, Ciudad de Buenos Aires, Argentina

Tel. (005411) 43049145

www.clacso.org

Editado en México

\section{- LiBRERIA LATINOAMERICANA Y CARIBENA DE CIENCIAS SOCIALES CONOCIMIENTO ABIERTO, CONOCIMIENTO UBRE}

Los libros de CLACSO pueden descargarse libremente en formato digital o adquirirse en versión impresa desde cualquier lugar del mundo ingresando a www.clacso.org.ar/libreria-latinoamericana

No se permite la reproducción total o parcial de este libro, ni su almacenamiento en un sistema informático, ni su transmisión en cualquier forma o por cualquier medio electrónico, mecánico, fotocopia u otros métodos, sin el permiso previo del editor.

La responsabilidad por las opiniones expresadas en los libros, artículos, estudios y otras colaboraciones incumbe exclusivamente a los autores firmantes y su publicación no necesariamente refleja los puntos de vista de la Secretaría Ejecutiva de CLACSO.

Este libro ha sido dictaminado por pares académicos, quienes garantizan su calidad, actualidad y pertinencia. Asimismo, la obra fue aprobada por el Consejo Editorial del CESMECA-UNICACH con apego a los procesos de aseguramiento de la calidad editorial. 


\section{ÍNDICE}

Prólogo. Gunther Dietz

Introducción

Capítulo 1. La interculturalidad: una aproximación teórica

Políticas de tratamiento a la diversidad

La multiculturalidad en Estados Unidos y Europa

Multiculturalidad, interculturalidad y educación intercultural en Latinoamérica

Latinoamérica y el pensamiento decolonial

Propuestas de educación superior intercultural en Latinoamérica

La práctica de la educación intercultural

La vinculación comunitaria desde una propuesta educativa intercultural

Capítulo 2. El contexto de la educación superior intercultural en México

La interculturalidad en el ámbito educativo: el caso mexicano

Propuesta emergente de "abajo hacia arriba”: CESDER-Moxviquil

Propuesta institucional de "arriba hacia abajo": UNICH-Oxchuc

Capítulo 3. Entre la resignificación y la institucionalización de la educación superior intercultural en Chiapas

Análisis de la interculturalidad

Cuestionamiento de las relaciones de poder entre las culturas

Establecimiento de relaciones para el enriquecimiento de la experiencia de vida 
Reafirmación como sujetos ante la vida

Re-producción de lementos culturales

130

Análisis de las prácticas educativas

136

El papel del personal docente

136

¿Cómo se enseña y aprende desde la educación intercultural?

140

¿Qué se enseña y para qué se enseña en la

146

educación intercultural?

Construcción de capacidades para la vinculación comunitaria

155

Estrategias de acercamiento:

universidad-comunidad-organizaciones

155

Alternancia educación/producción

Estancias en organizaciones sociales de la región

172

Desafíos de la vinculación comunitaria

179

Análisis integral de las experiencias de formación

185

CESDER-Moxviquil

185

UNICH-Oxchuc

Conclusiones

Referencias

197 


\section{Agradecimientos}

Este libro representa el esfuerzo y dedicación de muchas personas que directa o indirectamente contribuyeron en el proceso de la investigación. Agradezco a aquellas con las que he coincidido a través de los años; con su particular forma de ver, entender y sentir la realidad, hemos construido reflexiones, experiencias y conocimientos que han abonado al presente escrito.

Agradezco al personal docente y estudiantes del Centro de Formación para la Sustentabilidad Moxviquil, A.C. y de la Universidad Intercultural de Chiapas por la confianza y las facilidades que me concedieron para realizar el trabajo de campo en sus instalaciones y por compartirme sus experiencias y reflexiones generadas desde la interculturalidad. Mi gratitud es también para el Consejo Nacional de Ciencia y Tecnología por brindarme apoyo financiero a través del Centro de Estudios Superiores de México y Centroamérica de la Universidad de Ciencias y Artes de Chiapas (CESMECA-UNICACH) durante mis estudios de doctorado. De igual forma, deseo agradecer a Edgar Sulca, Antonio Saldívar, Gunther Dietz, Flor Marina Bermúdez y Saúl Velasco, por sus valiosas sugerencias y acompañamiento en todo el proceso de investigación. Igualmente aprecio las reflexiones compartidas con Felipe Galán sobre la educación intercultural y su amistad.

Mi gratitud también es para docentes, directivos y personal administrativo del CESMECA, Instituto en el que me he formado y donde he cosechado entrañables vínculos de fraternidad. Agradezco a Jesús Solís, Mónica Aguilar y Carlos de Jesús Gómez por las gestiones realizadas para la publicación del presente libro, así 
como al personal del área editorial del CESMECA-UNICACH, en especial a Isabel Rodríguez, por su dedicación y cuidado editorial. En ese tenor agradezco a la Dirección de Formación y Producción Editorial de CLACSO, en particular a Nicolás Arata, por aceptar colaborar en la coedición de esta obra.

A mi familia por el apoyo incondicional que me ha brindado para alcanzar mis sueños, en especial a Zury por ser mi cómplice en la consolidación de nuestras metas como familia. A Natalia e Iker por construir conmigo momentos de felicidad que han sido una fuente de inspiración. A mi madre por su cariño y palabras de aliento en todo momento. A la memoria de mi padre y de mis ancestros. 


\section{Prólogo}

En toda América Latina los sistemas educativos nacionales vienen arrastrando una importante deuda histórica con los pueblos originarios y con sus juventudes, a quienes se les ha negado el acceso a los diferentes niveles educativos o se les ha proporcionado una educación de baja calidad, descontextualizada, y cultural y lingüísticamente impertinente y enajenante. Mientras que en los primeros niveles de la educación inicial y primaria en México esta exclusión se ha ido revirtiendo paulatinamente, desarrollando una educación denominada intercultural y bilingüe con ciertos avances - siempre limitados - en cuanto a pertinencia cultural, en el uso académico de la lengua propia y en la vinculación escuela-comunidad, es en la educación superior donde la exclusión histórica y la discriminación hacia las y los jóvenes indígenas persisten de forma más alarmante. Muy recientemente, a finales de junio del año en curso [2020], el propio subsecretario de Educación Superior, el Dr. Luciano Concheiro Bórquez, calificó como "brutal desigualdad" el hecho de que únicamente un 1.2\% de las y los jóvenes hablantes de alguna lengua originaria de México logren ingresar a la educación superior (El Universal, "Jóvenes que hablan lenguas indígenas, en 'brutal desigualdad' en educación”, 29/06/2020).

Ante esta deuda histórica, a veces tildada algo eufemísticamente de "rezago educativo", en diferentes países latinoamericanos han ido surgiendo en las últimas dos décadas iniciativas novedosas de educación superior, más o menos heterodoxas, que procuran dar acceso a la juventud indígena, a la vez que proponen ofrecer programas educativos no convencionales, no enajenantes y no 
asimilacionistas. En México, una estrategia gubernamental federal denominó a estas iniciativas "universidades interculturales", término tal vez algo desafortunado ya que pareciera sugerir que estas universidades interculturales de nueva creación redimieran a las instituciones de educación superior (IES) ya existentes de interculturalizarse, de transformarse en universidades incluyentes respecto a los pueblos originarios y a otras comunidades históricamente subrepresentadas.

Como universidades interculturales entendemos desde entonces estas nuevas instituciones educativas de fuerte vocación regional, a menudo asentadas dentro de o cerca de una región históricamente indígena o multiétnica, que se dirigen particularmente a aquella juventud rural, indígena, afrodescendiente o campesina que no ha podido acceder a la educación superior, pero que aspira a culminar sus estudios universitarios con un proyecto de vida personal y profesional relacionado con su comunidad o región de origen. Esta novedosa orientación hacia la pertinencia local y regional de los programas de estudio genera grandes interrogantes educativos y académicos: ¿qué programas de estudio sirven para profesionalizar a jóvenes indígenas sin obligarlos a abandonar sus comunidades durante o después de sus estudios universitarios, como ha ocurrido con tantas generaciones de "fuga de cerebros" del campo a la ciudad, del mundo comunitario y macehual al mundo urbano, a la empleabilidad individual y al abandono de la lengua propia?

Es a esta gran interrogante a la que responde el libro Discursos y prácticas de la educación superior intercultural: la experiencia de Chiapas que nos presenta Sergio Iván Navarro Martínez. Ya disponemos de una serie de investigaciones empíricas dedicadas a distintos casos de universidades interculturales en México - Mateos Cortés y Dietz $(2013)^{1}$ ofrecen un primer balance del estado del conocimien-

\footnotetext{
${ }^{1}$ Mateos Cortés, Laura Selene y Gunther Dietz (2013). "Universidades interculturales en México”. En María Bertely Busquets, Gunther Dietz y María Guadalupe Díaz Tepepa (coords.), Multiculturalismo y educación 2002-2011. México: Consejo Mexicano de
} 
to sobre estas nuevas IES-, pero lo distintivo, novedoso y llamativo del presente libro consiste en que el autor analiza de forma comparativa y contrastiva dos tipos de universidades interculturales, aplicando las mismas preguntas, acompañando al mismo tipo de actores y generando así inéditas "miradas cruzadas" entre ambas experiencias. En un caso, se trata de una de las decanas de las universidades interculturales creadas por un decreto oficial entre el gobierno federal y un gobierno estatal; la Universidad Intercultural de Chiapas (UNICH) es una IES pública que ofrece programas educativos tanto en su sede urbana en San Cristóbal de Las Casas, como en sus sedes rurales. El autor eligió la Sede Oxchuc, donde la UNICH imparte la Licenciatura en Desarrollo Sustentable, precisamente para poder compararla con otra IES activa en la región, pero que constituye una iniciativa no gubernamental. En Moxviquil, el Centro de Estudios para el Desarrollo Rural, A.C. (CESDER) ofrece la Licenciatura en Planeación del Desarrollo Rural.

Con esta selección muy acertada de dos programas educativos temática y profesionalmente afines, impartidos en contextos rurales e indígenas comparables, Sergio Navarro despliega una investigación etnográfica con docentes y estudiantes de una institución educativa pública gubernamental y de otra institución educativa de tipo no gubernamental. Esta distinción no se limita a la figura jurídica y al carácter público versus privado, sino que tiene implicaciones acerca de cómo se concibe la interculturalidad: como detalla el autor desde un inicio, en un caso la interculturalidad universitaria es concebida "desde arriba hacia abajo", mientras que en el otro caso se trata de una noción pensada "desde abajo hacia arriba".

Para lograr una comparación coherente y convincente, el autor no solamente selecciona IES, campus y licenciaturas comparables, sino que además centra su acompañamiento etnográfico y su análisis de datos en tres ámbitos temáticos que la investigación educativa ha identificado como claves para determinar la interculturalidad,

Investigación Educativa, A.C., pp. 349-381. 
la pertinencia y el logro educativo de estas nuevas universidades. En primer lugar, el análisis empírico se centra en el ya mencionado concepto central de interculturalidad que se maneja en cada una de las IES; aunque al interior de muchas universidades interculturales obviamente coexisten distintas ideas, experiencias y normativas en cuanto a lo intercultural, es posible identificar en el discurso oficial de las instituciones públicas gubernamentales una tendencia a concebir lo intercultural como algo que promueve el entendimiento y la armonía entre miembros de diferentes culturas, mientras que en las iniciativas más autónomas y críticas hacia las relaciones de poder históricas tanto como actuales, la interculturalidad se torna una herramienta para descifrar y desenmascarar las asimetrías de poder, las exclusiones seculares y sus consecuencias en las relaciones interculturales contemporáneas, necesariamente conflictivas.

El segundo eje de análisis que caracteriza la comparación que realiza el autor en esta investigación lo constituyen las prácticas educativas: ¿qué se enseña en las clases tanto como en las actividades extraáulicas?, ¿cómo se enseña, cómo se aprende en una universidad intercultural? La densidad etnográfica con la que para ambas instituciones y carreras se describen y analizan estas prácticas constituye una gran aportación empírica, ya que en muchas investigaciones el análisis se limita al discurso oficial de la institución, mientras que aquí se narran y contrastan las experiencias de docentes y de estudiantes para identificar modelos didácticos subyacentes, uno más centrado en lo individual y lo cognitivo y otro más propenso a lo colectivo y lo procesual.

Y en tercer lugar Sergio Navarro elige una de las "señas de identidad" que en el discurso oficial caracteriza a toda universidad intercultural, la vinculación comunitaria, para identificar y contrastar formas de entender y de practicar los procesos de vinculación entre la IES y su entorno más cercano, las comunidades indígenas que pretende atender y beneficiar. Me resulta particularmente lograda la selección de este eje de análisis ya que en la vinculación pretendidamente profunda, sincera y duradera con 
las comunidades reside la legitimidad y, en cierto sentido, la razón de ser de las universidades interculturales. El contraste entre la UNICH y el CESDER arroja importantes divergencias: mientras que en un caso la vinculación se concibe desde la exterioridad institucional - la IES y sus actores son percibidos como externos a la región, que requieren de proyectos explícitos para vincularse con actores comunitarios-, en el otro caso la vinculación se construye de forma más cotidiana, articulada y fluida a través de procesos formativos que incluyen a estudiantes, pero igualmente a comunidades y a organizaciones de la sociedad civil.

Estos resultados, fruto de un conocimiento íntimo de ambas realidades institucionales, pero igualmente de un acompañamiento etnográfico de largo aliento, respeto y compromiso, son de suma relevancia para la educación superior intercultural, en particular, y para la investigación educativa, en general. Hoy en día, y más aún en crisis civilizatorias como la que estamos viviendo, toda institución educativa se ve desafiada a transformarse, a reinventarse y a repensarse "desde abajo", desde sus contextos de incidencia local y regional.

Una noción procesual y crítica de interculturalidad será una herramienta indispensable en este proceso de desaprender y reaprender en el que todos los actores educativos estamos necesariamente inmersos. En contextos de desigualdad y de exclusión, ¿qué relaciones sociales tanto como educativas requerimos tejer, en función de qué tipo de diversidad y de identidad?, ¿qué prácticas de enseñanza-aprendizaje son lo suficientemente pertinentes, contextuales, inductivas como para dotar de sentido a todo aprendiente?, ¿cómo enseñar y aprender más allá del individuo atomizado, en redes de actores, en comunidades y organizaciones?, ¿qué vínculos requerimos establecer y cultivar entre estos actores internamente diversos, que aportan distintos tipos de saberes, algunos más académicos y descontextualizados, otros más comunitarios y vivenciales? Obviamente, el presente libro no puede responder en términos generales a todas estas inquietantes, aunque necesarias, interrogantes, pero 
aporta, a través de la comparación entre dos IES muy disímiles, muchas pistas para la reflexión, para la crítica y para la transformación educativa.

Por último, lo mejor que se puede decir de un libro producto de una tesis doctoral es que en nada ya se parece a una tesis. El libro se nutre de los resultados de una investigación doctoral sumamente original y exitosa, por cierto galardonada con el Premio de la Cátedra Gonzalo Aguirre Beltrán 2017 para Tesis Doctoral en Antropología y Disciplinas Afines que otorgan la Universidad Veracruzana y el Centro de Investigaciones y Estudios Superiores en Antropología Social, Unidad Golfo, pero los resultados de esta investigación se nos presentan aquí en el formato de un libro monográfico sumamente narrativo y dialógico, que a través de una polifonía de voces y de experiencias nos conduce hacia lo esencial de la comparación entre dos "experimentos universitarios” igualmente novedosos. Inspirémonos en sus hallazgos, pero también en su camino recorrido, para generar investigaciones tan originales y a la vez tan prácticas en sus resultados y conclusiones, que van mucho más allá de dos universidades y de dos contextos, que nos interpelan a todas y todos quienes aspiramos a transformar y a interculturalizar nuestras instituciones educativas.

Gunther Dietz Julio de 2020 


\section{Introducción}

A principios del siglo XX prevalecía en la sociedad mexicana una desvalorización hacia los pueblos originarios, que eran señalados como parte del rezago y retraso del país y, por tanto, considerados como pueblos que no tenían cabida en un Estado-nación con pretensiones de modernidad. En la actualidad esta percepción continúa; por ejemplo, en la clase política particularmente prevalece una doble moral según la cual, por un lado, se celebra la diversidad cultural y se hacen constantes remembranzas de un pasado glorioso (que puede ser visto en los museos, en zonas arqueológicas y en pasajes de la Guerra de Independencia o de la Revolución mexicana), pero, por el otro, se reniega de la riqueza de las culturas actuales, de sus lenguas y cosmovisiones presentes en muchos territorios, al identificarlas como limitantes para entrar de manera plena a la era de la economía global.

En cuanto a las políticas educativas aplicadas e implementadas en las comunidades indígenas, es necesario reconocer que han sido diseñadas y desarrolladas en torno a los intereses de la sociedad nacional — predominantemente mestiza-, que históricamente ha sido reproductora de los intereses de una cultura hegemónica. Así, la educación oficial se ha encargado de transmitir valores culturales ajenos a los de los pueblos originarios, y ha tratado a toda costa de que los indígenas dejen de ser lo que son mediante su integración paulatina a la sociedad.

Paralelamente los pueblos originarios, desde hace por lo menos cuatro décadas, se han planteado la necesidad de una educación con pertinencia cultural; sus demandas han sido respaldadas por 
diferentes convenios internacionales y arropadas en los movimientos sociales de Latinoamérica. Se ha desafiado el discurso hegemónico al asumir como bandera de lucha la resistencia ante un sistema educativo con pretensiones de homogeneización sociocultural y se ha comenzado a construir una diversidad de propuestas educativas desde, para y con la diversidad.

Así, la atención a la diversidad paulatinamente comenzó a posicionarse en instituciones educativas como respuesta a demandas surgidas de movimientos sociales en Latinoamérica y México, pero también como reflejo de políticas implementadas a nivel global, particularmente de los contextos anglosajón y europeo, con importantes repercusiones en otros entornos.

Para el caso de México, Mateos, Mendoza y Dietz (2013) consideran que el enfoque intercultural surgió en las universidades desde un debate académico-pedagógico, pero, a diferencia de en otros países, no se aplicó en primer lugar a las propias universidades ni a la educación superior, sino, continuando con la tradición indigenista, a la educación básica.

En ese contexto, a partir de la fundación de la Coordinación General de Educación Intercultural y Bilingüe (CGEIB), en 2003, se creó la primera Universidad Intercultural (UI) en el estado de México como una institución: "destinada a formar jóvenes provenientes de regiones indígenas que no han tenido acceso a la educación superior y a quienes se les ofrecen carreras definidas que se imparten en sus propias regiones de origen" (Mateos y Dietz, 2013:349). Con ello se pretendía reorientar una política educativa destinada a sectores de la población que históricamente han enfrentado la "desigualdad que el Sistema Educativo Nacional le ha impuesto” (Casillas y Santini, 2006:19). Desde las UI se busca reforzar la identidad cultural de los estudiantes y que a su vez estos contribuyan al mejoramiento de las situaciones de vida de sus comunidades. Justamente la innovación destacada en los programas de estudio de las UI es que asumen la vinculación comunitaria como una acción sustantiva, a la vez que la conside- 
ran como un eje articulador de las actividades académicas de sus programas de estudio.

Sin embargo, desde la creación de las UI el debate gira alrededor de si la formación que reciben los estudiantes atiende las demandas más apremiantes de su entorno inmediato o si responde más a la lógica economicista de integración al mercado global. Sandoval y Guerra señalan que la diversidad vista desde el Estado es una oportunidad para: "exaltar el adoctrinamiento globalizador y reorientar los estudios culturales hacia el marketing folklórico (el ecoturismo y la traducción etnolingüística son extremadamente valorados)" (2007:276).

Hay que recordar que en México la educación intercultural promovida por el Estado se ha "institucionalizado" y ha dejado poco margen de acción para detonar procesos de apropiación con base en las propuestas educativas de las comunidades (Dietz y Mateos, 2011). A diferencia de lo que se observa en algunos países latinoamericanos, la educación superior para los pueblos indígenas y afrodescendientes en México cuenta con el respaldo de diferentes actores y organizaciones sociales, los cuales mantienen proyectos orientados, algunos de ellos, hacia procesos de decolonización y transformación de su realidad (por ejemplo, en Ecuador, Colombia o Bolivia).

Mato (2009a) propone una tipología de cuatro subtipos de Instituciones Interculturales de Educación Superior (IIES): las creadas directamente o por iniciativa de dirigencias, organizaciones indígenas o afrodescendientes (IIESIA), las creadas por IES o fundaciones privadas (IIESP), las creadas por organismos de Estado (IIESE) y las creadas por organismos de cooperación internacional (IIESOI).

Por su parte, Velasco (2010) señala que en México, además de las propuestas educativas "alternativas oficiales", existen otros dos tipos: las "independientes autónomas" y las "constructivistas" ubicadas entre las oficiales y las independientes. Todo ello habla de una amplitud en cuanto a los procesos educativos que actualmente están en marcha y que se encaminan hacia distintas maneras de interacción con la diversidad. Es imprescindible, de acuerdo con 
Rojas-Cortés y González-Apodaca (2016), comenzar a visibilizar otras iniciativas y proyectos "instituyentes" que actualmente se están gestando con el respaldo y la colaboración de las comunidades rurales e indígenas del país.

En ese sentido, este libro se centra en analizar, por un lado, la experiencia de la Licenciatura en Desarrollo Sustentable de la Universidad Intercultural de Chiapas (UNICH), en la sede de Oxchuc, que de acuerdo con Mato (2009a) se trata de una IIESE, y, por el otro, la experiencia de la Licenciatura en Planeación del Desarrollo Rural del Centro de Estudios para el Desarrollo Rural (CESDER), la cual se implementa en el Centro de Formación para la Sustentabilidad Moxviquil, A.C. Esta última, de acuerdo con Velasco (2010), se trata de una propuesta educativa "constructivista", al ser gestionada desde una organización de la sociedad civil.

En ambos espacios, oficiales y de la sociedad civil, la diversidad sociocultural y lingüística se considera como una oportunidad para enriquecer el proceso educativo a través de la recuperación de la experiencia y de las relaciones establecidas a partir del diálogo y del encuentro intercultural. Este texto demuestra que existen matices particulares en ambas experiencias, es decir, diferencias y coincidencias fundamentales sobre la forma en cómo se implementa y gestiona la interculturalidad. En consecuencia, se abona a la discusión que desde hace por lo menos dos décadas se comenzó a sistematizar a través del Consejo Mexicano de Investigación Educativa, A.C. (Bertely, Dietz y Díaz, 2013).

Este trabajo de investigación se posiciona bajo la perspectiva de la interculturalidad crítica (Walsh, 2005b, 2012; Tubino, 2005), la cual propone iniciar procesos "de abajo hacia arriba"; es decir, se asume la interculturalidad como un proyecto político, social, ético y epistémico que se construye desde la gente, con la necesidad de no únicamente cambiar las relaciones asimétricas, "sino también las estructuras, condiciones y dispositivos de poder que mantienen la desigualdad, inferiorización, racialización y discriminación” (Walsh, 2012:92). 
El área de investigación se localiza en dos espacios distintos geográfica e institucionalmente, pero similares en cuanto a la población estudiantil, que en su mayoría proviene de contextos rurales e indígenas, y ambas instituciones desarrollan propuestas educativas bajo un enfoque intercultural con programas de formación afines. Se trata de dos IES que promueven la interculturalidad, una desde la perspectiva del Estado, como es el caso de la UNICH-Sede Oxchuc (UNICH-Oxchuc), y otra que se desmarca de la propuesta educativa intercultural oficial, el CESDER-Sede San Cristóbal (CESDER-Moxviquil). Dichas IES se presentan como alternativas para la formación universitaria de jóvenes en Chiapas.

En ambas instituciones se enfatiza que el trabajo comunitario se desarrolle en la región, preferentemente en la comunidad de origen del estudiantado; es decir, buscan apoyar la transformación de las condiciones de vida de las personas con las que interactúan. No obstante, los caminos trazados para alcanzar dicho propósito son diferentes, por ello vale la pena reparar en su análisis. Más allá de que la educación intercultural sea un tema en boga, se sistematiza su práctica educativa con el afán de encontrar convergencias y divergencias que contribuyan a clarificar las propuestas de educación superior intercultural en Chiapas.

Para ello se plantean las siguientes preguntas: ¿de qué manera se presenta y trabaja la interculturalidad?, ¿cómo se retoman los fundamentos de la educación intercultural? y ¿cómo se generan las capacidades para la vinculación comunitaria? También se responde a la forma en cómo se retoma - o no- el contexto sociocultural de los jóvenes para la generación de aprendizajes significativos: ¿cuáles son las repercusiones generadas a nivel comunitario y cuáles son las consecuencias sociales de estudiar bajo un enfoque de ese tipo? Las IES con enfoque intercultural (oficiales o no) están formando jóvenes con la finalidad de contribuir al desarrollo de su región/comunidad, por ello cabe preguntarse: ¿qué tipo de desarrollo se piensa para las comunidades? y ¿de qué manera se establecen los vínculos con la comunidad? 
La investigación se abordó desde un posicionamiento decolonial, guiada bajo un enfoque etnográfico y una perspectiva constructivista. Desde la decolonialidad hay cabida para repensar nuestro quehacer como investigadores y orientarlo hacia una "decolonización epistemológica para dar paso luego a una nueva comunicación intercultural, a un intercambio de experiencias y de significaciones" (Quijano, 1992:447). Situarse desde esta posición implica un ejercicio de autorreflexión sobre nuestra participación en los espacios en los que interactuamos al momento de realizar la investigación; en palabras de Zemelman: "liberar el razonar de las estructuras teóricas acumuladas es una condición para abrirse hacia lo real, para hacerse sensible a las exigencias de objetividad expresadas en el supuesto de la realidad en movimiento" (2012:183).

Retomando la etnografía como lente de análisis, fue necesario implicarse en los procesos y prácticas educativas que se tejen de manera cotidiana en ambas instituciones. Velasco y Díaz de Rada señalan que: "la mejor estrategia para el análisis de los grupos humanos es establecer y operacionalizar relaciones sociales con las personas que lo integran" (1997:24). Investigar en las dos IES posibilitó un acercamiento a la forma en cómo se construye y aborda la educación superior intercultural "desde adentro" y "desde afuera”, 2 sin que eso significara la pérdida de objetividad; más bien siempre se trató de comprender los procesos educativos porque: "el investigador no es un mero recopilador, un mero coleccionista, sino que [construye] y proporciona información elaborada” (Velasco y Díaz de Rada, 1997:35).

Para Rockwell, "la etnografía no es una práctica que transforme por sí misma las prácticas educativas, aunque puede contribuir a

\footnotetext{
${ }^{2}$ Mi experiencia de colaboración como docente en dos propuestas educativas, una cimentada y gestionada por una asociación civil (desde adentro), y otra propuesta por la CGEIB-SEP (desde afuera), llegó a causarme cierto extrañamiento sobre las implicaciones de un modelo educativo con enfoque intercultural, en otras palabras: ¿Cómo se aborda la educación intercultural en el CESDER-Moxviquil y en la UNICHOxchuc?
} 
procesos encaminados a ello. De hecho, la transformación más importante que logra la etnografía ocurre en quienes la practicamos" (2009:30). Así, comprender la particularidad de cada contexto y experiencia educativa, con sus alcances y limitantes, hizo posible que las entendiera en su justa dimensión histórica y sociocultural.

Este trabajo consta de tres apartados. En el primero se retoma la discusión teórica sobre la multiculturalidad y la interculturalidad en diferentes latitudes, para posteriormente contextualizar algunas propuestas de educación intercultural en Latinoamérica. El aporte de este capítulo consiste en establecer la diferencia teórica entre multiculturalidad e interculturalidad y la forma en cómo se han posicionado en Latinoamérica.

En el segundo capítulo se describen algunas experiencias de educación superior en México, y más específicamente en Chiapas; se discute principalmente la situación política en la que emergieron y la vinculación que establecen con los diferentes actores sociales para su funcionamiento. En este apartado también se describen los rasgos generales de las dos IES con enfoque intercultural en las que se centra este libro: el CESDER-Moxviquil y la UNICH-Oxchuc.

En el tercer capítulo se analizan los resultados de la investigación bajo tres categorías de análisis: a) interculturalidad, b) práctica educativa y c) construcción de capacidades para la vinculación comunitaria. Los hallazgos encontrados permiten concluir que la interculturalidad tiene significaciones similares debido a que ambas IES identifican como elementos sustantivos para su interpretación el uso de las lenguas maternas, las relaciones basadas en el respeto y el intercambio de conocimientos. Sin embargo, la diferencia principal radica en que en la UNICH-Oxchuc se asume la institucionalidad "desde arriba", mientras que en el CESDER-Moxviquil se construye desde el encuentro experiencial tanto en el aula, como en la comunidad y con las organizaciones, “desde abajo". Además, en esta última experiencia aparece de manera consciente el cuestionamiento de las relaciones de poder, ele- 
mento fundamental para la comprensión de la perspectiva crítica y decolonial del enfoque intercultural.

Sobre la práctica educativa se encontró que los dos espacios educativos retoman el conocimiento previo de los estudiantes y los elementos del contexto para ponerlos en diálogo y discutirlos con la teoría. En este sentido, el enfoque que utiliza el CESDER-Moxviquil se basa en una perspectiva procesual y experiencial, es decir, se privilegia la experiencia de los estudiantes para la construcción o resignificación de conocimientos antes que la teoría, mientras que ocurre lo contrario en la UNICH-Oxchuc, donde lo instrumental tiene un peso fundamental.

En relación con la generación de capacidades para la vinculación comunitaria se concluye que los estudiantes del CESDER-Moxviquil las obtienen a partir de la articulación cotidiana, intencionada y construida durante el proceso formativo entre la institución, las organizaciones, las comunidades y los grupos de trabajo, lo cual determina que se involucren en las problemáticas de su comunidad "desde adentro". Los estudiantes de la UNICH-Oxchuc se ubican como agentes externos “desde afuera”, en colaboración, principalmente, con instituciones gubernamentales, lo que derivará en una determinante diferencia en su quehacer como profesionistas.

Finalmente las conclusiones se pueden sintetizar de la siguiente manera: en teoría, se infiere que la educación intercultural, ya sea implícita o explícitamente, conlleva la necesidad de traspasar la mirada multiculturalista (Meer y Modood, 2011), tan presente en los contextos educativos latinoamericanos, y en consecuencia asumir desde una perspectiva crítica la manera en que históricamente ha prevalecido la colonialidad del poder, del saber y del ser (Mignolo, 2006) para proponer formas de relación horizontales entre las culturas.

En el análisis de los estudios de caso se concluye que ambas propuestas educativas realizan aportes para atender la diversidad étnica y lingüística manifiesta a través de los estudiantes. Sin embargo, en la UNICH-Oxchuc obedece a una perspectiva, ya hecha, "institu- 
cionalizada" (Dietz y Mateos, 2011), que la CGEIB-SEP marca para las UI de México. El CESDER-Moxviquil, por su parte, atiende a un enfoque procesual, crítico y constructivo con la participación de diversos actores sociales. Uno de los aportes principales de esta investigación es entender cuáles son los alcances de la educación intercultural y las repercusiones de esta en las comunidades de influencia. 



\section{Capítulo 1 \\ La interculturalidad: una aproximación teórica}

\section{Políticas de tratamiento a la diversidad}

El término "interculturalidad" no se emplea de forma homogénea y no puede ser aplicado sin reconocer las particularidades que presenta en cada lugar, porque para orientar su utilización han de tomarse en cuenta factores lingüísticos, socioculturales y territoriales. Coincido con Fornet-Betancourt cuando menciona que: "cualquier definición de lo intercultural debe hacerse cargo de su contextualidad, tanto cultural como disciplinar, y presentarse no como la perspectiva que demarca los límites de lo que enfoca sino, por el contrario, como una ventana que permite ver sólo una parte del espacio abierto hacia el que se orienta” (2002:159).

En Latinoamérica la interculturalidad se posiciona a partir de movimientos sociales y populares que han buscado el reconocimiento étnico, cultural y político de sectores de la población que han sido marginados de la vida social y económica (Casillas y Santini, 2006; Dietz y Mateos, 2011; Mateos, 2011). En México, aunque también se han llevado a cabo acercamientos a lo intercultural desde los ámbitos comunitario, campesino, indígena y autónomo, el concepto ha tenido mayor eco en los recintos institucionales de la educación, la salud y lo jurídico, como parte de una política pública dirigida a establecer relaciones ante la diversidad. Por otra parte, en Europa y 
Estados Unidos las políticas para atender la diversidad se han orientado principalmente hacia la población inmigrante.

Cuando se establece una diferencia conceptual entre multiculturalidad e interculturalidad, se parte de que la primera reconoce la coexistencia de la diversidad cultural y lingüística sin cuestionar la forma en que se presentan las relaciones dentro de tal diversidad; en la segunda, se acepta la diversidad como una posibilidad de enriquecimiento y aprendizaje mutuos en condiciones de equidad haciendo un cuestionamiento sobre las relaciones de poder. Dietz y Mateos (2011) señalan que se debe entender la interculturalidad como un enfoque que analiza y visibiliza las interacciones a menudo desiguales y asimétricas entre miembros de grupos cultural e identitariamente diversos (ante la multiculturalidad, que solo constata la existencia de diferencias sin estudiar sus interacciones e hibridaciones).

Por lo general se piensa que la interculturalidad está intrínsecamente ligada a la educación, pero no necesariamente es así, porque en la actualidad hay una tendencia a "interculturalizar"3 diversos ámbitos institucionales sin que eso signifique obligatoriamente cuestionar las relaciones de poder o proponer relaciones más justas y equitativas entre los sujetos.

No obstante, a pesar de que estas distinciones contribuyen a clarificar sus elementos centrales, es necesario matizarlos y contextualizarlos con la finalidad de que no se asuman de manera superficial. Hay que destacar que las políticas para atender la diver-

\footnotetext{
${ }^{3}$ Siguiendo a Dietz (2008, 2012), el término "interculturalizar" se refiere a una versión atenuada de la gestión de la diversidad, principalmente hacia los pueblos indígenas, con miras a una educación superior intercultural "para todos" (López, 2001; Schmelkes, 2003). Sin embargo, para Dietz (2008) es imprescindible cuestionar si en dicha interculturalización se ha considerado que los propios pueblos indígenas decidan "sobre la educación que quieren y requieren". Concuerdo con el autor al señalar que es posible identificar dos tipos de interculturalización: una "desde arriba”, orquestada desde el Estado, y otra "desde abajo", donde convergen una serie de actores sociales (ONG, facciones disidentes del magisterio, colectivos, pueblos indígenas) que buscan construir una "educación pertinente para sus usuarios y sus realidades sociales y culturales” (Dietz, 2008:7).
} 
sidad presentan diferentes significaciones y posturas de acuerdo con el contexto en donde se desarrollen e implementen.

Por ejemplo, Meer y Modood (2011) señalan que, para algunos, el multiculturalismo ha facilitado la fragmentación social y ha ensanchado las divisiones sociales (Malik, 2007; Policy Exchange, 2007), mientras para otros se ha desviado la atención de las desigualdades socioeconómicas (Barry, 2001; Hansen 2006). Unos más argumentan que ha favorecido un mayor reconocimiento de la diversidad (Meer y Modood, 2011), enfocada en el descubrimiento o redescubrimiento de la identidad nacional (Orgad, 2009) o en la cohesión social o comunitaria (Dobbernack, 2010).

En su artículo titulado "How does Interculturalism Contrast with Multiculturalism?”, Meer y Modood (2011) realizan un análisis crítico sobre algunas de las formas en que las concepciones del interculturalismo están siendo contrastadas con el multiculturalismo. Los autores se plantean si en realidad el diálogo y la reciprocidad son las cualidades distintivas del interculturalismo, o más bien si en realidad dichos conceptos también son fundamentales para el multiculturalismo.

Estos temas se han discutido extensamente en una variedad de contribuciones [...] sin embargo, un término más "competente" se ha explorado mucho menos, a pesar de ser frecuentemente invocado en el discurso público y de que parece contener algo que concierne al multiculturalismo. Se trata del concepto de "interculturalismo" y la idea relacionada de "diálogo intercultural" (Meer y Modood, 2011:2, traducción propia).

Estos autores se cuestionan si el interculturalismo es una versión actualizada del multiculturalismo, a lo que argumentan que no: "es decir, que mientras los defensores del interculturalismo desean enfatizar sus cualidades positivas en términos de fomentar la comunicación, reconocer identidades dinámicas, promover la 
unidad y desafiar la intolerancia, cada una de estas cualidades ya se presentan (y en ocasiones son fundacionales) para el multiculturalismo también” (Meer y Modood, 2011:18, traducción propia).

Sin embargo, reconocen que actualmente el multiculturalismo supera al interculturalismo como una orientación política y concluyen que:

[...] hasta que el interculturalismo como discurso político sea capaz de ofrecer una perspectiva original, una que pueda abordar una variedad de preocupaciones que emanan de identidades complejas y asuntos de igualdad y diversidad de una manera más persuasiva que en la actualidad, no podrá, al menos intelectualmente, eclipsar al multiculturalismo (Meer y Modood, 2011:18, traducción propia).

Por su parte Kymlicka, en un artículo denominado "Comment on Meer and Modood” (2012), plantea que los debates académicos y públicos pasan a través de ciclos, y que una de las modas actuales consiste en defender un (nuevo, innovador, realista) interculturalismo contra un (cansado, desacreditado e ingenuo) multiculturalismo. Coincide con Meer y Modood (2011) al señalar que: “[...] hay muy poca sustancia intelectual subyacente de esta moda. No se basa en un cuidadoso análisis conceptual de los principios o presupuestos de los dos enfoques, sino que se basa en una burda tergiversación, incluso una caricatura, de las teorías y enfoques multiculturalistas” (Kymlicka, 2012:211, traducción propia).

Conviene subrayar que para Kymlicka (2012), en todo caso, aún está pendiente realizar un análisis claro para evidenciar cómo el interculturalismo difiere del multiculturalismo. De hecho, retoma algunos ejemplos para alcanzar una mejor comprensión entre ambas propuestas teóricas. Analiza la influencia de un documento del Comité de Ministros del Consejo de Europa titulado Libro blanco 
sobre el diálogo intercultural (2008), ${ }^{4}$ en el cual se argumenta que el interculturalismo debe llegar a constituirse en un nuevo modelo ante la falla del multiculturalismo. ${ }^{5}$ En consecuencia, Kymlicka (2012) argumenta que no es únicamente un fenómeno europeo, sino que también encuentra respaldo en el Informe Mundial sobre la Diversidad Cultural de la UNESCO del año 2008, donde se hace referencia de igual manera a la necesidad de una alternativa posmulticulturalista, es decir, el interculturalismo:

\section{Tanto el Consejo de Europa como la UNESCO histórica- mente han sido considerados como abanderados del mul- ticulturalismo, pero a partir de 2008 ambos declararon la necesidad de pasar del multiculturalismo al intercultura- lismo [...] diversos autores han concluido que es política- mente útil para construir una nueva narrativa en la cual}

\footnotetext{
${ }^{4}$ En dicho documento: “[...] se sostiene firmemente en nombre de los gobiernos de los 47 Estados miembros del Consejo de Europa que nuestro futuro común depende de nuestra capacidad para proteger e impulsar el respeto de los derechos humanos, tal y como están consagrados en el Convenio Europeo de Derechos Humanos, la democracia y el Estado de derecho, y para promover el entendimiento mutuo. Se defiende asimismo que el enfoque intercultural ofrece un modelo con visión de futuro para gestionar la diversidad cultural [...] El diálogo intercultural tiene una importante función que desempeñar a este respecto. Por una parte, nos permite evitar las divisiones étnicas, religiosas, lingüísticas y culturales. Por otra, nos permite avanzar juntos y reconocer nuestras diferentes identidades de manera constructiva y democrática conforme a valores universales comunes" (Consejo de Europa, 2008:3).

5 "A pesar de las buenas intenciones que le impulsaron, muchos consideran en la actualidad que el multiculturalismo ha favorecido la segregación de las comunidades y la incomprensión mutua, y que ha contribuido al debilitamiento de los derechos de las personas -en particular de las mujeres- dentro de las comunidades minoritarias percibidas como actores colectivos. Es preciso reconocer que la diversidad cultural de las sociedades actuales es un hecho empírico. Sin embargo, durante la consulta celebrada, los Estados interrogados señalaron en repetidas ocasiones que el multiculturalismo ya no era una política que gozaba de su beneplácito. Ninguno de estos modelos, ni la asimilación, ni el multiculturalismo, se aplica íntegramente en ningún Estado. Algunos de sus elementos se combinan con el nuevo paradigma interculturalista, que integra los mejores principios de ambos modelos. De la asimilación, adopta la prioridad que se concede a la persona, y del multiculturalismo, el reconocimiento de la diversidad cultural. Añade un nuevo elemento, esencial para la integración y la cohesión social: el diálogo, sobre la base de una igual dignidad y de valores comunes” (Consejo de Europa, 2008:23-24).
} 
el interculturalismo emerge en Europa de los extremos fallidos de la asimilación y el multiculturalismo (Kymlicka, 2012:213, traducción propia).

Se deduce que el interculturalismo es un enfoque que contribuirá de cierta manera a deshabilitar la política xenofóbica, sobre todo para aquellos que muestran descontento hacia la diversidad. Desde este punto de vista, para Kymlicka el interculturalismo ofrece una posición interesante e importante, sin embargo: "[...] visto como un análisis científico social objetivo, es intelectualmente débil, y a menudo no cumple ni siquiera los estándares mínimos de rigor académico u objetividad [...] es altamente retórico en lugar de analítico” (Kymlicka, 2012:214, traducción propia).

Este autor plantea que es un error el haber cambiado sin mucha información o insuficiente investigación el interculturalismo, y se cuestiona si es el remedio ante el fallido multiculturalismo, sobre todo porque no se está basando en una ciencia social objetiva, sino que está intentando ofrecer una nueva narrativa, "un nuevo mito" sobre el que aún hace falta un análisis más riguroso (Kymlicka, 2012). Algunos autores plantean que al adoptar el interculturalismo únicamente se está reetiquetando el multiculturalismo (Kymlicka, 2012; Levey, 2012; Meer y Modood, 2011), así el reto para los intelectuales progresistas está en decidir si invierten sus energías en desinflar el mito o en hacer que funcione (Kymlicka, 2012).

De acuerdo con algunos autores (Kymlicka, 2012; Meer y Modood, 2011), no se aprecia una diferencia clara entre el interculturalismo y el multiculturalismo porque, de cierta manera, las cualidades del segundo también se encuentran en el primero. No obstante, hay que enfatizar que dichas perspectivas pueden incluso presentar discrepancias en algunos países (Dietz y Mateos, 2011; Levey, 2012). Por ejemplo, en Latinoamérica, para "hacerla funcionar" (Kymlicka, 2012), la interculturalidad se ha construido desde una perspectiva más crítica de la realidad y, si bien se considera 
que las relaciones equitativas y el diálogo son imprescindibles, su rumbo político se orienta hacia la descolonización.

\section{La multiculturalidad en Estados Unidos y Europa}

La diversidad cultural ha tenido una constante presencia a lo largo de la historia moderna y comenzó a visibilizarse a través de movimientos sociales de reivindicación étnica. Uno de los más importantes se gestó en Estados Unidos a través de Martín Luther King quien, de acuerdo con Baumann, tenía una "visión de futuro sin discriminación étnica o cultural” (2001). Actualmente el discurso de King titulado "Yo tengo un sueño" ${ }^{6}$ resuena entre aquellos que aspiran a una sociedad más justa.

El Movimiento por los Derechos Civiles discutía sobre la "igualdad de derechos basada en derechos civiles, es decir, basada en la premisa de ciudadanía igualitaria e individual" (Baumann, 2001:14). No obstante, después del asesinato de King surgió con mucha fuerza el Movimiento Poder Negro (Black Power en inglés), pero este no luchó por conseguir los derechos de los norteamericanos como tales, sino de los afroamericanos como comunidad. ${ }^{7}$ De acuerdo con Baumann, la lucha por conseguir los derechos de los afroamericanos como comunidad (agrupados por su cultura y co-

\footnotetext{
6 "Así que les digo, amigos míos, que, aunque enfrentarnos a las dificultades del presente y del futuro, todavía tengo un sueño. Es un sueño enraizado profundamente en el sueño americano de que un día esta nación se levantará y vivirá bajo el verdadero significado de su credo. Mantenemos que es una verdad evidente que todos los hombres fueron creados iguales [...] sueño con que mis cinco pequeños hijos un día vivan en una nación donde no serán juzgadas por el color de su piel sino por su personalidad. ¡Hoy tengo un sueño! [...] Sueño [...] con que un día ahí, en Alabama, los niños y niñas negras podrán juntar sus manos con las de los niños y niñas blancas como si fueran hermanos y hermanas. ¡Hoy tengo un sueño!” (King, 1968:16-17, citado en Baumann, 2001:13).

${ }^{7}$ Los derechos comunitarios se diferencian de los derechos civiles en los límites que marcan. El hecho de poseer una ciudadanía nacional ya no es lo que importa en la lucha por la igualdad de derechos. Por el contrario, en su argumentación, la lucha por la igualdad se cimenta en la identidad de un grupo particular. Esta identidad se puede basar en dos criterios fundamentales: la etnia o la religión (Baumann, 2001).
} 
lor) fracasó en dos aspectos: "[en el aspecto] interno, porque había personas que se negaban a desarrollar una consciencia especialmente negra; en el externo, la nación, como tal, tardó en aceptar el concepto de derechos comunitarios, frente a los derechos individuales" (Baumann, 2001:13).

Sleeter apunta que la cuestión multicultural se posicionó fuertemente a partir del Movimiento de los Derechos Civiles, y luego con las luchas de otros grupos raciales minoritarios por tener el control sobre la educación de sus hijos y en contra del racismo y de otras formas de discriminación. En algunos países, como Estados Unidos, se hace frecuentemente la distinción entre "blanco" y "negro", que incluso ha encontrado respaldo en la creación de categorías raciales. "Así, las personas descendientes de europeos occidentales construyen un sistema racial específico con el propósito de proteger el control y el acceso a recursos como la tierra, el trabajo, las escuelas, etc." (Sleeter, 2004:11).

La misma autora señala que, si bien se han encontrado mecanismos legales para desmantelar la discriminación legalizada (raza, origen nacional, idioma, sexo y discapacidad), aún prevalece la discriminación institucionaliza, mediante la cual se realiza una distribución desigual e injusta de poder, privilegios y bienes materiales a favor de personas "blancas", es decir:

[...] divide a los estudiantes por raza o clase, ofertando una educación académicamente más desafiante a estudiantes de orígenes blancos que a otros niños; enseñan un currículum que representa mejor la experiencia, cultura y el punto de vista de los ancestros europeos, masculinos y de las clases sociales altas; y construyen relaciones más estrechas con padres que son blancos, de idioma inglés fluido, que con padres que son pobres, que no hablan el idioma inglés y no son blancos (Sleeter, 2004:12). ${ }^{8}$

\footnotetext{
${ }^{8}$ Hay que recordar que Estados Unidos ha sido históricamente un polo de atracción
} 
Lo anterior ha posibilitado que la preocupación política por el multiculturalismo se amplíe en las universidades norteamericanas ante el fracaso del "modelo de integración social de las diferencias conocido como el melting pot que, como es sabido, preconizaba un solo país hecho a partir de muchos" (Velasco, 2000:149). Esa discusión da lugar a que también desde otros espacios, no precisamente académicos, se multipliquen las manifestaciones vinculadas a la reafirmación de las diferentes identidades colectivas.

Si partimos del hecho de que las identidades ${ }^{9}$ se construyen a través de un proceso de subjetivación, es sugerente pensar que son atribuidas culturalmente de acuerdo con el contexto en el que se interactúa. Es decir, como afirma McDowell, el espacio cotidiano constituye un aspecto fundamental de la construcción de la identidad, la adquisición de conocimientos y la actuación social (2000:154). Este autor ejemplifica cómo una joven de "raza negra", que creció en el seno de una familia acomodada, no se percató de situaciones de racismo hasta que fue a la universidad, y en ese momento se dio cuenta de que el color de piel era una forma de distinguirse de "otros" (McDowell, 2000). Así, las valoraciones sobre "raza" son construcciones sociales que determinan la forma en que el "otro" debe ser tratado.

Sleeter plantea una situación similar, en casos en que los afroamericanos y los latinos son usualmente identificados de di-

para las personas que buscan mejorar sus condiciones de vida y la migración ha sido masiva en determinados periodos. Sartori menciona que: "[...] entre 1845-1925 —en ochenta años - alrededor de 50 mil millones de personas atravesaron el Atlántico; en los años 1900-1913 hubo 10 millones de inmigrantes. Pero esos recién llegados encontraban, en el nuevo mundo, un inmenso espacio vacío, buscaban y deseaban una patria y eran felices de convertirse en americanos: el melting pot (el crisol de orígenes, razas y lenguas), durante más de medio siglo y para un total de 100 millones de inmigrantes, ha funcionado estupendamente" (Sartori, 2001:51). Concuerdo en que la migración ha reconfigurado la sociedad norteamericana, aunque no estoy tan convencido de que "funcione estupendamente" para la formación de una sociedad multiétnica, democrática y con justicia social.

9 Para Giménez (1997) la identidad no sería más que el lado subjetivo de la cultura considerada bajo el ángulo de su función distintiva; en las personas la posibilidad de distinguirse tiene que ser reconocida por los demás en contextos de interacción y de comunicación. 
ferente manera. Por ejemplo: "Marta Cruz-Jansen, una negra puertorriqueña, no encaja en este sistema de clasificación [...] usa su identidad para enfrentar la naturaleza política de los sistemas de clasificación racial, cuestionando cómo las categorías raciales han sido construidas en un modo que permite la manipulación por una elite blanca” (Sleeter, 2004:12).

En consecuencia, la multiculturalidad es adecuada para nombrar la diversidad cultural, pero también para develar una política de su tratamiento. Baumann se refiere al multiculturalismo -en Estados Unidos - como un enigma, porque según él habría que "responder cómo establecer un Estado de justicia e igualdad entre tres partes: los que creen en una cultura nacional unificada, los que basan su cultura en su identidad étnica y los que ven su religión como cultura” (2001:22).

La política multicultural se inserta de manera adecuada en el discurso de la democracia liberal al no pretender transformaciones profundas en las relaciones sociales y, desde esa perspectiva, en el ámbito educativo se asume como una propuesta para trabajar con población migrante sin reconocer las relaciones históricas de opresión, es decir: "sin necesariamente cuestionar sus bases" (López, 2001:10), y sin plantear cómo eventualmente pueden generarse situaciones de transformación educativa. ${ }^{10}$ Para Terry (1993, citado en Sleeter, 2004), el punto central consiste en demostrar si mediante la educación multicultural los grupos "de arriba” aprenden a no ser controladores, dejan de ser una barrera y se transforman en potenciales aliados de los desposeídos.

En las últimas décadas la presencia de inmigrantes en varios países europeos y anglosajones — con mayor desarrollo tecnoló-

\footnotetext{
${ }^{10}$ Por ejemplo, Sleeter señala que, en Estados Unidos, la educación multicultural muchas veces es asumida desde una visión técnica antes que política, de ahí que su propuesta sea "que las relaciones fundamentales de poder se substituyan por diálogo y poder-compartido" (2004:10). La autora indica que "los profesores blancos a menudo ven el sistema como justo y la educación multicultural como innecesaria, o como un conjunto de prácticas diseñadas para mejorar las relaciones y la autoestima” (2004:17).
} 
gico y económico - se ha incrementado debido a las condiciones de pobreza, marginación y desigualdad económica y social en sus países de origen. Ellos y ellas migran generalmente con la esperanza de mejorar su situación de vida desempeñando actividades que la población autóctona pocas veces quiere realizar (Sartori, 2001), lo que genera que en ocasiones se enfrenten a situaciones de menosprecio y discriminación.

Los países receptores, en un intento por tratar con la diversidad, se han empeñado en hacer clasificaciones de los grupos sociales, lo que han emprendido generalmente desde una posición de poder con la intención de dotarse de un repertorio cultural que ayude a distinguir a los unos de los otros para controlar y mantener cierta homogeneidad al interior de las sociedades. Los sujetos pueden definirse por el color de piel, la lengua o la religión, pero también se pueden crear asociaciones por compartir una forma de pensar, sentir y estar en el mundo para distinguir a unos de los demás. Por ejemplo, "el gobierno de los Estados Unidos clasifica a las personas hispanohablantes como 'Hispanos', aun cuando esta categoría no tiene sentido fuera de sus fronteras; todavía más, al interior de este país las personas clasificadas como hispanas son muy diversas" (Sleeter, 2004:10).

Algunos autores han señalado que las nociones de multiculturalidad han sido asumidas para garantizar la separación entre grupos de distinto origen y hacen alusión a los migrantes - sobre todo en los contextos anglosajón y europeo-, pero no a las poblaciones autóctonas (Malik, 1997; Sartori, 2001; Velasco, 2000). Sin embargo, más allá del trasfondo de la migración, hay quienes plantean que esas nociones de multiculturalidad se comenzaron a apreciar también a partir de los movimientos sociales (Dietz y Mateos, 2008, 2011; Mateos, 2011), los cuales buscaban —o buscan - reivindicar sus diferentes modos de ser y estar en el mundo frente a la cultura hegemónica. Precisamente, el auge del multiculturalismo "ha hecho saltar a la palestra la cuestión de las identidades colectivas" (Velasco, 2000:147). 
Dietz y Mateos (2008) argumentan que la diversidad cultural se considera convencionalmente como el producto de la presencia de minorías étnicas o culturales o del establecimiento de nuevas comunidades migrantes en el seno de los “clásicos” Estados-nación de cuño europeo, y es estudiada en contextos escolares y extraescolares, en situaciones de discriminación que reflejan xenofobia y racismo en las distintas esferas de las sociedades multiculturalizadas.

Para Sartori "el multiculturalismo es hoy una palabra portadora de una ideología, de un proyecto ideológico” (2001:73). Este autor indica que para que se dé el multiculturalismo se necesita de una sociedad abierta que cree el valor del pluralismo (definido como una disposición tolerante y, estructuralmente, con asociaciones voluntarias no impuestas y afiliaciones múltiples). Por eso, en lugar de promover la multiculturalidad como un concepto que ayude a clarificar las relaciones en la diversidad, propone el pluralismo como una oferta viable, caracterizándola de la siguiente manera:

- El pluralismo está obligado a respetar la multiplicidad cultural con la que se encuentra, pero no está obligado a fabricarla.

- Para el pluralismo es necesario asegurar la paz intercultural, no fomentar una hostilidad entre las culturas.

- El pluralismo es hijo de la tolerancia y, por lo tanto, está llamado a desconocer la intolerancia que es, en resumidas cuentas, odio cultural que reivindica una superioridad cultural alternativa.

- Pluralismo es, sí un vivir juntos en la diferencia y con diferencias, pero lo es si hay contrapartida. Entrar en una comunidad pluralista implica, a la vez, adquirir y conceder. - El pluralismo defiende, pero frena, la diversidad. Para el pluralismo, la integración es un mal y la asimilación es un bien; además, como es tolerante, no es agresivo ni belicoso. Sin embargo, combate la desintegración, aunque lo hace de manera pacífica. 
- El pluralismo aprecia la diversidad y la considera fecunda, pero no supone que la diversidad tenga que multiplicarse, y tampoco sostiene, por cierto, que el mejor de los mundos posibles sea un mundo diversificado, en una diversificación eternamente creciente (Sartori, 2001).

Por lo antes descrito se puede argumentar que, en el pluralismo, para Sartori (2001) hay reconocimiento, tolerancia y respeto por la diversidad, pero al mismo tiempo se produce una negación a la propagación de la diversidad cultural, por lo que se deduce que puede acercarse más al multiculturalismo pluralista. El mismo autor enfatiza que se pueden ofrecer dos versiones del multiculturalismo: 1) aquel que está sometido a los criterios del pluralismo, y 2) la versión dominante actual, la del multiculturalismo antipluralista. Señala que esta última versión tiene sus orígenes en el marxismo, "cuyo enfoque se centra en la hegemonía y dominación de una cultura sobre otras" (Sartori, 2001:63).

Por ello, el multiculturalismo como política ha sido implementado como un concepto estático que demanda respeto por la diversidad cultural, pero prefiere mantener - desde una perspectiva liberal- las distancias entre grupos social y culturalmente distintos, es decir, prefiere no cuestionar las relaciones de poder. $\mathrm{Al}$ igual que en Estados Unidos y Europa, la política multicultural está dirigida a la población migrante y continúa imponiéndose como una ideología que "tolera" a los grupos culturalmente "minoritarios”. De acuerdo con López (2001), la propuesta de multiculturalismo, en el caso europeo, busca superar la xenofobia y el racismo, y promover la tolerancia frente a las diferencias culturales y lingüísticas.

Por ejemplo, después de la Segunda Guerra Mundial lo que más interesaba en Europa era velar por la integración de los hijos de inmigrantes, Besalú señala que: "constituían una especie de anomalía, que debía ser atendida en este horizonte de provisionalidad (de 
ahí la emergencia de los programas de lengua y cultura de origen, pensados sobre todo para estimular el retorno)" (s/f:1). El autor indica que los sistemas educativos ya estaban consolidados y de ninguna manera se modificaban el curriculum ni el funcionamiento porque se pensaba que sería una situación pasajera. Malik (1997) precisa que el concepto de sociedad multicultural se desarrolló en el mundo durante la posguerra, en gran medida como respuesta al impacto de las inmigraciones hacia Europa.

$\mathrm{Al}$ paso de los años, los inmigrantes en la Unión Europea se han incrementado, ${ }^{11}$ pero no solo por la movilidad entre países de ese continente, porque en la actualidad ha aumentado la llegada de población de otras partes del mundo, como Latinoamérica y Asía. Históricamente, la inmigración "deviene en uno de los factores de cambio social más visibles y más influyentes de la vida actual de los pueblos europeos" (Velasco, 2000:150). Desde esa perspectiva, uno de los retos actuales es repensar las diferentes formas de interacción que se tejen a partir de la aplicación de determinadas políticas púbicas y, específicamente, en el ámbito educativo significa buscar la forma más adecuada para atender esa circunstancia particular debido a que: "[...] sólo plantea la intervención educativa cuando hay alumnos de diferentes etnias —como si los otros no necesiten intervención alguna-” (Santos, 2013:40).

Besalú señala que el Consejo de Europa impulsó un importante cambio de perspectiva al promover que la educación intercultural debe ser para todo el alumnado y no solo para los hijos de los inmigrantes extranjeros, "de forma que el currículo escolar

\footnotetext{
${ }^{11}$ Este flujo migratorio ha sido ocasionado, principalmente, por la situación sociopolítica de Medio Oriente y del norte de África, cuya población migra a la Unión Europea, donde se enfrenta al rechazo en los países "receptores". De acuerdo con datos del Alto Comisionado de las Naciones Unidas para los Refugiados (ACNUR), a nivel mundial la cifra pasó de 51.2 millones de personas desplazadas por conflictos en 2013, a 59.5 millones en 2014. Asimismo, en una declaración del ACNUR de 2015 se indica que Europa se enfrentó en ese año a una de las mayores afluencias de refugiados en décadas, cuando más de 300000 personas arriesgaron sus vidas para cruzar el Mediterráneo.
} 
debería adaptarse de forma más rigurosa a la realidad de Europa y del mundo" (Besalú, s/f:3). Para López, "interculturalidad e inmigración son realidades que van de la mano" (2013:16), aunque eso no significa que las expresiones xenófobas hacia los inmigrantes se desvanezcan totalmente. El discurso multicultural en el caso educativo: "se ha convertido en la principal base ideológica de la actual gestión de la diversidad entendida ésta como una aproximación diferencial a la educación de minorías alóctonas, inmigradas" (Aguado, 2003; Giménez, 2003, citados en Dietz y Mateos, 2008:32).

Lejos de pretender abordar las hibridaciones que se tejen entre la interculturalidad y los procesos de inmigración en Europa, me parece necesario considerar los esfuerzos que están haciendo los diferentes países en el ámbito educativo. Por ejemplo, en España está garantizado por las leyes "el derecho a la educación de todos los niños y jóvenes menores de edad, independientemente de su situación administrativa” (Besalú, García y García, 2014:102), lo cual habla de cierta flexibilidad para abordar dicha problemática.

De igual forma, se han hecho esfuerzos interesantes por trascender de un sistema educativo que integra la heterogeneidad, hacia uno que promueva y desarrolle la educación "en y para la diversidad", es decir, por una "educación inclusiva"12 en la cual se asuman las diferencias culturales, personales o sociales como una posibilidad de enriquecimiento (Abellán, De Haro y Frutos, 2010).

Abellán, De Haro y Frutos señalan que la educación inclusiva: "se ha desarrollado de manera desigual y sin avances sostenidos" (2010:153). A pesar de ello, en los últimos años se han implementado una serie de experiencias educativas con la finalidad de recuperar e insertar la diversidad cultural en el aula, tanto para la población alóctona, como para la autóctona (López Belmonte, 2013; Sánchez, 2013). Incluso hay propuestas como la de la "escuela de familia", en la cual se busca generar lazos de cooperación y participación entre

\footnotetext{
${ }^{12}$ Este modelo tiene antecedentes en la Conferencia Mundial de Educación para Todos que se llevó a cabo en 1990 en Jomtien, Tailandia (Abellán, De Haro y Frutos 2010).
} 
la institución educativa y las familias de los estudiantes inmigrantes con la finalidad de establecer relaciones más solidarias con la población receptora (Lara, 2013). O propuestas como la del País Vasco para la recuperación etnolingüística, donde a través de las instituciones escolares (ikastolas) pretenden romper con un proceso histórico de marginación del sistema educativo; en ese sentido, la ikastola está "encargada de la educación y la socialización de las nuevas generaciones en euskera” (Tejerina, 1999:87).

De acuerdo con algunos especialistas en educación intercultural (Besalú, s/f; Besalú, García y García, 2014; López, 2013), en España se pretenden considerar los siguientes aspectos para abordar el tema:

- Exigir al profesorado que tome conciencia de su propio bagaje cultural, que lo analice críticamente y lo reconstruya sobre nuevas bases.

- Incluir la educación intercultural en el plan de formación.

- Respetar y reconocer todas las culturas de forma que la comunidad educativa pueda percibirlas con total dignidad y como factores enriquecedores.

- Mejorar el autoconcepto personal, social, cultural y académico de todo el alumnado como requisito imprescindible; esto demanda aceptar a todos como personas de forma incondicional y garantizar su seguridad afectiva.

- Promover estrategias didácticas que sirvan al mismo tiempo para aprender más y mejor lo que hay que aprender, y para mejorar el conocimiento, la relación y la convivencia con los demás.

- Cultivar actitudes y valores que ayuden y favorezcan la convivencia entre personas y grupos distintos, y hacerlo de una forma sistemática, planificada y eficaz, con base en elementos como: el respeto mutuo, la gestión pacífica y democrática de los conflictos, la simpatía, la compasión hacia los demás, el sentido crítico, etcétera. 
- Luchar contra todas las formas de discriminación, incluidas las de carácter racista; no solo contra las conductas, las actitudes, los prejuicios y los estereotipos, sino también contra sus formas cognitivas, ideológicas e institucionales, porque todas ellas impregnan la cultura occidental que se ha desarrollado a lo largo de los siglos (Besalú, s/f).

- Promover una reflexión crítica en el profesorado sobre sus propias prácticas docentes y profundizar en aquellas que se han revelado eficaces en entornos semejantes. Asimismo, impulsar los cambios necesarios en las prácticas docentes con el apoyo de programas efectivos de formación permanente (López, 2013).

- Fundamentar las relaciones entre todos los miembros de la comunidad educativa con base en el reconocimiento, el respeto y el diálogo, y proscribir cualquier forma de humillación y de supremacía. Las relaciones interpersonales merecen un cuidado escrupuloso porque a través de ellas se conforman percepciones, identidades y roles (Besalú, García y García, 2014).

- La interculturalización del currículo no pasa por añadir más contenidos a los programas. La atención a la diversidad se incorpora mediante las aportaciones, conocimientos y experiencias vitales del alumnado y del resto de la comunidad (Besalú, García y García, 2014).

Puede observarse que la educación intercultural exhorta a tener conciencia sobre el bagaje cultural de los estudiantes como una posibilidad de enriquecer el proceso educativo a partir de otras formas de aprender y relacionarse con los demás. Evidentemente, en cada el contexto se busca luchar en contra de las formas de discriminación y racismo abierto y encubierto. No obstante, "la reafirmación cultural —entre otros factores - está haciendo una escuela cada vez más sensible a las diferencias” (Santos, 2013:39). 
Phillips (1999) se refiere a la política de la presencia como un sistema justo de representación en el que se incluye como parte de las "acciones reparadoras" a grupos históricamente marginados dentro de las democracias liberales. Existe cierta subrepresentación en la inclusión política, aunque se afirma que el hecho de considerar cuotas de representación en los espacios públicos (educativos, políticos o económicos, entre otros) a través de políticas de "acción afirmativa o discriminación positiva" no genera cambios de conciencia o creencia, ni mucho menos de valores, sin embargo contribuye a hacer visibles a los grupos que históricamente han estado bajo opresión.

\section{Multiculturalidad, interculturalidad y educación intercultural en Latinoamérica}

Hablar de multiculturalidad invita a pensar en la diversidad sociocultural y en la exigencia de los grupos minoritarios de participar en las decisiones políticas del Estado, e incluso de diferenciarse étnicamente del resto de la sociedad. Para Díaz-Polanco, "el multiculturalismo con sus múltiples rostros benévolos, se despliega por todo el mundo, incluso Latinoamérica, con el prestigio de su defensa de la diversidad y la promoción del pluralismo" (2006b:173).

Actualmente, en la mayoría de las Constituciones de los países de Latinoamérica se reconoce la diversidad cultural, lingüística y étnica, lo que denota el carácter multicultural. Para Kymlicka (1996), una de las características de las culturas incorporadas a las del dominio llamado "minorías nacionales" es justamente el deseo de seguir siendo sociedades distintas respecto a la cultura mayoritaria de la que forman parte. Este autor señala que dichas minorías insisten, a pesar de haber sido incorporadas de manera involuntaria, en la autodeterminación y el autogobierno.

Abu-Laban y Stasiulus indican que se teme que el "multiculturalismo llevado a su extremo lógico" (1992:37, citado en Kymlicka, 1996:65) pueda justificar que cada grupo étnico tenga autoridad 
para imponer sus propias tradiciones legales a sus miembros, aun cuando dichas tradiciones se contradigan con los derechos humanos básicos y con los principios constitucionales.

Actualmente se encuentra una actitud más "tolerante" ante la diversidad, pero aún falta resolver cuestiones centrales que plantea la realidad latinoamericana, principalmente porque cuando se habla de multiculturalidad se dejan de lado las diferencias económicas y sociopolíticas (Díaz-Couder, 1998; Díaz-Polanco, 2006a, 2006b) y se oculta la permanencia de desigualdades e inequidades sociales que no permiten a todos los grupos relacionarse equitativamente y participar de manera activa en la sociedad, además de que se dejan intactas las estructuras e instituciones que privilegian a unos sobre otros (Walsh, 2005a).

Se prefiere hablar de derechos diferenciados, como los lingüísticos, antes de hablar de los derechos al territorio o a la autodeterminación. Malik (1997) apunta que al describir las sociedades fragmentadas - en una sociedad multiculturalista-caemos en el peligro de celebrar las diferencias impuestas por una sociedad racista, porque no se cuestionan las desigualdades sociales existentes.

Algunos autores como Taylor plantean la necesidad de una política de la diferencia en la que se reconozca la identidad única de un individuo o grupo, sustentando: "el hecho de que es distinto de los demás, esta identidad debe respetarse a todos por igual, pero al menos en el contexto intercultural surgió hace poco una exigencia más poderosa: la de acordar igual respeto a las culturas que de hecho han evolucionado" (Taylor, 1993:66).

No hay que olvidar, entonces, que bajo la bandera liberal se permiten la tolerancia y el respeto, y se promueven y admiten las diferencias, "pero sin que ello implique el derecho a ser otro" (Taylor, 1993:181). Para este autor, una sociedad liberal debe permanecer neutral ante la vida buena y limitarse a asegurar que, véanse como se vean las cosas, los ciudadanos se traten imparcialmente y que el Estado los trate por igual (Taylor, 1993). 
México se reconoce oficialmente como un país pluricultural donde se promueve una ideología liberal. Stavenhagen cuestiona "si el multiculturalismo no es una mera distracción que sirve a las clases dominantes para mantener una estructura altamente desigual en lo económico y social” (2013:40). De igual forma, Díaz-Couder denomina multiculturalismo "liberal" (1998:27) a aquel que reconoce a los grupos lingüística y culturalmente diferenciados considerando la necesidad de conservar su herencia cultural como parte de sus derechos privados, y que reconoce los derechos culturales, pero no políticos, de ahí que exista un creciente apoyo a actividades culturales y recreativas basadas en el folclore y en las tradiciones nativas (concursos de literatura en lenguas indígenas, danzas tradicionales, fiestas patronales).

Una segunda manera de concebir la multiculturalidad es la "pluralista", que consiste en el reconocimiento del derecho de grupos o pueblos culturalmente distintos a tener un estatuto político diferenciado dentro de la nación, en el que las culturas e idiomas nativos no son solamente una cuestión de interés público, sino que se les reconoce el estatuto de sujetos de derecho público (Díaz-Couder, 1998).

En México, la autonomía o el autogobierno reconocido por el Estado está lejos aún; en su lugar, se prefiere hablar de respeto y tolerancia, recurriendo constantemente a explicitar la coexistencia de varias culturas sin cuestionar las asimetrías existentes entre ellas. Quizás ahora se entienda la trascendencia que ha tenido para el Ejercito Zapatista de Liberación Nacional (EZLN) implementar la autonomía indígena como mecanismo que permita, entre otros factores:

[...] tener los instrumentos legales para proteger los derechos indígenas, la democratización de la vida política nacional y el establecimiento de un Estado de derecho basado en pluralismo legal, el derecho de la gente a defender sus intereses y controlar sus vidas y recursos, la biodiversidad 
de sus territorios, el ejercicio de derechos políticos, el respeto a las leyes y costumbres de sus ancestros y el reconocimiento como sujetos con derechos (Franco, 2004:79).

El movimiento armado influyó de manera determinante en la promoción de los derechos y la cultura de los pueblos indígenas de México a través de los Acuerdos de San Andrés, firmados en 1996 entre el gobierno federal y el EZLN. En ellos se reflexionó y analizó "cuáles deberían ser los principios históricos, políticos, sociales, económicos y culturales que debieran convertirse en Leyes Nacionales para acabar con el racismo, la marginación y la exclusión de todos los pueblos indios de México, no sólo de Chiapas" (Gobierno del Estado de Chiapas, 2003:9).

Entre las propuestas conjuntas que tanto el gobierno federal como el EZLN se comprometieron a enviar a instancias de debate y decisión nacionales se encuentra el punto 3, titulado "Conocimiento y respeto a la cultura indígena", donde se señala la necesidad de "elevar a rango constitucional el derecho de todos los mexicanos a una educación pluricultural que reconozca, difunda y promueva la historia, costumbres, tradiciones y, en general, la cultura de los pueblos indígenas, raíz de nuestra identidad nacional" (Acuerdos de San Andrés, 1996:59).

Como se sabe, los Acuerdos de San Andrés fueron rechazados por el gobierno de Ernesto Zedillo, lo que significó la ruptura entre el EZLN y el gobierno federal. Fue el presidente Vicente Fox quien retomó la iniciativa de la Ley Cocopa ${ }^{13}$ y la envió al Congreso de la Unión, lo que derivó en la aprobación de la Ley de Derechos y Cultura Indígena; sin embargo, el EZLN, al considerar que dicha ley no recuperaba el espíritu de los Acuerdos de San Andrés, ${ }^{14}$ ni mucho

\footnotetext{
${ }^{13}$ La Ley Cocopa fue elaborada en diciembre de 1996 por los legisladores (pertenecientes a los partidos políticos más representativos de México) de la Comisión de Concordia y Pacificación (COCOPA). En dicha ley se retomó lo esencial de los Acuerdos de San Andrés. ${ }^{14}$ González Casanova (2001) señala que los Acuerdos de San Andrés no solo precisan los derechos de los pueblos indios a la autonomía de su gobierno y a la preservación
} 
menos la iniciativa de la Ley Cocopa, inició nuevamente un distanciamiento con el gobierno federal que terminó con cualquier intención de diálogo (Navarro y Bermúdez, 2019).

Si dichos acuerdos se aprobaran tal cual, ello podría "propiciar la fragmentación de la República” (Franco, 2004:79) e incluso atentaría contra "la estabilidad e integridad del país" (Stavenhagen, 2013:39), por ello claramente se percibieron, en ese momento, "como una amenaza considerable para el poder ejecutivo” (Mattiace, 2002:240).

No obstante, de acuerdo con Díaz Polanco, a pesar de la falta de reconocimiento gubernamental el EZLN inició una: "[...] búsqueda de formas superiores de organización que permitan afianzar el proyecto de emancipación” (2006a:44), lo cual se ha logrado a través de la creación de los Caracoles y las Juntas de Buen Gobierno, ambos organismos: "[...] constituyen una forma de desobediencia civil, válida y legítima, ante la falta de reconocimiento de derechos fundamentales de los pueblos indígenas” (Díaz Polanco, 2006a:49). Dicho proceso de autogobierno ha sido conducido, además, por las "propias comunidades” (Subcomandante Insurgente Marcos, 2003).

El levantamiento del EZLN contribuyó a cuestionar diversos ámbitos de las políticas públicas destinadas a los pueblos indígenas, además de que fue un parteaguas para iniciar propuestas de educación autónomas ${ }^{15}$ (Baronnet, 2012, 2015; Martínez et al., 2015) e inspirar a otros sectores de la población a gestionar una educación con pertinencia social y cultural para las comunidades, algunas "desde adentro" y, otras, “desde afuera”. Más adelante se pre-

de sus culturas, sino también apuntan hacia la construcción de un Estado pluriétnico que fortalezca la unidad en la diversidad y la articulación de las comunidades locales, municipales, regionales y nacionales, con inclusión de lo particular y lo universal.

${ }^{15}$ En la educación, en tierras en las que no había escuelas ni mucho menos maestros, los Consejos Autónomos (con el apoyo de las sociedades civiles) construyeron escuelas, capacitaron promotores de educación y, en algunos casos, hasta crearon sus propios contenidos educativos y pedagógicos. En algunas partes las bases zapatistas han establecido acuerdos con maestros de la sección democrática del sindicato del magisterio para que no hagan labor de contrainsurgencia y respeten los contenidos recomendados por los Consejos Autónomos (Subcomandante Insurgente Marcos, 2003). 
sentará con detenimiento la apropiación de la interculturalidad en la educación superior en México.

Es necesario decir que, al igual que las propuestas del EZLN en México, se han implementado en otros países proyectos educativos basados en la Educación Intercultural Bilingüe (EIB); por ejemplo, en los años ochenta se llevaron a cabo en Bolivia, Ecuador y Nicaragua importantes campañas de alfabetización de adultos en la propia lengua, acciones que se constituyeron en verdaderos antecedentes de lo que hoy es la EIB (López y Küper, 1999).

No podemos dejar de reconocer que la interculturalidad en Latinoamérica se ha ido manifestando a través de programas de EIB, con la participación de organizaciones indígenas, organizaciones no gubernamentales, personal académico e instituciones gubernamentales, actores que han incorporado, en diferentes momentos, la lengua y elementos socioculturales del contexto en busca de una mejor educación para las poblaciones indígenas y afrodescendientes.

Los países andinos influyeron en otras regiones del continente en cuanto al tema de socializar la interculturalidad. En algunos casos, las iniciativas fueron "endógenas" porque reivindicaban los derechos indígenas y la territorialidad, y en otros la motivación fue "exógena", sea proveniente de centros de investigación, de instancias gubernamentales o de la sociedad civil, aunque casi siempre en interacción y consulta informada con las poblaciones indígenas involucradas (López, 2009).

En cualquiera de las dos situaciones se buscó superar la visión exclusivamente lingüística para trascender hacia posicionamientos epistémicos y políticos que permitieran incorporar las relaciones de poder y conflicto entre indígenas o afrodescendientes con la sociedad mestiza, reconociendo, además, la necesidad de su participación en la construcción de propuestas educativas acordes con su realidad (Castillo y Caicedo, 2015; López, 2009). Hay que enfatizar que esas experiencias se generaron a partir del impulso de los movimientos indígenas en su búsqueda por emanciparse de la política impuesta por actores ajenos a su realidad (Baronnet, 2015) 
y, en consecuencia, por promover proyectos educativos de manera autogestionada (Velasco, 2015).

Así, cada país ha desarrollado una particular apropiación de la interculturalidad, la cual se asume, en la mayoría de los casos, como un cuestionamiento a las condiciones socioeconómicas y políticas educativas que se promueven desde el Estado para los pueblos indígenas y afrodescendientes, mientras en otros casos se mimetiza en propuestas favorables para los intereses del Estado. ${ }^{16}$ Por ejemplo, Castillo y Caicedo señalan que las movilizaciones contra el racismo y la invisibilidad entre las décadas de los cincuenta y setenta originaron la "emergencia por los derechos civiles y la afirmación cultural”, que a su vez incidieron en el “ámbito de las luchas por los derechos de Colombia” (2015:101). Con ello lograron, en consecuencia, la reforma constitucional de 1991, en la que se reconoce a las poblaciones negras, afrocolombianas o raciales como grupos étnicos; dos años más tarde se reglamentó la Ley 70 en la cual se promueve la etnoeducación.

En esa coyuntura, en Colombia se decretó la implementación de la Cátedra de Estudios Afrocolombianos (CEA) con el propósito de combatir el racismo epistémico y la invisibilidad hacia los afrodescendientes. Castillo y Caicedo indican que esto se hizo con prácticas pedagógicas y curriculares para valorar sus saberes y así "afectar el sistema educativo oficial a través de la divulgación de los saberes históricos, culturales e intelectuales de las poblaciones afrocolombianas" (2015:109).

De igual manera, en Perú la adopción del concepto de interculturalidad se llevó a cabo a mediados de la década de los setenta a partir de proyectos y programas escolares implementados por profesionales (lingüistas y antropólogos) que trabajaban con poblaciones indígenas, de ahí que se otorgara cierta relevancia al bilingüismo (López, 2009). A pesar de que los proyectos pretendían

${ }^{16}$ En México, a diferencia de en otros países de Latinoamérica, la educación intercultural a nivel superior se implementa bajo la dirección del Estado. 
la transformación de la realidad adversa de las poblaciones indígenas, ${ }^{17}$ fue con la Asociación Interétnica de la Selva Peruana como se comenzó a:

[...] reivindicar la nueva noción en su propuesta de formación docente [...] la noción se incrustó en el contexto de lucha permanente indígena por el territorio y por la supervivencia en general, apareciendo, cada vez más, como indesligable de un marco general de relaciones conflictivas con la sociedad hegemónica y sobre todo con el Estado (Trapnell, 2008, citado en López, 2009:148).

Lindenberg (1996, citado en López, 2009) señala que en Brasil la noción de interculturalidad se inscribió en un marco de educación popular indígena, bajo los principios de Paulo Freire, a través de la cual se formaron maestros indígenas comunitarios en relación directa con la cotidianeidad indígena (su historia, geografía y vida en sociedad). Esa tarea fue apoyada tanto por organizaciones no gubernamentales, como por universidades y centros de investigación. Sin embargo, a pesar de que se contaba con el respaldo del Estado brasileño para implementar una educación basada en su propia lengua y modos de aprendizaje, no se logró trascender debido a que muchas instituciones hegemónicas: "no lograban despojarse de la visión del indígena como un ciudadano tutelado, antes que como un ciudadano diferente que buscaba afirmarse en sus especificidades culturales y sociales" (Repetto, citado en López, 2009:152).

Como se ha señalado, la denominación "intercultural" en Ecuador fue adoptada a través de un proyecto de alfabetización con la utilización del quichua, además de que se involucró directamente

\footnotetext{
${ }^{17}$ Es importante decir que la EIB en Perú contó con respaldo legal para reconocer que la educación debía cumplir con la superación de las condiciones de opresión histórica y de explotación de la población indígena. En 2006, a partir de una nueva ley de educación, se asumió "la educación intercultural para todos" así como la educación comunitaria (López, 2009:150).
} 
a los indígenas en la gestión y toma de decisiones rebasando "la discusión sobre contenidos curriculares, para poner en discusión la cuestión del poder en la educación” (López, 2009:161). De igual manera, cuando en Bolivia los indígenas asumieron el rol de actores políticos clave, demandaron la transformación de la educación nacional para considerar la diversidad cultural y lingüística, lo que se logró con el respaldo del Estado y de las organizaciones sociales (López, 2009).

Una clara innovación en los programas educativos se observa a partir de la incorporación de propuestas de los propios indígenas y afrodescendientes en los planes y programas de estudio oficiales, con el acompañamiento de movimientos sociales, organizaciones de la sociedad civil y académicos. Por ejemplo, en Bolivia y Ecuador se han realizado reformas constitucionales para que los Estados se reconozcan como plurinacionales.

A pesar de que se han presentado avances significativos en cuanto a interculturalidad, y en particular sobre educación intercultural, concuerdo con López (2009) cuando señala que prevalece en el concepto un sesgo hacia lo indígena y el uso de las lenguas originarias "para los indígenas", lo cual, sin duda, desarrolla una conciencia crítica, pero únicamente de un lado de la balanza; en este sentido, el reto es que los mestizos y no indígenas generemos contrapesos para iniciar procesos de interculturalización.

\section{Latinoamérica y el pensamiento decolonial}

Las instituciones del Estado neoliberal promueven una globalización hegemónica que responde tan solo a las demandas del mercado, lo que ha ocasionado una serie de resistencias y movilizaciones contrahegemónicas que rechazan la idea de que "no hay alternativas”. Santos y Rodríguez (2007) mencionan que las movilizaciones implican potenciar la voz de quienes viven en la pobreza y están excluidos de los beneficios sociales por cuestiones de clase, género, raza u opresión étnica. 
Las formas de interacción en un espacio y un tiempo se han visto drásticamente modificadas por la lógica de acumulación de capital y explotación de la fuerza de trabajo. En los países de Latinoamérica no es extraño que presenten un Estado cada vez más debilitado o inexistente, que deja a los grupos empresariales el control y la disposición de los recursos naturales, sociales y culturales. Se entiende que esto es parte de la flexibilidad del Estado y de las instituciones para atender las demandas que las nuevas dinámicas globales imponen a la población, aunque ocasiona desajustes de los mercados locales y erosión de los tejidos sociales.

A manera de ejemplo, se encuentran dos visiones de desarrollo e integración regional radicalmente opuestas: por un lado, la promovida por Estados Unidos - sobre todo con mayor énfasis en la seguridad después de los ataques a las torres gemelas del 11 de septiembre de 2001-y, por el otro, la impulsada por países como Venezuela y Cuba, en un intento por lograr otra forma de interacción de la región de América. Sobre la primera visión, hay que decir que se retoma la propuesta inicial del Tratado de Libre Comercio de América del Norte (TLCAN), ${ }^{18}$ pero lo hace con un interés centrado no solo en México, Estados Unidos y Canadá, sino también en Centroamérica y Sudamérica a través del Área de Libre Comercio de las Américas (ALCA). De forma paralela también se ha impulsado nuevamente el Plan Puebla-Panamá (en la actualidad Proyecto de Integración y Desarrollo de Mesoamérica).

Por consiguiente, es entendible que frente a esa situación se generen procesos de resistencia "contrahegemónica", como la Alianza Bolivariana para los Pueblos de Nuestra América (ALBA), promovida principalmente por Venezuela, Cuba y Bolivia, con la cual se crean alianzas cooperativas para reducir las asimetrías entre los

\footnotetext{
${ }^{18}$ Los tratados que firmó México durante la década de los noventa responden a la lógica globalizadora del mercado. Esta lógica ha llevado a la destrucción de pequeñas y medianas industrias, al empobrecimiento del campo y de los campesinos, así como a la creación de grandes contingentes de pobres e indigentes en zonas urbanas (Villafuerte, 2004).
} 
países de América, por lo que es considerada una visión opuesta al ALCA. Estas dos posturas generan una continua reconfiguración del espacio y del territorio en América.

La primera obedece más a un ordenamiento de tipo geoeconómico global y la segunda tiene aspiraciones de "desarrollo regional”; es importante continuar analizando cómo se va renegociando el espacio y las implicaciones que causa a la población, sobre todo porque se van encontrando grietas en el sistema capitalista que permiten plantear "otros mundos posibles". ${ }^{19}$ Un ejemplo es la Cumbre de Estados Latinoamericanos y Caribeños (CELAC), desde la cual se gestiona un tipo de integración y desarrollo económico sin la participación de Estados Unidos: "Los dominados, los subalternos, sobreviven y resisten porque encuentran o construyen sus espacios y sus dinámicas propias; porque crean sus propias formas políticas” (Ceceña, 2008:21).

En este caso, otros marcos interpretativos podrían ayudar a entender lo que sucede en nuestras realidades latinoamericanas, por ejemplo, el pensamiento decolonial. Con esto no quiero decir que este sea el mejor parámetro para comprender determinada realidad social, simplemente considero que contribuye a profundizar sobre las formas de relación entre los sujetos y las culturas, las cuales generalmente se dan desde una posición dominador/dominado.

\footnotetext{
${ }^{19}$ El EZLN en repetidas ocasiones ha argumentado la posibilidad de la construcción de "otro mundo posible", es decir, "un mundo donde quepan todos los mundos posibles", en interacción con las comunidades indígenas, con personas y con movimientos a nivel internacional. En la Cuarta Declaración de la Selva Lacandona se menciona que: "En el mundo del poderoso no caben más que los grandes y sus servidores. En el mundo que queremos nosotros caben todos. El mundo que queremos es uno donde quepan muchos mundos. La Patria que construimos es una donde quepan todos los pueblos y sus lenguas, que todos los pasos la caminen, que todos la rían, que la amanezcan todos" (Comité Clandestino Revolucionario Indígena-Comandancia General del Ejército Zapatista de Liberación Nacional, 1996). Las frases "otro mundo posible", "un mundo donde quepan todos los mundos posibles" y "muchos mundos" ahora también son retomadas por diversos grupos académicos, movimientos sociales, organizaciones civiles y personas interesadas en la construcción de una sociedad más justa.
} 
Para Mignolo (2006) significa desnaturalizar la matriz colonial del poder que posibilite, además, adoptar un posicionamiento crítico ante la ideología hegemónica dominante. No se trata de negar el pasado ni las aportaciones del mundo occidental a la sociedad, pero el pasado se puede reactivar no en su pureza, sino como "pensamiento fronterizo", ${ }^{20}$ es decir, ya no es posible ignorar las contribuciones de Occidente a la historia de la humanidad, como tampoco se puede desconocer que tales contribuciones no son soluciones para toda la humanidad.

Pero a partir de lo anterior surge la pregunta de cómo lograr que eso suceda del otro lado del pensamiento fronterizo crítico, es decir, en el lado occidental. Difícilmente se puede alcanzar una respuesta cuando las sociedades se rigen bajo un sistema de acumulación de capital. Sin embargo, muchos países —como se ha señalado- a través de sus diferentes actores sociales comienzan a cuestionar su papel dentro del sistema actual, de ahí que se impulsen alianzas políticas y económicas o bien se apoyen iniciativas de educación superior que vayan acordes con sus necesidades terri-

\footnotetext{
${ }^{20}$ Para Mignolo (2003) el "pensamiento fronterizo" germina para identificar el potencial de un pensamiento que nace desde la subaltemidad colonial. "El pensamiento fronterizo surge del diferencial colonial de poder y contra él se erige [...] es un pensamiento desde la subalternidad colonial (como en Anzaldúa, Fanon o el zapatismo) o desde la incorporación de la subalternidad colonial desde la perspectiva hegemónica (como en Las Casas o en Marx) [...] es uno de los caminos posibles al cosmopolitismo crítico y a una utopística que nos ayuda a construir un mundo donde quepan muchos mundos [...] el pensamiento fronterizo sería precisamente el de los desheredados de la modernidad; aquellos para quienes sus experiencias y sus memorias corresponden a la otra mitad de la modernidad, esto es, a la colonialidad" (Mignolo, 2003:27, 58). En ese sentido, se debe profundizar en un posicionamiento crítico para poder discernir entre las diferentes posibilidades que se presentan para la construcción de mundos posibles. Para Walsh, esto significa identificar un "posicionamiento crítico fronterizo" como una posibilidad para "resaltar la agencialidad de grupos subalternizados [...] el propósito de este posicionamiento crítico fronterizo es el de interculturalizar críticamente a partir de la relación entre varios modos de pensar, incluyendo entre pensamientos-otros (en su pluralidad), una relación conflictiva y de lucha en, entre y alrededor de conocimientos no simplemente al nivel de teoría, sino dentro de contextos vividos de sujetos cuya agencia necesariamente está enraizada en una red compleja de relaciones del poder" (Walsh, 2005b:30, citado en Restrepo y Rojas, 2010:176-177).
} 
toriales y su contexto sociocultural. Se trata de comenzar a cuestionar y a "desprenderse" de la colonialidad del poder, ser y saber ${ }^{21}$ que se ha impuesto en diferentes dimensiones de la sociedad.

Los antecedentes históricos de la decolonialidad se encuentran, de acuerdo con Mignolo (2014), en la Conferencia de Bandung de 1955, en la cual se reunieron 29 países de Asia y África con el objetivo de encontrar las bases y la visión común de un futuro que no fuera ni capitalista ni comunista. El camino que hallaron fue la descolonización. Más tarde, en la Cumbre de los Países No Alineados celebrada en Belgrado en 1961 se sumaron varios representantes latinoamericanos. Para Restrepo y Rojas (2010) los antecedentes de la "inflexión decolonial" en Latinoamérica se encuentran en las obras clásicas del colonialismo desarrolladas por Aimé Césaire, Frantz Fanon y Orlando Fals Borda. ${ }^{22}$

En años recientes un colectivo de intelectuales de Latinoamérica y el Caribe, denominado grupo modernidad/colonialidad, ${ }^{23}$ han profundizado sobre núcleos de discusión que abordan la perspectiva decolonial y sus contribuciones han alcanzado repercusión en otros países y grupos de académicos y sociales. Esa "colectividad de argumentación ha ido construyendo un vocabulario compartido, ha definido una serie de problemáticas y agendas de trabajo [con]

\footnotetext{
${ }^{21}$ La lógica de la colonialidad opera en tres dimensiones: 1) colonialidad del poder (político y económico), 2) colonialidad del saber (epistémico, filosófico, científico y en relación de las lenguas con el conocimiento) y 3) colonialidad del ser (subjetividad, control de la sexualidad y de los roles atribuidos al género) (Mignolo, 2006).

${ }^{22}$ Dichas obras en cierto sentido contribuyeron a cuestionar los procesos de colonización, las repercusiones en los sujetos colonizados y colonizadores (Césaire), el colonialismo y el racismo (Fanon) y el eurocentrismo y colonialismo intelectual (Fals Borda). En el caso de Césaire y Fanon, el énfasis está más orientado a denunciar la experiencia histórica y los efectos del colonialismo en términos de la deshumanización que produce en ambos extremos de la relación colonial. En el caso de Fals Borda, el énfasis se asocia más a la posibilidad de construcción de proyectos políticos en los que la ciencia sea factor de liberación y de subversión de las jerarquías que son parte de la herencia colonial (Restrepo y Rojas, 2010).

${ }^{23}$ Entre sus representantes se encuentran: Aníbal Quijano, Edgardo Lander, Ramón Grosfoguel, Walter Mignolo, Catherine Walsh, Arturo Escobar, Enrique Dussel, Santiago Castro-Gómez, Nelson Maldonado, entre otros.
} 
un proyecto tanto intelectual como político, que los mismos participantes han llamado proyecto decolonial” (Restrepo y Rojas, 2010:31).

En dicha "colectividad de argumentación de la inflexión decolonial” se encuentran una serie de planteamientos ideológicos con la finalidad de proponer otras formas de interacción social. Restrepo y Rojas (2010) identifican algunos rasgos centrales que resumo a continuación.

Distinción entre colonialismo y colonialidad. En términos analíticos no hay que confundir el colonialismo (una forma de dominación político-administrativa a la que corresponde un conjunto de instituciones o metrópolis/colonias) con la colonialidad (que se refiere a un patrón de poder global más comprehensivo y profundo). Una vez concluye el proceso de colonización, la colonialidad permanece vigente como esquema de pensamiento y marco de acción que legitima las diferencias entre sociedades, sujetos y conocimientos. Se refiere a un patrón de poder que opera a través de la naturalización de jerarquías territoriales, raciales, culturales y epistémicas, posibilitando la reproducción de relaciones de dominación (Restrepo y Rojas, 2010).

La colonialidad es el "lado oscuro" de la modernidad. A diferencia de muchos teóricos de la modernidad, que solo ven en ella un proyecto emancipador, la inflexión decolonial llama la atención sobre su cara menos visible —incluso oculta—, que es la colonialidad. Si aquellos teóricos de la modernidad consideran el colonialismo como una "desviación" o un "momento" superado de la modernidad, para la inflexión decolonial la modernidad se encuentra indisolublemente asociada a la historia del colonialismo y a la colonialidad (Restrepo y Rojas, 2010). La colonialidad no es equivalente al colonialismo, no se deriva de la modernidad ni la antecede. La colonialidad y la modernidad constituyen dos lados de una misma moneda (Grosfoguel 2006, citado en Restrepo y Rojas, 2010).

Problematización de los discursos eurocentrados e intramodernos de la modernidad. Desde la inflexión decolonial se puede argumentar que hay que entender Europa desde una perspectiva de siste- 
ma-mundo, lo que es también resultante de un sistema geopolítico que incluye las tecnologías de gobierno y las formaciones discursivas que la producen como tal. Cuestiona tanto la supuesta vocación de poder universalizante de la modernidad como el imaginario de su etiología exclusivamente intraeuropea y eurocentrada (Restrepo y Rojas, 2010).

Pensar en términos de sistema mundializado de poder. La inflexión decolonial no se queda en el análisis de países, Estados o regiones aisladas, sino que intenta comprender lo que sucede en un país o región en relación con un sistema mundializado de poder. Este énfasis analítico en el sistema mundializado de poder es lo que constituye la perspectiva geopolítica de la inflexión decolonial pues, dado que no existe modernidad sin colonialidad, es necesario pensar en términos de sistema-mundo moderno/colonial (Restrepo y Rojas, 2010).

Antes que un nuevo paradigma, la inflexión decolonial se considera a sí misma como un paradigma Otro. Lo que estos autores buscan no es consolidarse como un nuevo paradigma teórico dentro de la academia, sino cuestionar los criterios epistémicos de producción del conocimiento académico articulados al eurocentrismo y a la modernidad. De ahí que se pretenda consolidar un conocimiento no eurocéntrico y desde la herida colonial, es decir, un paradigma Otro emergente desde la diferencia colonial (Restrepo y Rojas, 2010).

La inflexión decolonial aspira a consolidar un proyecto decolonial. La crítica epistémica que supone la inflexión decolonial como paradigma Otro no solo busca problematizar la colonialidad del saber, también busca contribuir a hacer posibles otros mundos desde intervenciones decoloniales que comprenden las diversas dimensiones de la existencia; la inflexión decolonial hace referencia a una ética y a una política de la pluriversalidad que constituyen una apuesta por visibilizar y hacer viables la multiplicidad de conocimientos, de formas de ser y de aspiraciones sobre el mundo (Restrepo y Rojas, 2010).

Los rasgos distintivos de la inflexión decolonial muestran que existen una serie de perspectivas que pueden guiar e introducir 
el análisis para las realidades latinoamericanas y son útiles para proponer la construcción de proyectos contextualizados en oposición a la modernidad eurocéntrica. El caso más representativo es la educación intercultural, cuyos significados, apropiaciones y puesta en práctica, en algunas experiencias se llevan a cabo bajo "otra" lógica epistémica.

A pesar de que cada vez existe mayor interés por conocer los elementos de la inflexión decolonial, también son notorios los cuestionamientos y críticas a dicha perspectiva, y presentarlos y discutirlos ayuda a dar cabida a las diferentes posturas epistémicas que contribuyen a la consolidación y construcción continua del pensamiento decolonial.

Restrepo y Rojas argumentan que, para la intelectual boliviana Silvia Rivera Cusicanqui, lo que ha generado la colectividad de argumentación: "[...] antes que problematizar el colonialismo es una manera sutil de reproducirlo puesto que, por su genealogía, sus formas de operación predominantes y sus proponentes más visibles, constituye una modalidad de colonialismo intelectual" (2010:198). Y es que para Rivera Cusicanqui algunas ideas eran retomadas, por Quijano principalmente, "[...] en un discurso de la alteridad profundamente despolitizado" (2010:64-65). Además, señala que, "[...] se ha creado un nuevo canon académico [...] gracias al reconocimiento y la certificación desde los centros académicos de los Estados Unidos".

En ese sentido es que Rivera Cusicanqui propone que, en lugar de llamarse "geopolítica del conocimiento", ${ }^{24}$ se hable de una "economía política del conocimiento", en el entendido de que en la primera no se lleva a la práctica e incluso "[...] más bien, se contradice a través de gestos de recolonización de los imaginarios y las mentes de la intelectualidad del sur" (2010:65). La propuesta de esta au-

\footnotetext{
${ }^{24}$ Boaventura de Sousa Santos considera que la perspectiva de la geopolítica del conocimiento supone: "[...] quién produce el conocimiento, en qué contexto lo produce y para quién lo produce” (Santos, 2009:340, citado por Restrepo y Rojas, 2010:201).
} 
tora consiste en crear otra forma de vinculación entre sur-sur que posibilite desprenderse de la academia del norte. En ese sentido, las exigencias para la "colectividad de argumentación” parten de que se encuentren vinculados de manera directa los grupos subalternos, esto para evitar contradicciones, dejar la teoría y pasar a la práctica (Rivera, 2010).

Otra de las críticas que identifican Restrepo y Rojas se centra en cómo se construye la argumentación teórica, lo cual supone la existencia de un lector con cierto bagaje intelectual y filosófico que le permite seguir los planteamiento; sin embargo, la paradoja es que en los escritos se habla a nombre de los subalternos coloniales, negros e indígenas, "[...] y los silencios e invisibilizaciones históricas, epistémicas y ontológicas que introduce... pero, y ¿quién está hablando?, ¿cómo lo está haciendo?, ¿de qué está hablando?, ¿para quién habla?, ¿para qué habla como lo está haciendo?” (Restrepo y Rojas, 2010:202).

Más allá de las acertadas críticas, lo que interesa resaltar es que se están recuperando las formas de pensamiento que han sido invisibilizadas y silenciadas por la colonialidad y, en consecuencia, la decolonialidad orienta a "otro" modo de pensar, aunque el reto, como bien lo plantea Rivera Cusicanqui, es asumir la posibilidad de politizar el discurso a través de acciones concretas con los grupos subalternos sobre los que se escribe.

Hasta el momento se ha encontrado que en Latinoamérica se están gestando ciertas formas de resistencia, pedagógicas, sociales, culturales, políticas, teóricas y económicas, ante un modelo hegemónico que no visibiliza otras formas de ser y estar en el mundo, por lo que es imprescindible generar una reflexión y análisis profundo para la resignificación del poder, del saber y del ser y, en consecuencia, generar situaciones que permitan enriquecer y fortalecer las capacidades de los grupos de población menos favorecidos. 


\section{Propuestas de educación superior intercultural en Latinoamérica}

Algunos autores (Godenzzi, 2005; López, 2001; Tubino, 2009; Walsh, 2012, entre otros) destacan el origen latinoamericano del concepto de interculturalidad, e incluso subrayan que la propuesta no se limita a luchar por el reconocimiento y la reivindicación de las diferencias como en el caso del multiculturalismo —en su forma más tosca- ni a establecer medidas que contribuyan a facilitar cierta asimilación de los pueblos indígenas o comunidades afroamericanas, sino que apunta a cambiar las condiciones y modalidades en las que se dan las relaciones e intercambios sociales.

Entonces, hablar de interculturalidad en Latinoamérica implica ir más allá de proponer nuevas formas de relación y comunicación entre las culturas desde un plano de equidad que permitan el aprendizaje mutuo y el respeto; lo que se exige, desde algunas propuestas, es descolonizar a la población oprimida para cambiar la interacción entre las culturas desde una relación sujeto a sujeto, erradicando así la correlación dominador/dominado. Esto tiene que hacerse cuestionando las condiciones históricas de desigualdad social y económica por las que atraviesan las personas afrodescendientes e indígenas. Hay quienes señalan que la aplicación de una política intercultural no aspira a transformar la realidad social y cultural de los pueblos originarios, sino más bien a llamar de diferente manera la desigualdad.

La interculturalidad tiene muchas significaciones, usos y aplicaciones. En ese sentido, algunos autores (Tubino, 2005; Walsh, 2002, 2012) señalan ciertas perspectivas que contribuyen a identificar y diferenciar ciertos enfoques. Una de ellas es denominada interculturalidad desde la perspectiva relacional, la cual se refiere al contacto e intercambio entre culturas, que podría darse en condiciones de igualdad o desigualdad. Visto de este modo, la interculturalidad es algo que siempre ha existido en Latinoaméri- 
ca debido al contacto y la relación entre los pueblos; no obstante, se ocultan o minimizan la conflictividad y los contextos de poder (Walsh, 2012).

Otra es la perspectiva funcional. Walsh (2012) y Tubino (2005) señalan que se pretende un reconocimiento de la diversidad y diferencia cultural con la intención dirigida "hacia la inclusión de la misma al interior de la estructura social establecida, [donde] — se busca promover el diálogo, la convivencia y la tolerancia-, la interculturalidad es 'funcional' al sistema existente; [al] no toca[r] las causas de la asimetría y desigualdad social y cultural” (Walsh, 2012:91).

La interculturalidad desde la perspectiva crítica se asume como la posibilidad de posicionarla como un proyecto político, social, ético y epistémico que se construya desde la gente, con la necesidad de no únicamente cambiar las relaciones asimétricas, "sino también las estructuras, condiciones y dispositivos de poder que mantienen la desigualdad, inferiorización, racialización, discriminación” (Walsh, 2012:92). Es esta última postura desde la cual me posiciono en la presente investigación.

Walsh identifica dos tendencias en el marco del debate sobre la interculturalidad: por un lado, aquella que intenta naturalizar y armonizar las relaciones culturales a partir de la matriz hegemónica y, por el otro, se encuentra la perspectiva crítica, que a diferencia de la primera inicia:

[...] desde abajo hacia arriba, desde la acción local, que busca producir transformaciones sociales, esta posición necesariamente implica procesos de subalternización y decolonialización. En la práctica, está dirigida a fortalecer lo propio como respuesta y estrategia frente a la violencia simbólica y estructural, a ampliar el espacio de lucha y de relación con los demás sectores en condiciones de simetría, y a impulsar cambios estructurales y sistémicos (Walsh, 2002:8). 
Guerra, Meza y Sandoval (2011) argumentan que, si en el nuevo paradigma latinoamericano se trata de revertir todos los esquemas de colonización, entonces hace falta que los latinoamericanos, sin caer en estar renombrando por renombrar, recreemos y creemos conjuntamente uno o varios términos que se ajusten a nuestras realidades. Esta tarea sin duda implica encaminarse hacia la construcción de procesos de subjetivación más acordes con la realidad social y cultural de nuestras sociedades. Y eso es justamente lo que se realiza cuando surgen propuestas como la interculturalidad desde una perspectiva crítica.

Contextualizar la interculturalidad en Latinoamérica implica remontarse a los movimientos sociales y populares que se crearon como una forma de rechazo ante el discurso hegemónico y asumieron como bandera de lucha la resistencia ante un sistema (educativo, económico, cultural) con pretensiones claramente integracionistas. Como se ha mencionado líneas arriba, una de las exigencias de estos movimientos ha sido el reconocimiento por parte del Estado de la diversidad cultural, étnica y lingüística, situación que se ha visto reforzada por varios acuerdos internacionales que promueven "el derecho de los pueblos a una educación culturalmente adecuada" (Convenio 169 de la OIT), la "satisfacción de las necesidades básicas de aprendizaje” (Declaración de Jomtien), o donde la diversidad cultural se eleva a la categoría de "patrimonio común de la humanidad, tan necesaria para el género humano como la diversidad biológica para los organismos vivos" (Declaración Universal sobre la Diversidad Cultural de la UNESCO).

El proceso de construcción de la interculturalidad para América Latina tiene que partir desde lo que sentimos y pensamos, desde lo que somos y no desde lo que nos han impuesto ser, significa un acto de liberación. Y en esta búsqueda teórica y conceptual que oriente nuestras prácticas me parecen ineludibles las preguntas: "¿quiénes somos culturalmente?, ¿cuál es nuestra identidad histórica?” (Dussel, 2005:18). La multiplicidad de respuestas segu- 
ramente establece la posibilidad de entender lo que cada grupo sociocultural puede aportar para plantear alternativas al sistema capitalista. El mismo Dussel (2005) denomina proyecto "trans-moderno” al intento liberador; significa la irrupción desde la nada, desde la exterioridad alternativa de lo siempre distinto, de culturas universales en proceso de desarrollo que asumen los desafíos de la modernidad, y aún de la posmodernidad europeo-norteamericana, pero que responden desde otro lugar.

Rauber (2011) indica que una propuesta de "sociedad horizontal” con raíz intercultural supone aceptar e incorporar las diferencias en aras de construir una totalidad sociocultural compleja que, en vez de anular la diversidad, la presuponga y exprese. Además, puntualiza, se debe encaminar hacia la coexistencia y el derecho de todos y todas a existir, pensar y actuar (vivir) de manera acorde con sus identidades y cosmovisiones, es decir, de un modo propio, diferente.

La propuesta latinoamericana en torno a la interculturalidad evidentemente exige nuevas formas de relación y comunicación entre los sujetos y culturas, pero también se trata de luchar contra los esquemas de colonización y encontrar estrategias políticas que se ajusten a nuestras realidades

Se trata de comenzar a distinguir otra sociedad para construir un nuevo modo de vida, sin jerarquías discriminatorias o excluyentes, con equidad, justicia y oportunidades para todas y todos, con el reconocimiento y respeto de todas las identidades, culturas, costumbres, con modos de producción y reproducción que protejan el ambiente y — sobre la base del reencuentro del ser humano con la naturaleza - aseguren el equilibrio entre la sociedad y la naturaleza (Rauber, 2011).

No está de más insistir en que en nuestro continente existe una íntima relación entre modernidad y colonialidad; en las últimas décadas se ha puesto en evidencia la intensa interacción entre las diferentes culturas, lo que ha dejado ver un proceso histórico de dominación, de ahí la necesidad de establecer otras formas en las 
cuales se valoren de forma equitativa los distintos conocimientos y sea posible crear otros mundos.

Entonces, la interculturalidad no podría - ni puede- construirse desconectada del contexto social e ideológico de la propia diversidad cultural, desligada del análisis de las relaciones sociales u ocultando las estructuras políticas y económicas que la condicionan. Para nuestro contexto de Latinoamérica, el estudio de la interculturalidad requiere de un análisis riguroso que reconozca los conflictos que se encuentran presentes en el día a día (aculturación, marginación social, relaciones de poder, crisis sociales, segregación, desigualdad social y económica, educación descontextualizada, entre otros) y, a la vez, analice el proceso histórico de reflexión teórica en torno al concepto y lo que ello ha propiciado en experiencias concretas.

En el caso particular de la educación intercultural, Baronnet y Tapia señalan que: "la implementación de los proyectos de educación intercultural ha sido objeto de luchas políticas regionales" (2013:10); los proyectos de este tipo, en algunos casos, construyen ejemplos de una justificada “desobediencia civil” ante las políticas integracionistas dirigidas hacia los pueblos indígenas y afrodescendientes de Latinoamérica.

Bermúdez (2015) indica que la apertura de las universidades indígenas e interculturales en Latinoamérica comenzó en la década de los noventa, y muchas de esas experiencias educativas ${ }^{25}$

\footnotetext{
${ }^{25}$ Por mencionar algunas, se relacionarán algunas experiencias. En Nicaragua: la Universidad de las Regiones Autónomas de la Costa Caribe Nicaragüense (URACCAN), que fue la primera universidad indígena en América Latina; en Ecuador: la Universidad de la Cuenca, el Programa Académico Cotopaxi de la Universidad Politécnica Salesiana, y Pluriversidad Intercultural de las Nacionalidades y Pueblos Indígenas-Amawtay Wasi; en Colombia: la Escuela de Salud Indígena, la Escuela de Derecho Propio Cristóbal Secué Tombé y la Licenciatura en Etnoeducación de la Universidad del Cauca; en Brasil: la Universidad de los Pueblos Indígenas de la Amazonia, el Programa de Educación Superior Indígena Intercultural de la Universidad de Mato Grosso y la formación de profesores indígenas en el Instituto Insikiran de Formación Superior Indígena de la Universidad Federal de Roraima; en Guatemala: la Universidad Pop Wuh, EDUMAYA de la Universidad Rafael Landívar
} 
pretenden responder a los sueños, necesidades y conocimientos de los contextos regionales donde se encuentran ubicadas. En su mayoría se crearon: "con el arduo trabajo y la tenacidad de comunidades y pueblos indios que, con creces, han superado muchas de las clásicas escuelas y facultades de antropología para quienes los indios no son más que simples objetos de estudio” (Sandoval, 2002:1).

A fines de la década pasada, en el año 2007, se comenzó a implementar el Proyecto Diversidad Cultural e Interculturalidad en Educación Superior en América Latina, del Instituto Internacional de la UNESCO para la Educación Superior en América Latina y el Caribe (IESALC), con la intención de: "realizar investigación sobre experiencias de IES de América Latina dedicadas a atender necesidades y demandas de formación terciaria de comunidades de pueblos indígenas y afrodescendientes y a formular recomendaciones de políticas en la materia” (Gazzola, 2008:11).

De acuerdo con Mato (2010a), se han documentado 52 estudios de caso en 11 países, lo cual significa un esfuerzo importante para "observar la existencia de una amplia diversidad de formatos institucionales", que de una u otra forma buscan crear mejores condiciones educativas para la población donde inciden dichas IES. En la Tabla 1 se encuentran los principales logros y dificultades de las experiencias documentadas bajo la coordinación de Mato (2008, 2009a, 2009b).

y la Universidad Maya; en Perú: la Universidad Nacional Nativa de la Amazonia; en Chile: la Universidad Indígena de los Mapuches, el Centro de Estudios Socioculturales de la Universidad Católica de Temuco en la Región de la Araucanía y El Instituto de Estudios Andinos de la Universidad Arturo Prat; en Costa Rica: la Universidad Madre Tierra (Bermúdez, 2015); en Argentina: el Centro de Investigación y Formación para la Modalidad Aborigen, y en Venezuela: la Universidad Indígena de Venezuela (para más información se sugiere revisar, Mato: 2008, 2009a, 2009b). 
Tabla 1. Logros y dificultades de los programas de estudios de las IES

\section{Logros}

1) Mejoran las posibilidades de que individuos indígenas y afrodescendientes accedan a oportunidades de educación superior y culminen exitosamente sus estudios;

2) ajustan su oferta educativa a necesidades, demandas y proyectos de las comunidades y la relacionan con oportunidades locales y regionales (subnacionales) de empleo, generación de iniciativas productivas y servicio a la comunidad;

3) desarrollan modalidades participativas de aprendizaje, frecuentemente centradas en la investigación aplicada; 4) integran aprendizaje, investigación y servicio a las comunidades;

5) integran diversos tipos de saberes y modos de producción de conocimiento; 6) promueven la valorización y, según los casos, incorporan las lenguas y saberes propios de estos pueblos y comunidades, contribuyen proactivamente a su fortalecimiento y realizan investigación sobre dichas lenguas y saberes; 7) desarrollan docencia e investigación orientadas por criterios de valoración de la diversidad cultural, interculturalidad, equidad, inclusión, gobernabilidad democrática, desarrollo humano y sostenible;

8) forman egresados que contribuyen al desarrollo sostenible local y regional, y al mejoramiento de la calidad de vida de sus comunidades;

9) buena parte de las IES "convencionales” en cuyo interior se desarrollan algunos de los programas estudiados han sido favorablemente impactadas por estas experiencias.

\section{Dificultades}

1) Insuficiencia o precariedad presupuestaria;

2) actitudes de discriminación racial por parte de funcionarios públicos y diversos sectores de población que afectan el desarrollo de sus actividades;

3) dificultades derivadas de la rigidez de los criterios aplicados por las agencias especializadas de los Estados encargadas de otorgar reconocimiento o acreditación;

4) obstáculos institucionales administrativos derivados de la rigidez de procedimientos, los cuales afectan la ejecución de sus planes y actividades; 5) obstáculos institucionales académicos derivados de la rigidez de criterios y procedimientos aplicados por las IES en las cuales funcionan algunos de los programas estudiados o por agencias gubernamentales que otorgan fondos para investigación y proyectos académicos especiales, los cuales afectan labores docentes y de investigación de las IES y los programas estudiados;

6) dificultades para conseguir docentes y otro personal con adecuada sensibilidad y recursos personales y técnicos para el trabajo intercultural; 7) dificultades económicas de los estudiantes para poder dedicarse más y mejor a su formación;

8) insuficiencia de becas;

9) diversos tipos de dificultades derivadas de las situaciones de precariedad económica y jurídica en las que hacen sus vidas buena parte de las comunidades atendidas por estas IES.

Fuente: Elaborado a partir de Mato (2010a). 
Resalta entre los logros que las experiencias de formación responden a las necesidades inmediatas del contexto, no únicamente de los estudiantes sino también de las comunidades con las que interactúan. Además, se observa un énfasis en fortalecer la identidad, principalmente a través del uso de las lenguas originarias. También destaca que las IES “convencionales” se han visto permeadas por dichas experiencias, lo cual representa un avance significativo para la transversalización de la interculturalidad en la educación superior. No obstante, entre las dificultades aparece la poca flexibilidad de los organismos gubernamentales para el reconocimiento o la acreditación de los programas educativos, problemas económicos y la falta de docentes con formación o sensibilidad hacia la educación intercultural y la interculturalidad.

Algunos casos de los cuatro subtipos de IIES, documentados por Mato (2009a), se mencionan a continuación.

En Argentina se encuentra el Centro de Investigación y Formación para la Modalidad Aborigen, que tiene como propósito la formación de profesores bajo un enfoque intercultural bilingüe. La propuesta inicial surgió a partir del reclamo y la preocupación de las comunidades toba, wichí y mocoví por una educación en la cual los niños fortalecieran su lengua indígena y el español. Desde 1987 cuentan con una escuela inclusiva que favorece la construcción de una pedagogía para la diversidad que responda a las necesidades de su contexto. Inicialmente comenzaron con la formación de auxiliares docentes aborígenes, lo cual incluía la elaboración de material didáctico, y el seguimiento y la animación del programa de educación bilingüe intercultural. Desde el año 2000 implementan la carrera de Profesor Intercultural Bilingüe para la Educación General Básica (Valenzuela, 2008).

De igual forma se encuentra la experiencia que, desde el Área de Estudios Interdisciplinarios en Educación Aborigen de la Universidad Nacional de Luján (Argentina), propone generar espacios para pensar y actuar sobre los contextos educativos donde "coexisten conflictivamente la escuela tradicional y los pueblos originarios 
y/u otro grupo social, cultural y económicamente marginados” (Gualdieri, Vázquez y Tomé, 2008:93). Se trata de un programa de formación abierto a distintos destinatarios interesados en aportar y generar cambios en la educación.

En Bolivia, desde 2001 se ha impulsado el Programa de Formación de Técnicos Superiores en Justicia Comunitaria de la Universidad Mayor de San Andrés, con la finalidad de "contribuir a una relación complementaria entre la justicia comunitaria y el derecho positivo dentro del marco de los derechos humanos" (Mallea, 2008:108). En la mencionada experiencia se ha logrado atender las necesidades comunitarias en materia jurídica, porque la apuesta es la "construcción de un nuevo modelo político económico en el que la justicia comunitaria tenderá a convertirse en el puntal de los cambios estructurales jurídico-políticos” (Mallea, 2008:114).

Asimismo, de acuerdo con Saavedra (2008), la Universidad Intercultural Indígena Kawsay (UNIK) de Bolivia se gestó en 1995 a partir de un encuentro de organizaciones de países andinos -Perú, Bolivia y Ecuador- en el que se creó la Red Intercultural Tinku. Con este impulso establecieron su propia universidad, pero no entró en operación hasta 1997, con la carrera de Pedagogía Intercultural, y en 1999 se abrió la carrera de Derechos Indígenas. El propósito de la UNIK es contribuir al "fortalecimiento de la organización territorial comunitaria de las naciones originarias para alcanzar el gobierno propio, teniendo el trabajo educativo como instrumento principal” (Cerruto, 2009:125).

Desde un inicio la UNIK, junto con las comunidades y organizaciones, planteó como prioridades temas educativos y productivos. Actualmente desarrolla programas de formación enfocados en el turismo comunitario, la pedagogía intercultural, los derechos indígenas, los gobiernos comunitarios y la ecoproducción (Saavedra, 2008). Para quienes no cuentan con estudios previos para ingresar a una carrera, se encuentra la modalidad de educación continua (semipresencial), para que no "desarraigue a los participantes de 
su realidad familiar ni comunal, al contrario, le permita consolidar su cultura territorial comunitaria” (Cerruto, 2009:138).

En Brasil se encuentra el Centro Amazónico de Formación Indígena (CAFI), que fue creado en 2006 por la Coordinación de las Organizaciones Indígenas de la Amazonia Brasilera:

CAFI fue creado para atender las demandas específicas e históricas de los pueblos indígenas de Brasil, es decir, para capacitar política y técnicamente a líderes indígenas de la Amazonía a fin de defender sus derechos y territorios, así como para administrar las tierras indígenas en los nueve estados de la Amazonía —que representa 110 millones de hectáreas y equivale al $10 \%$ de todo el territorio nacional(Flores, 2008:139, traducción propia).

Para Mato (2008) se trata de un espacio para la formación de profesionales especialmente capacitados para actuar en las organizaciones indígenas.

En Colombia se encuentra la Universidad Autónoma Indígena e Intercultural (UAIIN), la cual se creó con el respaldo del Consejo Regional Indígena del Cauca (CRIC) ${ }^{26}$ en 2003. El CRIC es una organización que desde 1971 ha estado fuertemente vinculada a las

\footnotetext{
${ }^{26}$ Otra experiencia educativa que se enmarca en estrecha colaboración con el CRIC es la Institución Educativa de Tumbichucue, ubicada en el Resguardo Indígena de Nasa de Tumbichucue (Cauca), en la cual se atienden los niveles básico y medio; en ella se asumen la creación e implementación de una educación propia, "dando inicio a un proyecto educativo comunitario que lleve a cabo procesos de investigación de la historia del resguardo, fomento de la lectura y escritura nasa yuwe. También se promueve la formación de líderes comunitarios, al igual que un fortalecimiento de las prácticas culturales enmarcadas en la tradición y cosmovisión, pero que a su vez relacione estos saberes con otros conocimientos modernos necesarios para la pervivencia de la comunidad timbichucueña" (López y Poveda, 2015:173). Sin embargo, se reconoce que falta materializar la propuesta educativa que impulsa el CRIC, principalmente por la usencia de metodologías y herramientas pedagógicas que orienten la educación propia, la repetición de prácticas coloniales que condiciona el actuar de los niños limitando su formación como sujetos críticos y transformadores, la falta de un plan común entre los diferentes grados y la poca participación comunitaria (López y Poveda, 2015).
} 
luchas reivindicativas de los pueblos indígenas por el reclamo de sus derechos territoriales e identitarios. Aunque cuenta con el reconocimiento del Estado, el consejo asume la administración de la educación en los territorios indígenas de la región en búsqueda de una "educación propia". ${ }^{27}$ Se trata de una propuesta vinculada directamente con los intereses de cada pueblo indígena, y uno de sus primeros programas fue el de Pedagogía Comunitaria, en el que se contó, además de con la participación de los maestros de las comunidades, especialistas y personas mayores, con la asesoría del CESDER (Bolaños, Tattay y Pancho, 2008; Saldívar, 2012).

La Universidad Intercultural de las Nacionalidades y los Pueblos Indígenas Amawtay Wasi, de Ecuador, instaurada en 2004, de acuerdo con Mato (2010b) y Sarango (2008) es una experiencia respaldada por la Confederación de Nacionalidades Indígenas del Ecuador y el Instituto Científico de Culturas Indígenas que surgió desde el movimiento indígena. A través de sus programas educativos -Agroecología, Ciencias de la Educación con mención en Pedagogía Intercultural y Arquitectura con mención en Arquitectura Ancestral, entre otros- se busca que los egresados respondan "al mejoramiento de la calidad de vida de los sectores históricamente marginados, pues el ámbito de acción de la UIAW son los sectores rurales menos favorecidos" (Sarango, 2008:271).

Sarango relata que, inicialmente, entre las necesidades prioritarias para los pueblos y nacionalidades del Ecuador se encontraban las especialidades en Derecho Indígena y Salud Intercultural, pero en la etapa de peritaje realizado por otras universidades fueron eliminadas por considerar que "no eran necesarias" (2009:201). En 2013 la universidad fue cerrada porque no aprobó los estánda-

\footnotetext{
${ }^{27}$ La educación propia, de acuerdo con López y Poveda: "se entiende como un proceso histórico y ancestral. Esta experiencia educativa se inscribe en el escenario de la interculturalidad, entendida como proyección política de voces subalternas en la que la escuela es uno de los tantos lugares para la afirmación de la cultural, lo que permite promover procesos de resignificación política de la lucha indígena y la concienciación de los indígenas como sujetos históricos” (2015:168).
} 
res de evaluación establecidos por el Consejo de Evaluación, Acreditación y Aseguramiento de la Calidad de la Educación Superior; no obstante, eso no ha limitado que siga con la operación de sus programas educativos, ahora bajo el nombre de Pluriversidad Amawtay Wasi, en común acuerdo con el Consejo de Desarrollo de Nacionalidades y Pueblos del Ecuador.

En las propuestas educativas antes mencionadas se pueden observar dos elementos importantes: por un lado, la existencia de experiencias previas de organización a nivel local o regional y, por el otro, que responden a demandas de movimientos sociales. También se distingue que han sido construidas a partir de las propias demandas y de los contextos específicos de la población para contribuir a generar otras condiciones de vida en su territorio.

A pesar de lo anterior, como ya se ha documentado en diferentes trabajos (Berlanga, 2014; Gasché, 2010; Lehmann, 2015), estos avances se han visto limitados al no posibilitar los cambios esperados en la construcción de relaciones más horizontales con el resto de la sociedad. La mayoría de las experiencias educativas aparecen como "burbujas" donde se promueven ciertas prácticas de reivindicación y reafirmación cultural que pocas veces trascienden más allá del espacio educativo y que en sí mismas muestran las profundas contradicciones de un concepto que poco ha logrado consolidarse en términos metodológicos y pedagógicos (Navarro y Saldívar, 2011).

Zemelman (1990) señala que la viabilidad de la propuesta de la interculturalidad se refiere a la capacidad de los sujetos sociales para elaborar, impulsar y sostener proyectos de sociedad; estos últimos son resultado de su construcción como fuerzas sociales, como expresión de opciones ideológicas y políticas enraizadas en su cultura. Esta capacidad se expresa como la posibilidad de impulsar iniciativas que se oponen a las elaboradas desde el poder legitimador de las desigualdades. Esta idea de viabilidad contiene y se define en función de la utopía, en cuanto proyecto que expresa la visión de futuro de sus portadores. 
Las IIES proponen considerar los conocimientos propios, omitidos dentro del sistema educativo convencional, y construir programas educativos enmarcados en la cosmovisión particular de los pueblos en estrecha vinculación con los saberes universales. Para Mato (2009b), las experiencias de educación superior impulsadas por el movimiento indígena, más allá de formar cuadros técnicos, profesionales y políticos, crean la capacidad para hacer una reflexión crítica y concebir posibilidades futuras en las sociedades contemporáneas. Al mismo tiempo, generan en los egresados un potencial deseo de contribuir en su contexto comunitario. Dichos proyectos, al posicionarse desde un lugar propio, establecen los términos de la discusión que desafían la hegemonía del conocimiento eurocéntrico de pretensiones universalistas (Restrepo y Rojas, 2010).

Puede comprenderse entonces que el concepto de interculturalidad tiene una significación en Latinoamérica: "ligada a geopolíticas de lugar y espacio, desde la histórica y actual resistencia de los indígenas y de afrodescendientes, hasta sus construcciones de un proyecto social, cultural, político, ético y epistémico orientado a la descolonización y a la transformación” (Walsh, 2007:47). Desde esta perspectiva, considero imprescindible recuperar las múltiples subjetividades inmiscuidas en el discurso de la interculturalidad, que posibiliten involucrar a los actores sociales como sujetos en la construcción de diferentes formas de vida y no como meros objetos receptores de formas de vida impuestas.

Gasché (2008) plantea que no puede pensarse la interculturalidad sin el binomio dominación/sumisión. Considerar la interculturalidad como una relación horizontal no es más que un eufemismo para disfrazar relaciones verticales. Dadas las condiciones históricas de desigualdad y negación de las culturas originarias en Latinoamérica y el peso que la modernidad está teniendo en la construcción del imaginario de vida, es difícil pensar la interculturalidad como algo ya establecido. En ese sentido, las propuestas educativas antes mencionadas abonan a la construcción y consolidación de la educación intercultural en Latinoamérica. 


\section{La práctica de la educación intercultural}

Difícilmente se puede hablar de una práctica de la educación intercultural homogénea, más bien de una heterogeneidad tanto de las prácticas, así como de las instituciones y los sujetos involucrados en el proceso educativo. Desde una perspectiva intercultural, la transmisión de conocimientos no es suficiente cuando no se asume un compromiso por transformar las situaciones de vida, no únicamente de los estudiantes, sino también de las comunidades con las que se interactúa. Se trata de generar condiciones de aprendizaje cargadas intencionalidad que contribuyan a la acción y la transformación.

Por práctica educativa puede entenderse: "cualquier forma coherente y compleja de actividad humana cooperativa, establecida socialmente, mediante la cual se realizan los bienes inherentes a la misma” (Mcintyre, 1987:233, citado por Bárcena, 2005). Debe considerarse que una práctica es más que un conjunto de habilidades técnicas; si bien puede ser un proceso de iniciación, es también un lugar para la búsqueda, al menos en la educación: "del personaje al que se aspira y del autoconocimiento. Esta búsqueda, a la vez individual y social, a la vez privada y pública, tiene una connotación política, en un sentido primario y fundamental del término" (Bárcena, 2005:128).

Generalmente en la educación convencional se privilegia la transmisión de conocimientos a través de una enseñanza memorística y guiada por expertos en el tema, en la que regularmente predomina una visión economicista de la realidad. Para Quintar, se puede denominar como "pedagogía del bonsái", la cual ha sido instaurada para subordinar y para oprimir:

Para hacer un bonsái hay que ir manipulando, con mucho cuidado, con mucho cariño y con mucha suavidad la raíz central de lo que podría llegar a ser un gran árbol. En 
el ámbito educativo esta raíz es el pensamiento [así] se va cortando también el pensar y la potencialidad del sujeto (Quintar, en Rivas, 2005:125).

Bárcena, Larrosa y Mèlich (2006) señalan que la educación actual se enfoca más en el saber-hacer, que en la experiencia del saber-expresar, y que predomina un interés por la destreza, la habilidad y la competencia.

Desde el enfoque intercultural debe considerarse la construcción de una educación que posibilite recuperar al sujeto y permita generar conciencia histórica para reconstruirnos como personas-sujetos. Pensar la educación como una experiencia reflexiva:

[...] implica tener presentes al menos tres cualidades: la presencia del otro, su diferencia, la equivalencia de su discurso, porque solo puedo hablar y cuidar del otro si escucho lo que me dice; porque los individuos están en una historia singular, y porque si repitiésemos el mismo discurso en eco no seríamos capaces de comunicarnos; y porque si no concedo al discurso del otro una importancia equivalente al del mío, seré incapaz de entender y dialogar con él (Bárcena, 2005:136).

El hecho de retomar la experiencia educativa es relevante para los procesos de enseñanza-aprendizaje porque, en la mayoría de ellos, el programa metodológico se basa en la simple transmisión de contenidos irrelevantes, a la vez que el estudiante se percibe como un objeto de recepción de información, que se evalúa a través de la cuantificación del conocimiento, y cuyo aprendizaje no alcanza a ser significativo, sino memorístico y repetitivo (Suárez, 2007).

Desde esa postura la educación que se transmite crea "analfabetos contextuales, gente que sabrá mucho, que tendrá mucha información, pero que no sabe leer su mundo" (Fornet-Betancourt, 2009:14). Persiste, en términos de Freire, una educación bancaria en 
la cual "el único margen de acción que se ofrece a los educandos es el de recibir los depósitos, guardarlos y archivarlos” (Freire, 2002:52).

Por ello, cada vez hay más sectores de la sociedad (principalmente desde los movimientos sociales y las organizaciones no gubernamentales) que reclaman una educación con mayor pertinencia sociocultural, que favorezca la creación de aprendizajes significativos y en la que, además, se retome lo cotidiano, lo lúdico, lo afectivo y lo experiencial como parte esencial del proceso educativo. ${ }^{28}$ Para Mateos (2011), estas propuestas se verán retroalimentadas de acuerdo con las inclusiones heterogéneas de actores académicos, extraacadémicos, gubernamentales, no gubernamentales, locales, nacionales e incluso globales.

Entre las propuestas más innovadoras en el ámbito de la educación intercultural destaca el planteamiento de Dietz y Mateos de "educar para descolonizar" (2011:57). En esta propuesta se reconoce el sesgo hacia lo indígena en el seno del discurso intercultural, pero también se constata un "giro poscolonial/decolonial" y aparece la metáfora del "diálogo y el debate" como una característica central de la interculturalidad, lo cual tiene resonancia con lo que plantea Bárcena (2005).

Desde el pensamiento decolonial latinoamericano se busca un posicionamiento epistémico, metodológico y ontológico distinto al

\footnotetext{
${ }^{28} \mathrm{La}$ experiencia es lo que nos pasa, o lo que nos acontece, o lo que nos llega. No lo que pasa, o lo que acontece, o lo que llega, sino lo que nos pasa, o nos acontece, o nos llega. En consecuencia, el sujeto de experiencia es un sujeto ex-puesto. Desde el punto de vista de la experiencia, lo importante no es ni la posición (nuestra manera de ponernos), ni la o-posición (nuestra manera de oponernos), ni la imposición (nuestra manera de imponernos), ni la pro-posición, sino la ex-posición, nuestra manera de exponernos, con todo lo que eso tiene de vulnerabilidad y de riesgo. Por eso es incapaz de experiencia el que se pone, o se opone, o se impone, o se propone, pero no se ex-pone. Es incapaz de experiencia aquel a quien nada le pasa, a quien nada le acontece, a quien nada le sucede, a quien nada le llega, a quien nada le afecta, a quien nada le amenaza, a quien nada le hiere. El sujeto de la experiencia tiene algo de ese ser fascinante que se expone atravesando un espacio indeterminado y peligroso, poniéndose en él a prueba y buscando en él su oportunidad, su ocasión (Larrosa, 2003). Retomando el argumento anterior, es imprescindible decir que la experiencia en todo proceso educativo debe ser primordial, ya que a través de ella se puede accederse a la ex-posición del otro.
} 
que hegemónicamente se ha presentado en el ámbito educativo. Se continúa insistiendo en la necesidad de mejorar los procesos de enseñanza-aprendizaje y se proponen otros paradigmas educativos, otras pedagogías en las que lo intercultural se discute, resignifica y apropia desde otra perspectiva.

Difícilmente se puede hablar de una sola propuesta metodológica para y desde la educación intercultural porque esta debe obedecer, entre otros aspectos, al contexto donde se interactúa. No obstante, hay varios autores que problematizan sobre los retos y perspectivas para construir una pedagogía intercultural. ${ }^{29}$

Para Quintar (en Rivas, 2005) se trata de la recreación de modos de hacer con otros, donde se recupera la idea de "común-unidad"; no se trata de un discurso de grandes transformaciones, sino que desde esa "común-unidad" se trabaja en un diálogo para problematizar lo que cada uno piensa no tanto como opinión, sino desde la lógica del razonamiento que está en cada discurso. Quintar (en Rivas, 2005) y Zemelman (2005b) plantean que la teoría no puede remplazar al sujeto, sino es el sujeto el que se debe sentir afectado para que le dé sentido al discurso de otros en su realidad. A eso le denominan "ruptura de parámetro". ${ }^{30}$ Desde esa postura el papel del maestro es fundamental no solo para recuperar la memoria histórica y los elementos socioculturales

\footnotetext{
${ }^{29}$ Véase: Baronnet, 2012, 2013; Berlanga, 2005, 2007; Dietz y Mateos, 2011; FornetBetancourt, 2009; Gasché, 2008, 2010; López, 2009; Rivas, 2005; Saldívar, 2006; Walsh, 2005a; Zemelman, 2005a, 2005b.

${ }^{30}$ Estela Quintar narra una experiencia que puede contribuir a ejemplificar cómo se puede generar un diálogo para problematizar la realidad desde una perspectiva crítica: "Recuerdo que ese año fui a dar allá un seminario y alguien me preguntó: Estela, eso que estás diciendo está muy bien, pero ¿cómo se hace para enseñar cuando los chicos tienen hambre o se duermen porque lo único que toman es mate cocido?, y contesté: si les quieres enseñar historia y geografía eurocéntrica, como nos marcan los textos en cualquiera de los libros que estudiamos, seguramente a ese chico que tiene hambre no le va a interesar, pero si uno puede transformar su propia situación de hambre como fenómeno social para poder interpretarlo, para poder entenderlo, pues así seguramente no sólo va a apropiarse de su realidad más compleja como aprehensión, como comprensión, sino que además va a poder pensar y actuar alternativas. De eso se trata la crítica” (en Rivas, 2005:119).
} 
del contexto, sino también para contrastarlos con otros saberes y conocimientos.

Walsh (2004) señala que el camino hacia la descolonización no debe partir simplemente de relacionar conocimientos (ancestrales, occidentales, orientales) entendidos como bloques claramente identificados y encerrados, sino de contribuciones críticas a nuevos procesos de interacción y diálogo a partir de debates intelectuales sobre la creación de conocimientos y nuevos de modos de pensar que cruzan fronteras. Señala también que, en general, hay una relación desigual al momento de entablar el diálogo porque el conocimiento indígena se asume como algo siempre local y temporal —asociado con el pasado, con lo tradicional— al frente del no-lugar y la no-temporalidad del conocimiento occidental.

Para Walsh, el procedimiento de la interculturalidad en la educación debe considerar tres referentes centrales: "1) el contexto sociocultural del centro escolar; 2) la realidad sociocultural de los alumnos y sus familias y, 3) el perfil de los docentes y su relación con la comunidad de los alumnos y sus familias" (Walsh, 2005a:27). Sin lugar a dudas, al retomar los tres criterios se puede alcanzar una diversidad de experiencias educativas y comunitarias.

Algunos aspectos a considerar en toda práctica educativa, de acuerdo con Berlanga (2005), son: a) la intencionalidad: se refiere a que la práctica educativa tiene que ver con la idea de transformar, de construir un mundo mejor y más justo; b) la cotidianeidad: es el reto de crear el proceso educativo siempre desde un aquí y un ahora; c) la relación pedagógica: considerar al otro como persona o como personas y no como categorías o abstracciones; d) el poder: reconocer y hacer consciente que en las prácticas educativas están presentes el poder y la posibilidad de transformarlo, y e) la interculturalidad: cómo lograr que la interculturalidad sea realidad, es decir, cómo "interculturactuamos", y no solo plantearlo como una cuestión teórica.

Incorporar la "cotidianidad", la "intencionalidad", la "presencia del otro", "su diferencia” y la "equivalencia de su discurso" no úni- 
camente implica una transformación del proceso educativo, sino que también abre la posibilidad de cuestionar las relaciones de poder e inequidad presentes en distintos ámbitos de la sociedad en la que estamos inmersos como actores sociales.

Para Zemelman, la cuestión de la intencionalidad nos obliga a generar en el sujeto la necesidad de hacer algo, al contrario de lo que sucede en el sistema económico que: "busca la minimidad y por lo tanto crear sujetos necesitados, sujetos mínimos o sujetos bonsái a los que han sido cortadas sus raíces” (2005a:3). Este autor plantea también la idea del sujeto erguido, es decir, un sujeto que sea capaz de construir posibilidades de futuro (2005b).

De ahí que, desde y para la interculturalidad, se trate de educar desde la memoria, desde la experiencia y desde la utopía (Berlanga, 2007). Educar desde y para la interculturalidad es trazar horizontes de vida posibles que contribuyan a dignificar la cotidianidad de los sujetos y los pueblos. En ese sentido, representa una posibilidad para trascender hacia otros procesos de aprendizaje en los que se incluya la resolución de problemas articulados al contexto, el desarrollo de la creatividad, la colaboración y el trabajo en equipo.

La utilización de la realidad sociocultural es fundamental para la generación de situaciones socioeducativas. Propiciar aprendizajes significativos implica, para Saldívar (2006), abrir la escuela a diferentes espacios (sociales, ambientales y culturales) y dinamizar la relación con los distintos actores sociales presentes en la comunidad y la región (ancianos, médicos, mujeres, productores, autoridades, etcétera). En la misma dirección, para la educación intercultural una categoría pedagógica es el mundo de vida como ámbito de aprendizaje y enseñanza de las comunidades, donde la familia, la escuela, las instituciones, todo es parte de ese mundo.

Baronnet (2013) señala que, para generar la transformación de un modelo educativo que posibilite un aprendizaje situado y que refuerce la autoestima, parece ineludible operar una ruptura contundente con la marginalización política de las comunidades y organi- 
zaciones indígenas para que puedan erigirse como sujetos activos y responsables de la orientación de su propio quehacer educativo.

Como puede intuirse, la práctica educativa tiene inherente la dimensión política, de ahí que preferentemente las acciones que se implementan persigan un objetivo común, aunque Bárcena apunta que: “[...] los fines propios de una práctica no tienen por qué coincidir con los fines de las instituciones que les dan cobijo. Toda práctica necesita instituciones ad hoc, que tienen un enclave social determinado" (2005:128).

La educación intercultural, como práctica, depende tanto de factores externos (política educativa, iniciativas gubernamentales, movimientos sociales, contextos comunitarios), como de factores internos (práctica educativa, acompañamiento para la construcción, reconocimiento del sujeto en formación, la escucha como posibilidad de diálogo y la disponibilidad de los sujetos) que pueden facilitar la apropiación e implementación de formas creativas y no convencionales de educación.

\section{La vinculación comunitaria desde una propuesta educativa intercultural}

El concepto de vinculación ha cobrado relevancia durante los últimos años al cuestionarse el papel que podrían desempeñar las universidades y los centros de investigación frente a los principales problemas sociales, ambientales y productivos de las regiones donde se ubican. Su marcado "academicismo" ha derivado en una tendencia clara de separación entre los procesos de formación y la atención a los problemas (violencia, deterioro ambiental, migración, pobreza, etcétera) que viven de manera cotidiana amplios sectores de la sociedad.

La influencia mercantilista en la educación ha llevado a que la atención de las interacciones de las universidades y centros de investigación prioritariamente se centre en los sectores institucionales, empresariales e industriales, que responden más a una 
intención de inserción laboral que de formación crítica de los sujetos y de transformación de las condiciones sociales de inequidad e injusticia que prevalecen.

La vinculación en las IES, junto con la docencia y la investigación, se ha convertido durante los últimos años en una de las actividades sustantivas del quehacer educativo ya que permite desarrollar aprendizajes significativos durante el proceso de interacción con los diferentes contextos socioculturales donde se ubican..$^{31}$

En el Programa Nacional de Extensión de los Servicios, Vinculación y Difusión de la Cultura de México se entiende por vinculación:

[...] la estrategia institucional que involucra a funcionarios, académicos y estudiantes de las IES en acciones orientadas a la transferencia y aplicación del conocimiento a los sectores público, social y productivos de bienes y servicios, para contribuir al desarrollo socioeconómico del entorno y coadyuvar a la pertinencia institucional (ANUIES, 2012:11).

En el Plan de desarrollo al 2016 de la Asociación Nacional de Universidades e Instituciones de Educación Superior (ANUIES) se menciona la necesidad de: "buscar nuevas formas de proyectar y vincular a las instituciones de educación superior y centros de investigación con su entorno para la suma de esfuerzos y capacidades en beneficio mutuo" (ANUIES, 2012:11). Mediante la encuesta efectuada en México por el Consejo Nacional de Ciencia y Tecnología (CONACyT) y la ANUIES, aplicada a 341 IES y centros de investigación con el objetivo de conocer el estado de la vinculación, se obtuvo que más del $80 \%$ de las IES del país realizan actividades de vinculación con los sectores público, productivo y social. Asimismo, el $82.5 \%$ de las IES ofrece servicios de consultoría, el $84.2 \%$ se dedica a dar asesorías y el $77.2 \%$ a servicios de asistencia técnica.

${ }^{31}$ Véase: Alvarado, 2009; Campos y Sánchez, 2005; Gould, 1997; Malagón, 2006; Moreno y Maggi, 2011; Saldívar, 2012; Vallaeys, 1999. 
En lo que se refiere a otras formas de vinculación, se encontró que:

- El 35.1\% de las instituciones de educación superior encuestadas ha realizado transferencia de tecnología.

- El 26.3\% ha llevado a cabo investigación básica contratada y licenciamiento de tecnología (24.6\%).

- El 20\% de las IES incorpora, entre las estrategias para fortalecer la vinculación al interior de sus programas académicos, la elaboración de diagnósticos para identificar las necesidades de su entorno.

- El 18.7\% de las universidades públicas y el 10.3\% de las universidades particulares han publicado catálogos de los servicios que ofrecen.

- La mayor parte de los recursos para la vinculación proviene del propio presupuesto de las IES. Un 5\% de los recursos procede de programas del sector público y otro porcentaje similar de recursos emana de las empresas (ANUIES, 2012).

En el mismo plan se señala que algunos de los problemas más significativos que enfrentan las IES para impulsar las actividades de vinculación son:

- El 63.2\% de las universidades públicas y el 58.3\% de las particulares señalan que hay insuficientes recursos humanos calificados, tanto del área administrativa como del sector académico, para desarrollar proyectos de vinculación.

- El 80.7\% de las universidades públicas registra la falta de estímulos y reconocimientos dirigidos a profesores y estudiantes que participan en proyectos de vinculación.

- Al interior de las IES existe poca precisión en la misión de los programas de desarrollo institucional acerca del significado y la importancia de las actividades de vinculación con el entorno, y en particular con el sector productivo. 
- Se observa poca flexibilidad de las estructuras curriculares para la formación de recursos humanos, lo cual inhibe la vinculación.

- Al interior de las IES falta una cultura de vinculación que estimule la comunicación, la cooperación, el interés y la identificación de la capacidad institucional para resolver los problemas del entorno (ANUIES, 2012).

El peso que tiene el discurso mercantilista de la vinculación se muestra en el estudio de Moreno y Maggi (2011), donde los autores analizan el ámbito de la vinculación en seis universidades mexicanas que concentran el 35.6\% de la matrícula nacional de licenciatura. Dichos autores insisten en la necesidad de generar estrategias para articular las IES con el sector empresarial y con la sociedad en su conjunto. Se reconoce que la vinculación aporta herramientas necesarias para atender los requerimientos de todos los actores sociales y que además ayuda a establecer puentes de comunicación e intercambio entre sectores para facilitar a los estudiantes su inserción en los sectores social y productivo. Esa misma idea se encuentra en el Plan Nacional de Desarrollo 2013-2018, donde se afirma que:

[...] es importante fomentar las carreras técnicas y vocacionales que permitan la inmediata incorporación al trabajo, propiciando la especialización, así como la capacitación en el trabajo. Para lograr una educación de calidad, se requiere que los planes y programas de estudio sean apropiados, por lo que resulta prioritario conciliar la oferta educativa con las necesidades sociales y los requerimientos del sector productivo (Poder Ejecutivo Federal, 2013:62).

Lo anterior muestra un panorama sobre el estado de la vinculación ejercida por parte de las IES afiliadas a la ANUIES, en el cual se observa una tendencia a ligar la educación superior prioritariamente 
con el sector empresarial. Aunque se menciona la necesidad de hacer vinculación con otros sectores sociales, no se señala con claridad cuáles son ni qué estrategias se utilizarán para dicha tarea.

Saldívar (2012) define desde una perspectiva más amplia la centralidad de la vinculación comunitaria como un conjunto de estrategias o mecanismos que se constituyen en el puente que permite dar sentido y significado (motivo) al hecho educativo. De acuerdo con Malagón (2006), la vinculación está ligada intrínsecamente al contexto social. No obstante, el autor identifica dos ejes de discusión: por un lado, la universidad simplemente es un reflejo de la sociedad y en ese sentido se constituye en un mecanismo para la reproducción de la mano de obra calificada que las demandas sociales y económicas así lo exigen, y por otro lado, la universidad es un ente autónomo para construir interpretaciones del entorno que permitan interaccionar e incidir en los procesos de cambio de la sociedad.

Otras diferencias, más bien de tipo conceptual, se enmarcan en las siguientes posiciones:

- Quienes consideran que la vinculación tiene un contenido básicamente económico.

- Quienes consideran que la vinculación se resuelve exclusivamente mediante un acercamiento físico con la sociedad (visión de aproximación física, que también está fuertemente asociada a una visión asistencial).

- Quienes consideran que la vinculación es una nueva función sustantiva de las universidades (Campos y Sánchez, 2005:6).

Sobre este último aspecto, Campos y Sánchez (2005) mencionan que, cuando las universidades reconocen la vinculación como parte sustantiva de su quehacer educativo, esto les permite identificarse como instituciones interesadas en participar en la solución de las problemáticas que enfrentan los ciudadanos de las regiones en las cuales están localizadas. 
En ese sentido, se puede interpretar la vinculación como aquella que busca establecer relaciones de colaboración auténtica para generar situaciones de aprendizaje y, al mismo tiempo, contribuir a mejorar la situación de vida de las comunidades y atender los problemas centrales que enfrentan de manera cotidiana.

Campos y Sánchez (2005) indican que las universidades mexicanas han emprendido "acercamientos" con la planta productiva y con la sociedad a partir de un desconocimiento, especialmente teórico, de la función de la vinculación; ese desconocimiento hace que se confunda con otras actividades como la extensión, la difusión y la prestación de servicios. También señalan que hay diversas formas y enfoques de entender lo que es la vinculación, no obstante, prevalece aquella que alude a las relaciones que existen —o deben existir- entre la universidad y la sociedad.

La interculturalización de las IES del país —oficiales y no oficiales - abre una nueva brecha para interactuar desde una postura diferente en contextos rurales o indígenas donde las políticas públicas históricamente han tenido presencia a través de programas asistencialistas. En ese sentido, el énfasis de renovar la vinculación no se dirige hacia el beneficio económico, sino más bien a la construcción de manera consensuada de horizontes de acción acordes con las necesidades sociales, culturales, políticas y ambientales de la población, sin olvidar la responsabilidad social que le corresponde al Estado.

La utilización de metodologías participativas para la construcción de saberes desde la interculturalidad es una herramienta indispensable para partir desde un conocimiento culturalmente situado y negociado, con el desafío de promover la ruptura del individualismo, "fortaleciendo con ello estrategias de construcción colectiva que permitan recuperar la centralidad de los sujetos" (Navarro y Rojas, 2015:25).

A pesar de que la vinculación en muchas IES aparece ligada al sector productivo y a instituciones gubernamentales, e incluso está abierta a la cooperación internacional, independientemen- 
te hacia qué sector se incline ${ }^{32}$ se considera como una "región de aprendizaje”: "La región aparece como el espacio natural de pertinencia entre la universidad y la sociedad, por cuanto en la región se condensan las dinámicas de la globalización en lo internacional y lo nacional” (Malagón, 2006:85).

El concepto de "vinculación" se plantea en este trabajo como una forma de construir conocimientos, habilidades y actitudes, al articular el aprendizaje de los sujetos que participan en procesos educativos y de formación con las actividades cotidianas que realizan y con los contextos socioculturales en los que viven. De igual forma, la vinculación implica reconocer que existen diferentes formas de conocimientos y saberes culturales, sociales, científicos, populares, y que todos son fundamentales para la construcción de caminos que permitan enfrentar los complejos problemas que experimenta la sociedad.

La importancia radica en que estos cuerpos de conocimiento o pensamiento distribuido, como menciona Moll (1997), son motores vitales para la innovación y la transformación de la sociedad. La vinculación se presenta también como una manera de promover y facilitar la innovación social y el mejoramiento de las condiciones de vida, no solo de los estudiantes, sino también de sus familias y de las comunidades donde viven.

En las IES las áreas de vinculación han sustituido poco a poco a los departamentos de extensión universitaria, convirtiéndose en propuestas más dinámicas de interacción y articulación con los distintos actores sociales e institucionales, y en espacios o territorios más allá de las instalaciones educativas.

A pesar de ello, como se ha señalado anteriormente, el peso de la visión productivista ha ganado terreno y, en muchos casos, la

\footnotetext{
${ }^{32}$ Schugurensky (2002, citado en Malagón, 2006) señala una dinámica de tránsito de instituciones autónomas (control de su agenda) a instituciones heterónomas (agenda compartida y a veces impuesta desde afuera), como resultado de la presión de la "doble hélice”: Estado y sector productivo.
} 
vinculación ha quedado reducida a contratos con empresas o industrias para la realización de diferentes actividades de investigación, asesoría y formación, ignorándose, por tanto, la diversidad de actores sociales que existen en las comunidades (organizaciones sociales, cooperativas, consejos vecinales, organizaciones indígenas, grupos de mujeres, jóvenes, adultos mayores, etcétera), y que cotidianamente enfrentan problemas de distintas índoles para mejorar su situación de vida.

El término original de "extensión" fue duramente criticado por Freire (1973) porque presenta un sentido semántico implícito de transmisión, entrega, donación, invasión cultural y manipulación, frente a lo que este autor proponía que debería ser el hecho educativo: un acto de comunicación y dialogicidad. La vinculación presupone entonces no solo un acto de transmisión o de mejoras en el campo de la financiación de la investigación y el desarrollo tecnológico, sino, sobre todo, una oportunidad de construir situaciones de aprendizaje, comunicación y diálogo durante los procesos de formación de los estudiantes a lo largo de su carrera profesional en sus contextos socioculturales y territorios. 



\section{Capítulo 2 \\ El contexto de la educación superior intercultural en México}

\section{La interculturalidad en el ámbito educativo: el caso mexicano}

Para Bertely (1998), el resultado de las políticas educativas hacia los indígenas en el siglo XX fue paradójico. Por un lado, se avanzó en el reconocimiento de la diversidad etnolingüística y sobre el estado de inequidad económica, política y social que padecen los pueblos originarios, pero, por otra parte, se institucionalizó una identidad homogénea y un modelo de educación indígena precario y segregador, que borra las diferencias entre los pueblos e ignora su diversidad de expectativas en torno a la escuela.

Un hecho significativo en la historia de la educación en México es que en el artículo $3^{\circ}$ de la Constitución mexicana de $1917^{33}$ se establece que la educación a impartir será: laica, gratuita, democrática y nacional. Ello propició la inclusión al sistema educativo de sectores de la población que, por su condición social, habían sido ignorados.

\footnotetext{
33 “Todo individuo tiene el derecho a recibir educación. El Estado-Federación, Estados y Municipios- impartirán educación preescolar, primaria y secundaria [...] La educación que imparta el Estado tenderá a desarrollar armónicamente todas las facultades del ser humano y fomentará en él, a la vez, el amor a la Patria y la conciencia de solidaridad internacional, en la independencia y la justicia” (Diario Oficial de la Federación, 2002:12).
} 
De acuerdo con Robles (1977), a partir de 1920 México confrontó la difícil tarea de integrar un modelo de gobierno capaz de homogenizar las políticas de desarrollo nacional para satisfacer las demandas de una población restringida por su alto grado de desigualdad cultural, económica y social. Fue en 1921 cuando se creó la Secretaría de Educación Pública (SEP), con José Vasconcelos como titular, que promovió una educación dirigida a contribuir al desarrollo económico y tecnológico del país.

Dentro de la SEP estaba el Departamento Indígena, que de acuerdo con Vasconcelos no tenía otro propósito "que preparar al indio para el ingreso a las escuelas comunes, dándole antes nociones de idioma español” ([1937]2011:72). En ese sentido, la propuesta de desarrollo nacional se centraba en el mestizaje.

Junto con la SEP se crearon algunos proyectos que tuvieron repercusiones sobre la población indígena, entre ellos se pueden mencionar las Misiones Culturales, que se dedicaron a enseñar artes y oficios en todo el país (Gamboa, 2007). El misionero fue un tipo de maestro cuya primera labor consistía en visitar los centros rurales y en forma especial las comunidades indígenas; de esas visitas rendía informes a las autoridades educativas y trataba de reclutar maestros rurales para destinarlos a las poblaciones más necesitadas (Tinajero, 1993). En la capital de la República se estableció la Casa del Estudiante Indígena con la finalidad de demostrar que los indios, no obstante sus diferencias raciales con los europeos, podían superar la distancia cultural evolutiva que los separaba de la civilización occidental (Bertely, 1998).

Algunos proyectos en países de Latinoamérica obedecieron a ese propósito, como por ejemplo el reclutamiento de jóvenes en las comunidades para entrenarlos en tareas de educación con el fin de que regresaran e introdujeran las ideas del progreso, la modernización y el desarrollo que proclamaban las élites dominantes (González, 1965).

En un esfuerzo por promover el desarrollo socioeconómico y lograr la "integración” a la vida económica, política y cultural de 
los pueblos indios, se creó en 1948 el Instituto Nacional Indigenista (INI), a partir del Congreso Indigenista Interamericano celebrado en Pátzcuaro, Michoacán, en 1940. Con ello se dio continuidad al proyecto de incorporar al indígena a la sociedad nacional.

La política indigenista partió de una serie de acciones promovidas por medio de los Centros Coordinadores Indigenistas del INI. Uno de los primeros se estableció en San Cristóbal de Las Casas, Chiapas, en 1951, donde Aguirre Beltrán fungió como director y a través del cual se realizaron aportes desde la antropología a los estudios indigenistas de Los Altos de Chiapas. Dietz y Mateos indican que la noción de "lo intercultural" aparece con un sentido más aplicado en el mismo INI, en la definición del modelo de "regiones interculturales" o "regiones de refugio" (2011:97). Estas regiones, en las que los indígenas y mestizos o "ladinos" entraban en contacto en relaciones desiguales, se convirtieron en espacios para la promoción de una política indigenista. ${ }^{34}$

El aporte de Aguirre Beltrán al concepto de interculturalidad es innegable. Para Fábregas (2005), Aguirre distinguió con claridad una interculturalidad contextualizada por el dominio de una cultura sobre otra, y además tomó partido por los pueblos indios pero, en contraste, no confió en la capacidad de los indios mexicanos para desarrollar sus mundos y sobrevivir a la modernidad capitalista.

Una de las principales críticas a las políticas implementadas por el INI es que se promovió un discurso que moldeaba las minorías étnicas a imagen y semejanza de la sociedad mestiza: si se de-

\footnotetext{
${ }^{4}$ Báez-Jorge, en el prólogo a la obra Regiones de refugio de Gonzalo Aguirre Beltrán, define la política indigenista como aquella en la que: "Se conjugan admirablemente las categorías abstractas priorizadas por la actividad intelectual, con las preocupaciones prácticas orientadas al beneficio social. La obra proyecta relaciones indisolubles entre la esfera cognoscitiva y la pragmática. La síntesis de estas vertientes configuró una propuesta orgánica que singularizó al indigenismo mexicano, generando simultáneamente planteamientos ideológicos que se convertirían en fundamento de los programas orientados en beneficio de las comunidades indígenas [...] con razón Regiones de refugio es considerada una obra fundamental del indigenismo en Latinoamérica” (Báez-Jorge, 2009:10).
} 
seaba formar parte de una "sociedad moderna" tendrían que dejar de hablar la lengua indígena, olvidar sus usos y costumbres e inmiscuirse en el sistema político nacional homogeneizante. Bonfil (1982) señala que las décadas del desarrollo modernizador fueron un periodo de negación porque el proyecto propuesto de país implicaba la adopción de una cultura nueva, extraña y moderna en la que las culturas populares solo tenían cabida como obstáculos, los cuales había que superar. Para Stavenhagen (2013), el indigenismo fue desde el principio una política del Estado mexicano diseñada y llevada a cabo por intelectuales mestizos dirigida al beneficio de los indígenas, pero sin la participación de estos.

En los años cincuenta se debatió entre la castellanización directa o la alfabetización en lengua indígena como paso preliminar a la castellanización. Unos afirmaban que era más eficaz proceder directamente a la enseñanza del español y que no debía perderse el tiempo en enseñar las lenguas indígenas, que al final no tendrían ninguna utilidad para los indígenas; otros sostenían que los niños respondían mejor a la enseñanza en su propia lengua materna, por lo que había que alfabetizar en lengua indígena (Citarella, 1990). En 1951 la UNESCO recomendó el uso del idioma vernáculo para la alfabetización de los pueblos indios, aunque lo consideraba solo como un instrumento para la castellanización.

A finales de los años setenta se creó la Dirección General de Educación Indígena (DGEI) dependiente de la Subsecretaría de Educación Básica. En esta instancia se distingue una planeación idiomática; lo que se pretendía era fortalecer la integración sociocultural étnica por medio de la revitalización de la lengua nativa, favoreciendo la integración geopolítica con el dominio del castellano (Bertely, 1998).

Así, el INI y la DGEI son una muestra del indigenismo integracionista; no es de extrañar entonces que desde diferentes sectores se criticaran tanto la ideología como la práctica promovidas por el Estado. Desde diversos sectores sociales se comenzó a plantear la necesidad de reconocer la diversidad de grupos culturales en el 
país, e inició la gestión de una educación bilingüe bicultural como una meta en sí misma y no simplemente como un paso para facilitar la castellanización. Para Bonfil (1982), el término bicultural fue suplantado por el calificativo de intercultural, reforma que deriva del Convenio 169 de la Organización Internacional del Trabajo (OIT) ratificado en 1990.

La educación pública llegó a ser uno de los espacios esenciales en los se aplicaron los postulados del indigenismo y se dirimieron numerosas controversias teóricas y metodológicas sobre el tema de la educación indígena. Esos debates comenzaron desde los años veinte en torno a temas como la escuela rural, los programas de castellanización y la escolarización en lengua indígena, hasta que a finales del siglo se llegó al concepto de educación intercultural bilingüe (Stavenhagen, 2013).

La educación indígena ha sido el punto central de diversas discusiones; por un lado, ha sido considerada como una respuesta a las necesidades de reconocimiento de las comunidades étnicas y, por otro, como parte fundamental del acceso de las personas indígenas al llamado mundo moderno. De ello se desprenden las diversas reformas que ha realizado el Estado a los planes y programas de estudio como parte de una política integracionista para los pueblos indígenas (Navarro y Saldívar, 2011). Bertely (1998) se cuestiona si la solución es ofrecer un modelo de educación indígena especial que segregue a los alumnos a partir de su identificación étnica o si, por el contrario, se trata de proporcionar una educación convencional y castellanizadora que niegue su especificidad lingüística y cultural.

En consecuencia, no se puede negar que en décadas pasadas el Estado-nación ha proyectado cierto tipo ideal sobre el ser mexicano; es decir, el nacionalismo aparece como una invención para categorizar desde una posición política a quienes son diferentes. Para Hobsbawm, desde una posición objetiva la idea de "nación" hace pensar que las personas hablan la misma lengua y comparten el mismo territorio y los mismos rasgos culturales e históricos. Así, 
es fácil pensar cómo se crean sentimientos nacionalistas a través de: "un grupo de prácticas normalmente gobernadas por reglas aceptadas abierta o tácitamente y de naturaleza simbólica o ritual, que buscan inculcar determinados valores o normas de comportamiento por medio de su repetición” (Hobsbawm, 1992:8).

El mismo autor precisa que, para efectos de análisis, "el nacionalismo antecede a las naciones. Las naciones no constituyen estados y nacionalismos, sino que ocurre al revés” (Hobsbawm, 1992:1718). De ahí que el afán de políticas culturales como el mestizaje se oriente hacia la construcción de una identidad nacional uniforme con la que se pretende alcanzar un sentimiento de unidad a través de simbolismos socialmente compartidos.

La diversidad en México históricamente ha sido poco valorada y, a pesar de que en recientes años el país se ha reconocido como una nación pluricultural, todavía se proyecta una imagen ideal de persona a través de los medios de comunicación, lo que genera la imposición de valores ajenos a la realidad. Es contradictorio que se reconozca la diversidad de lenguas indígenas y que paradójicamente su uso ocasione situaciones abiertas de discriminación.

En términos generales prevalece una tendencia a la construcción de una identidad uniforme que borra la diversidad social y cultural, además de que ignora los procesos de cambio constantes en las sociedades. En contrapartida, la educación intercultural surge como respuesta a partir de los movimientos sociales en pro de una formación con pertinencia social y cultural..$^{35}$

En la primera década del siglo XXI se han realizado esfuerzos gubernamentales para fomentar el reconocimiento de la diversidad cultural del país que se han expresado a través de la creación del Instituto Nacional de las Lenguas Indígenas (INALI), ${ }^{36}$ la CGEIB-

\footnotetext{
35 Por ejemplo, el Movimiento 500 Años de Resistencia Indígena de 1992 (con el lema: "Nunca más un México sin nosotros").

${ }^{36}$ Surgió a partir de la Ley General de Derechos Lingüísticos de los Pueblos Indígenas, publicada en el Diario Oficial de la Federación en 2003.
} 
SEP y las UI. Todas estas instituciones se establecieron en el sexenio en el que fue presidente Vicente Fox Quezada.

La CGEIB-SEP se creó en el año 2001. De acuerdo con Schmelkes (2008), a partir de la creación de esta dependencia del gobierno federal se plantearon dos nuevos objetivos de política educativa: 1) ofrecer una educación cultural y lingüísticamente pertinente para los indígenas en todos los niveles educativos y 2) ofrecer una educación intercultural a todo el alumnado del sistema educativo. La creación de las UI responde a ambos objetivos.

Las UI se fundaron en distintos estados del país; nueve de ellas se establecieron desde el año 2003 al 2020. Tres más se incorporaron al modelo educativo intercultural de la CGEIB-SEP, como es el caso de la Universidad Veracruzana Intercultural (UVI), la Universidad Autónoma Indígena de México (UAIM) ${ }^{37}$ en Sinaloa y la Universidad Comunitaria de San Luis Potosí. Las UI parten del principio de reconocer "la diversidad y no pretenden desarrollar un modelo único de institución. Cada una de ellas tendrá que construirse en función de las características, necesidades y potencialidades de la región en la que se encuentran” (Schmelkes, 2008:9).

$\mathrm{Al}$ inicio ofrecieron un conjunto de licenciaturas que fueron diseñadas en las oficinas centrales de la CGEIB y que tenían como fundamento el modelo de educación intercultural diseñado por la SEP. Estos programas fueron las licenciaturas en Lengua y Cultura, Desarrollo Rural/Sustentable, Turismo Alternativo, Comunicación Intercultural y Gestión Intercultural para el Desarrollo. Posteriormente se amplió la oferta con las licenciaturas en Derecho Intercultural, Enfermería y Salud Intercultural. En algunas universidades se abrieron ingenierías como la Forestal Comunitaria, Sistemas

\footnotetext{
${ }^{37}$ Sus orígenes se remontan a la fundación, en 1982, del Departamento de Etnología, que derivó en el Instituto de Antropología, en 1984, de la Universidad de Occidente (UDO). En agosto de 1999 este instituto admitió a los primeros 350 estudiantes, que posteriormente fueron reincorporados a la UAIM. En 2005 fue reconocida por las autoridades de la CGEIB con algunas condicionantes, como ser parte de las universidades interculturales (Guerra y Meza, 2009).
} 
Computacionales y Sistemas de Calidad, además de licenciaturas como Psicología Social Comunitaria, Contaduría, Derecho, Turismo Empresarial y Sociología Rural. ${ }^{38}$

Estas últimas ingenierías y licenciaturas corresponden a dos experiencias de educación superior con programas para atender a la población indígena que operaban antes de la creación de la CGEIB. Tal es el caso de la UAIM y la Universidad Comunitaria de San Luis Potosí (ahora llamada Universidad Intercultural de San Luis Potosí). Estas dos instituciones son parte de la Red de Universidades Interculturales (REDUI), transformada recientemente en la Asociación Nacional de Universidades Interculturales, por lo que cuentan con reconocimiento oficial de la SEP, de la que reciben presupuesto para operación.

Con la aparición de las UI se pretendía cambiar una política indigenista orientada a la integración de sectores de la población históricamente subordinados por el sistema educativo, y transitar hacia una educación que contribuyera a reforzar la identidad cultural del estudiantado y favorecer el mejoramiento de las condiciones de vida de las comunidades. La misión de las UI es:

[...] formar intelectuales y profesionales comprometidos con el desarrollo económico, social y cultural, particularmente, de los pueblos indígenas del país, revalorar los saberes de los pueblos indígenas y propiciar un proceso de síntesis con los avances del conocimiento científico; fomentar la difusión de los valores propios de las comunidades, así como abrir espacios para promover la revitalización, desarrollo y consolidación de lenguas y culturas originarias para estimular una comunicación pertinente de las tareas universitarias con las comunidades del entorno (Casillas y Santini, 2006:149).

${ }^{38}$ Ofrecidas en la Universidad Intercultural de San Luis Potosí y en la Universidad Indígena Autónoma de México. 
Desde su creación se ha cuestionado si la formación que recibe el alumnado en las UI atiende las demandas más apremiantes del entorno inmediato y si contribuye a generar mejores condiciones de vida para la población. Una de las mayores críticas es que las UI han sido diseñas e implementadas desde instancias gubernamentales centrales, es decir, “desde arriba”, con poca participación de las comunidades. En este sentido, la educación intercultural en México, para Dietz y Mateos (2011), se ha "institucionalizado".

Algunas propuestas educativas creadas por la sociedad civil $u$ organizaciones indígenas y comunitarias se enfrentan a diferentes escenarios: 1) no son reconocidas por la SEP y otras autoridades gubernamentales como instancias educativas a pesar de contar con un fuerte respaldo comunitario, ${ }^{39}$ 2) surgieron de demandas académicas, comunitarias o de organizaciones, pero fueron absorbidas por la SEP y en la actualidad son reconocidas en su presu-

\footnotetext{
${ }^{39}$ Por ejemplo, la Universidad Indígena de Chiapas en el municipio de Rayón surgió en 2005 tras un acuerdo del cabildo y se cerró unos años después ante la negativa de las autoridades educativas para asignarle clave de reconocimiento, a pesar de que tenía el respaldo de varios municipios y comunidades de la región Norte del estado. También se encuentra la Universidad Intercultural de los Pueblos del Sur (UNISUR), en Guerrero, que de acuerdo con Flores y Méndez (2012), después de un proceso de cerca de diez años de movilización, reflexión, consulta en más de 250 asambleas comunitarias y municipales, y tres Congresos sobre Educación Intercultural en el Estado, se abrió en 2007. Ofrecía las siguientes licenciaturas: Cultura, Lengua y Memoria; Gobierno y Administración de Territorios; Desarrollo Comunitario Sustentable; Justicia y Derechos Humanos, y Salud Comunitaria (aunque hasta la fecha no cuenta con reconocimiento oficial). En lugar de aprovechar la experiencia y estructura generadas por quienes impulsaron ese proyecto educativo, las autoridades gubernamentales decidieron "abrir en 2006 la Universidad Intercultural de Guerrero (UIEG), con otras carreras y otro enfoque similar a las otras universidades interculturales" (Warnholtz, 2013). En condición similar se encuentra la Universidad Comunal Intercultural del Cempoaltépetl (UNICEM), en la cual se articulan la educación comunitaria y la promoción de actividades productivas. Iniciaron sus propios procesos de formación a través de dos licenciaturas: la licenciatura en Comunicación Comunal y la licenciatura en Desarrollo Comunal, las cuales se han construido en estrecho diálogo con las comunidades: "[...] la universidad somete sus formas de trabajo a las que ha desarrollado la comunidad y no pretende imponer una forma de interacción educativa y social, como ocurre en las universidades convencionales" (Jablonska, 2015:243). La UNICEM surgió como un proyecto etnopolítico, y a pesar de haber establecido negociaciones con instancias federales y estatales, se posiciona como una institución propia y autogestionada (Jablonska, 2015).
} 
puesto y estructura, aunque gran parte de sus objetivos políticos de transformación se han desdibujado, ${ }^{40}$ 3) son promovidas por organizaciones no gubernamentales o religiosas y cuentan con el aval de la SEP para su operación académica, pero no logran una mayor cobertura, ${ }^{41}$ y 4) se desmarcan de los parámetros de la educación oficial ${ }^{42}$ y nacen como procesos de reflexión sobre el papel de la educación en la sociedad, operando sin presupuesto gubernamental y sin reconocimiento alguno por parte del Estado.

Dentro de este marco de diversificación de las IES subyace el propósito explícito de ofrecer una educación con pertinencia cultural y lingüística; sin embargo, como bien señala Bermúdez: "en Chiapas, se encuentra en desarrollo una línea que explora los procesos étnicos de apropiación y resignificación cultural que se producen en los espacios de formación llamados interculturales” (2015:165). Una experiencia es la UNICH-Oxchuc, y otra el CESDER-Moxviquil.

\section{Propuesta emergente de "abajo hacia arriba": CESDER-Moxviquil}

El CESDER inició sus actividades en 1982 en San Andrés Yahuitlalpan, comunidad indígena náhuatl de la Sierra Norte de Puebla, a partir del interés del maestro lasallista Gabriel Salom (supervisor de zona), quien decidió comenzar en una telesecundaria un proyecto educativo alternativo vinculado a la producción agrícola con la intención de contribuir a mejorar las condiciones de vida de los habitantes de la región. Inició esta propuesta educativa como un esfuerzo por vincular la formación con los elementos del contexto sociocultural y productivo de los estudiantes.

\footnotetext{
${ }^{40}$ Como los casos ya mencionados de la Universidad Autónoma Indígena de México, en Sinaloa, y la Universidad Comunitaria de San Luis Potosí (ahora llamada Universidad Intercultural de San Luis Potosí).

${ }^{41}$ La experiencia de formación media-superior como en Guaquitepec o el CESDER.

42 Para el caso de Chiapas se pueden mencionar la Universidad de la Tierra, la Universidad de la Montaña o las mismas Escuelas Autónomas Zapatistas.
} 
De acuerdo con Díaz (2001), el proyecto de la secundaria de San Andrés Yahuitlalpan estuvo marcado, en un primer momento, por la construcción de la escuela y la producción agrícola, ${ }^{43}$ ambas acciones realizadas con el apoyo de la comunidad. En esta fase, el trabajo escolar estaba organizado de acuerdo con el programa oficial de la SEP. Lo alternativo de la propuesta educativa se produjo cuando paulatinamente se fueron abandonando las emisiones televisivas para vincular los contenidos de las asignaturas con ejemplos tomados de la vida productiva de la comunidad. Se comenzó, de esa manera, con el modelo de las Escuelas Rurales de Formación para el Trabajo, primero con la educación secundaria bilingüe y posteriormente con la educación media superior, ambas vinculadas al contexto rural e indígena del alumnado.

En 1984 se creó en Zautla, Puebla, una preparatoria con el objetivo de formar promotores de desarrollo comunitario que funcionaba como sistema abierto para facilitar la participación de los jóvenes en las actividades productivas: "Hacia 1986 se adquiere —en ese municipio- el predio denominado "La Cañada" y se logra el establecimiento del Programa de Promoción del Desarrollo Comunitario, a través del cual se vinculan los estudiantes a las comunidades" (Saldívar, 2012:101).

Díaz (2001) señala que esta opción les permitía continuar con los estudios de nivel medio superior $\mathrm{y}$, al mismo tiempo, acceder a una formación de real incidencia en el trabajo rural comunitario, y con ello arraigar a los jóvenes en sus comunidades. Para Berlanga y Márquez (1995) se trata de un modelo de alternancia educación/producción que incorpora una lógica tanto educativa, como productiva, lo cual constituye una de las bases centrales de la estrategia pedagógica de su modelo educativo.

\footnotetext{
${ }^{43}$ El hecho de que el trabajo productivo tuviera un espacio importante se debía a la experiencia previa de Gabriel Salom, quien desde comienzos de los años sesenta había sido promotor y partícipe de acciones enfocadas en el "desarrollo rural" en diversas comunidades campesinas en extrema pobreza: en una escuela telesecundaria había construido ya una granja escolar integrada (Díaz, 2001).
} 
Además, el programa educativo se alternaba con otros programas de desarrollo comunitario, como el del Instituto de Educación para Adultos, en los cuales los estudiantes participaban como alfabetizadores y promotores sin remuneración alguna (Díaz, 2001). La centralidad otorgada al estudiante durante todo ese proceso de consolidación del modelo educativo (secundaria y preparatoria) se lograba a partir de las observaciones hechas por ellos mismos sobre su educación y sus actividades como promotores, lo cual permitió realizar ciertas adecuaciones curriculares e incorporar de manera más intencionada la realidad que experimentaban en su vida cotidiana: en su parcela, su familia y su comunidad (Pries, 1991).

A medida que egresaron las primeras generaciones de la preparatoria, las necesidades para continuar estudiando se hacían evidentes; en ese sentido, el colectivo de docentes y estudiantes decidió dar continuidad al proceso de formación a través de la Licenciatura en Planeación del Desarrollo Rural (LPDR), que inició formalmente en 1989 como respuesta a las necesidades de formación profesional para campesinos e indígenas de diferente regiones geográficas del país (Puebla, Chiapas, Veracruz, Oaxaca, Tabasco y Estado de México principalmente).

Si bien existen diferencias por su lugar de origen, los jóvenes que ingresan presentan semejanzas en cuanto a condiciones familiares (contextos marginados y empobrecidos) y por su interés en cualificarse para incidir de una manera más técnica y política en la transformación de su realidad (Huerta, Serrano y Comunidad, 2008).

En 2010, en Chiapas se comenzó a trabajar con la licenciatura en Planeación del Desarrollo Rural en la ciudad de San Cristóbal de Las Casas, lo cual fue posible a partir de la colaboración entre el CESDER-Puebla y el Centro de Formación para la Sustentabilidad Moxviquil, A.C., que ya llevaba varios años en la región formando líderes indígenas y campesinos, jóvenes y mujeres, bajo la propuesta de "comunidad de aprendizaje".

Históricamente, San Cristóbal ha sido un centro regional donde las comunidades indígenas de la zona Altos Tsotsil-Tseltal reali- 
zan distintas actividades administrativas, de servicios, culturales, sociales y económicas y donde convive población de varias regiones del estado. En este sentido, muchos jóvenes de la región encuentran en el CESDER-Moxviquil una alternativa para culminar sus estudios universitarios.

Antes de que Moxviquil comenzara con la LPRD, había implementado en 2002 la Escuela de Liderazgo Campesino e Indígena, cuyo diseño curricular acompañó Benjamín Berlanga, especialista en procesos de formación rural, quien además había participado en la construcción del plan de estudios del CESDER (Puebla) y del Bachillerato Técnico Bivalente "Bartolomé de las Casas” en Guaquitepec (Chiapas). En 2009 se comenzó a plantear la necesidad de abrir la licenciatura e iniciar un proceso de educación formal. Entre los motivos para comenzar un proceso similar —además de las coincidencias en la metodología de trabajo - se encontraba que muchos jóvenes de Chiapas viajaban mensualmente a la Sierra Norte de Puebla para estudiar en el CESDER.

A principios de 2010 se comenzaron a llevar a cabo reuniones sistemáticas con el equipo de CESDER en Zautla (Puebla) para hacer la transferencia del modelo. Oficialmente inició en septiembre de ese mismo año. Antes de la apertura, se realizó un taller con organizaciones de la región para presentar la licenciatura e invitar a líderes comunitarios a continuar con su formación educativa en el nivel superior.

La licenciatura se dirige principalmente a campesinos o indígenas de escasos recursos económicos que asumen el compromiso de contribuir al mejoramiento de las condiciones de vida de su región. Uno de los requisitos de ingreso (al igual que en Zautla, Puebla) es que los alumnos y alumnas cuenten durante sus estudios con el respaldo moral y económico de una organización de la sociedad civil a la cual preferentemente estén vinculados, con lo que se establece un compromiso del estudiante con la comunidad y con su organización, y de la organización con el estudiante. 
Esta acción constituye una base central para comprender los procesos de vinculación y su importancia en la educación superior. Los jóvenes que participan en esta experiencia no solo aspiran a continuar formándose en una licenciatura, sino que además hacen explícito su interés por participar o acompañar a una comunidad, organización o grupo para que sus aprendizajes tengan sentido y utilidad social. En las formas convencionales de educación superior el objetivo final es que los jóvenes obtengan un grado académico que les permitirá acceder al mercado laboral, generalmente lejos de sus comunidades. Esto por supuesto que favorece la movilidad social de los estudiantes de comunidades rurales e indígenas - e incluso urbanas-, pero genera una ruptura estructural con sus comunidades y barrios.

Quienes no entran con el respaldo de una organización de la sociedad civil se espera que en el transcurso de su formación puedan obtenerlo, aunque no es un requisito para concluir sus estudios universitarios. Lo que sí es imprescindible es que puedan llevar a cabo distintas formas de participación - productiva, organizativa, económica, cultural o educativa - en sus comunidades, en tres distintos niveles: familiar, grupal y comunitario. Este proceso no necesariamente tiene que ser secuencial porque dependerá de la experiencia previa de trabajo comunitario del estudiante.

La licenciatura cuenta con validez y reconocimiento por parte de la SEP y tiene como característica ser un sistema semiescolarizado; a lo largo del año se realizan ocho concentraciones de seis días de clases intensivas, cinco semanas de curso de verano y asesorías para el estudio de la intervención en la práctica. El diseño curricular de la licenciatura está organizado para favorecer en todo momento la interacción y la articulación con los actores sociales del contexto y para promover aprendizajes entre el estudiantado.

La primera generación (2010-2015) estuvo marcada por una amplia experiencia de los estudiantes a nivel organizativo y comunitario producto de su participación vinculada a organizaciones sociales. Esta situación, sin embargo, no se ve reflejada en las siguientes 
generaciones (2012-2017 y 2014-2019), lo cual se debe a que en la actualidad, además de continuar invitando a integrantes de organizaciones de la sociedad civil o líderes comunitarios de la región, también se realiza difusión en escuelas de nivel medio superior.

En el plan de estudios de la LPDR se menciona que los estudiantes deben formarse para responder a las demandas y transformaciones generadas en el sector rural a través de competencias que promuevan la construcción de relaciones equitativas, interculturales y con autonomía a partir de la reflexión sobre el papel de cada persona, resignificando sus roles en la transformación del mundo de vida (Documento base de la licenciatura, 2008).

Los objetivos de la licenciatura son: 1) formar personas capaces de impulsar procesos de desarrollo en el medio rural, 2) promover la articulación entre organizaciones y grupos sociales de diversas regiones del país, propiciando la producción y gestión de conocimientos para el desarrollo local y 3) establecer el proceso formativo bajo la metodología de comunidad de aprendizaje, que toma como punto de partida a la persona en su mundo de vida para aumentar la posibilidad de construir y consolidar colectivos capaces de realizar proyectos de vida buena (convocatoria de la licenciatura). El plan de estudios cuenta con cuatro líneas de formación: a) gestión del conocimiento sobre la realidad, b) intervención comunitaria y sujetos sociales, c) gestión ambiental y d) apoyo al desarrollo personal y el desempleo profesional (Documento base de la licenciatura, 2008).

Las líneas de formación tienen el propósito de adentrarse en la realidad recreando procesos de resignificación del mundo de vida tanto de los estudiantes, como de los grupos y organizaciones con los que interactúan. De la misma manera, se busca que los propios proyectos investigación del alumnado se conviertan en alternativas para contribuir a formas de vida digna.

A pesar de que algunos de los estudiantes no cuentan con experiencia en trabajo comunitario, se pretende que gradualmente puedan ir estableciendo vínculos con su comunidad. Esto, además, 
forma parte de su perfil de egreso. En general, se pretende que quien egresa cuente con capacidades para:

- Arraigarse, comprometerse con lo rural, con elementos para facilitar la comprensión de la realidad e impulsar y participar en la construcción colectiva de soluciones y alternativas.

- Vivir y promover relaciones interpersonales y sociales de equidad en los diferentes aspectos de su vida personal y profesional.

- Ser persona, con identidad propia, que asuma su ciudadanía y se comprometa con la construcción y el fortalecimiento de instancias de transformación social y política concretadas localmente y articuladas globalmente.

- Interactuar sensible y respetuosamente con el medio ambiente, proponiendo y participando en acciones que promuevan el desarrollo sustentable (Documento base de la licenciatura, 2008:4).

El plan de estudios se desarrolla en cinco años y consta de 34 asignaturas. Se busca que los estudiantes establezcan una relación de compromiso con su comunidad. En la línea de formación sobre "gestión ambiental" se otorga mayor énfasis al trabajo comunitario; desde que ingresan los asesores insisten en que los estudiantes profundicen en el conocimiento del lugar donde viven, para que se reconozcan en su comunidad y procuren en todo momento que el aprendizaje recibido pase por su experiencia de vida. Generalmente, los estudiantes ponen en práctica lo reflexionado en las clases con sus familias, sus grupos de trabajo o sus comunidades; la intención es aplicar lo aprendido. Algo que sobresale en el CESDER-Moxviquil es el acompañamiento que un equipo de docentes realiza de manera personalizada al alumnado en sus comunidades.

La transferencia del modelo curricular del CESDER de Puebla al CESDER-Moxviquil, en Chiapas, se realizó de manera satisfacto- 
ria cumpliendo con la impartición de las asignaturas propuestas en el plan de estudios. Sin embargo, a partir de la identificación de necesidades cognitivas, afectivas y sociales particulares de los estudiantes del CESDER-Moxviquil, se han implementado cursos y talleres específicos de lectura y redacción, sesiones individuales de terapia psicológica y meditación, y clases de ajedrez. También un día de la semana el alumnado presta servicio en la reserva ecológica de Moxviquil.

En el CESDER-Moxviquil hay libertad de cátedra y cierta autonomía para ejecutar el plan de estudios de acuerdo con las necesidades y exigencias del contexto y de los estudiantes. En el quinto año de la primera generación el personal docente se enfocó en ofrecer acompañamiento tutorial (individual) para apoyar el proceso de titulación de los estudiantes, dejando de atender las asignaturas propuestas en el mapa curricular de la licenciatura del CESDER.

Por cada periodo de concentración cada estudiante paga $\$ 600.00$, recurso que sirve en parte para comprar algunos de los alimentos que utilizarán durante la semana de concentración (verduras, tortillas, agua, fruta, pan, café, etcétera), y en parte para pagar a los docentes (quienes reciben $\$ 600.00$ por una sesión de cuatro horas).

Tabla 2. Estudiantes inscritos en la licenciatura del CESDER-Moxviquil, 2014-2015

\begin{tabular}{clllllll}
\hline Año & Hombres & Mujeres & Total & HLI $^{*}$ & Tsotsil & Tseltal & $\%$ HLI \\
\hline Primero & 10 & 6 & 16 & 8 & 4 & 4 & $50 \%$ \\
Tercero & 14 & 5 & 19 & 10 & 3 & 7 & $52.6 \%$ \\
Quinto & 11 & 7 & 18 & $12^{* *}$ & 9 & 2 & $66.6 \%$ \\
\hline
\end{tabular}

Fuente: Elaboración propia a partir de la base de datos de la licenciatura.

* HLI: hablantes de una lengua indígena.

** Se registró un estudiante hablante de la lengua mixe. 
La licenciatura cuenta con la participación de docentes-asesores ${ }^{44}$ de varias asociaciones civiles como, por ejemplo, Pronatura Sur, Educreando, Pequeño Sol, Jlumantik, Foro para el Desarrollo Sustentable, Voces Mesoamericanas, UCI-Red y centros de investigación como El Colegio de la Frontera Sur y el Centro de Estudios Superiores de México y Centroamérica (CESMECA), entre otros.

Para las clases disponen de un auditorio y tres salones; los espacios cuentan con un pizarrón blanco para rotafolios y una pantalla para proyecciones, además de las sillas y mesas, siempre acondicionadas en forma de "herradura" para facilitar el desarrollo de actividades grupales. También se cuenta con un área de dormitorios tanto para hombres, como para mujeres. El equipo coordinador de la licenciatura es responsable de la alimentación, el hospedaje, el servicio médico y la provisión de materiales para las clases durante la semana de concentración.

Tanto en Puebla como en Chiapas, la licenciatura no depende del presupuesto de la federación, sino principalmente del financiamiento que brindan organizaciones internacionales como Ayuda en Acción y la Fundación Kellogg. En el caso de Chiapas, además cuenta con el apoyo del Instituto Nacional de Desarrollo Social (INDESOL), que a través del Programa de Fortalecimiento de Capacidades de Jóvenes para su Profesionalización, Autoempleo y Participación Social en Chiapas cubre parte de la alimentación y el hospedaje de los estudiantes durante la semana que asisten a clases.

La toma de decisiones se realiza a través de reuniones periódicas del equipo coordinador de la licenciatura con el colectivo de docentes, aunque rara vez logran coincidir todos debido a que muchos están involucrados en otras actividades laborales. Generalmente en las reuniones se discuten asuntos que previamente han

\footnotetext{
${ }^{44}$ Administrativamente se llama "facilitador" a quien desempeña una labor docente; es considerado un facilitador del aprendizaje ya que a través de técnicas y dinámicas vivenciales busca que los estudiantes se apropien de los aprendizajes, aunque dentro del aula estos últimos se dirigen a los facilitadores como "profe", "maestro", y ocasionalmente por su nombre.
} 
sido seleccionados por el equipo coordinador ${ }^{45}$ o que derivan de inquietudes puntuales de algún docente.

Aunque no existe un organigrama, está al mando el director del Centro de Formación para la Sustentabilidad Moxviquil, A.C., quien toma la mayoría de las decisiones apoyado por una coordinación general. Las reuniones del personal docente de la licenciatura son de dos tipos: por un lado, para aquellos que están asesorando estudiantes para su titulación, ${ }^{46}$ y por el otro, para los miembros del colectivo de docentes.

Los estudiantes se organizan para realizar actividades solidarias durante la semana de clases, y para ello se distribuyen en equipos, de los cuales los más significativos son:1) aseo y cocina, 2) relatoría y fotos durante las clases, 3) facilitación de dinámica y 4) facilitación de asamblea grupal.

Para "aseo y cocina" se forman equipos compuestos por hombres y mujeres de las diferentes generaciones que se encargan de preparar y servir alimentos durante la semana de concentración. En cada grupo hay un equipo que se ocupa de hacer el aseo de los salones al terminar el día.

Otra actividad consiste en documentar lo acontecido durante cada asignatura; si bien parecería una tarea insignificante, es de valor para recordar los temas abordados en clases anteriores. En este sentido, si bien este sistema semiescolarizado contribuye a planear de mejor manera las actividades y el material bibliográfico, en la práctica se dificulta la continuidad; además, si algún es-

\footnotetext{
${ }^{45}$ El equipo coordinador se encarga de dar seguimiento puntual a las demandas y necesidades de cada grupo de estudiantes.

${ }^{46}$ En una reunión de trabajo del colectivo de docentes se planteó que se dedicaría únicamente el quinto año de formación para que los estudiantes pudieran titularse en agosto de 2015 y lograr tener una eficiencia terminal aceptable. Es importante señalar que los estudiantes que en la actualidad [2020] se encuentran inscritos en la licenciatura de Moxviquil, oficialmente ante la SEP se encuentran inscritos en el CESDER-Puebla, por lo que su título saldrá emitido en Puebla y no en Chiapas. Hasta el momento solamente tienen la opción de titulación por tesis y el examen de titulación lo deberán presentar en Puebla.
} 
tudiante no asiste a la concentración cuenta con desventaja sobre quienes asisten regularmente.

En la facilitación de dinámicas participan únicamente estudiantes con la finalidad de promover mayor integración y reflexionar sobre algún tema en particular (autoestima, identidad, comunicación, género, etcétera). Implementar estas dinámicas tiene el propósito de generar un ambiente de confianza entre el estudiantado y de prepararse para la facilitación y el manejo de grupo.

En las asambleas se tratan problemas relacionados con la estancia en Moxviquil y también se discuten las actividades a realizar en la siguiente concentración. Generalmente, surgen propuestas que son presentadas al equipo coordinador de la licenciatura. Se realizan por la noche una vez han realizado todas sus encomiendas:

Lo que sucede en la concentración es como la vida en comunidad: la organización que ellos tienen, las asambleas que realizan, las actividades que se distribuyen [...] es lo que viven en su comunidad [...] en el transcurso de las sesiones se reflexionaba sobre la distribución de roles, porque en un principio las mujeres solo estaban en la cocina. En las primeras mesas directivas solo había hombres, eso poco a poco ha ido cambiando (entrevista a director del Centro de Formación para la Sustentabilidad Moxviquil A.C.).

En 2014 el colectivo de docentes que conformaban la LPDR de Moxviquil comenzó a implementar su propio diseño curricular como parte del compromiso adquirido con el CESDER de Zautla. En septiembre de 2016 inició la Licenciatura en Autogestión Sustentable del Territorio (LAST), la cual también cuenta con el Reconocimiento de Validez Oficial de Estudios (RVOE). En la malla curricular no se encuentra alguna asignatura con el adjetivo "intercultural", sin embargo, de manera implícita entre los contenidos curriculares se encuentran temáticas como diversidad sociocultural, identidad y género. 


\section{Propuesta institucional de "arriba hacia abajo": UNICH-Oxchuc}

La UNICH es la segunda universidad con enfoque intercultural que se estableció en el país. Su creación se registra a partir de un decreto emitido por el Congreso del estado de Chiapas en 2004. Comenzó a funcionar en agosto de 2005 en San Cristóbal de Las Casas, y en el año 2006 inició la construcción de las instalaciones de la Ciudad Universitaria Intercultural ${ }^{47}$ (UNICH, 2008a). Se encuentra ubicada al sur-poniente de la ciudad, aledaña a la zona de conservación ecológica de los Humedales de la Montaña María Eugenia.

Según el informe de la administración 2005-2008, la apertura de la UNICH y de sus licenciaturas se realizó tras un proceso de debate entre intelectuales, académicos y representantes de comunidades y pueblos indígenas, que discutieron y analizaron la pertinencia de su funcionamiento. "Para tal efecto, la Secretaría de Educación contrató a un despacho especializado para llevar a cabo un estudio de factibilidad que guio la selección de los primeros programas académicos" (UNICH, 2008a:1).

El resultado de la consulta y del diagnóstico fortaleció el acuerdo entre los funcionarios de la CGEIB-SEP y las autoridades educativas del estado de Chiapas. La UNICH comenzó con cuatro licenciaturas: Lengua y Cultura, Turismo Alternativo, Comunicación Intercultural y Desarrollo Sustentable, que fueron avaladas por la Comisión Estatal de Planeación de la Educación Superior (COEPES), bajo el argumento de que "no hay otra institución de Educación Superior, pública o privada en Chiapas, que imparta dichas licenciaturas" (UNICH, 2008a:8).

En la indagación que realicé con algunos docentes y administrativos de la UNICH para conocer más sobre el estudio de factibili-

\footnotetext{
${ }^{47}$ Una de las críticas fuertes en torno a la construcción de las instalaciones de la UNICH es que su diseño arquitectónico denota influencia colonial, uno de los aspectos que precisamente la interculturalidad busca erradicar.
} 
dad, constaté que desconocen su existencia, por lo que es sugerente pensar que las licenciaturas se crearon en función de los intereses de la CGEIB-SEP, debido a que la oferta educativa es similar a la de las otras UI del país.

En el Plan Institucional de Desarrollo 2008-2016 (UNICH, 2008b) se menciona que uno de los problemas de la educación superior en Chiapas es la alta demanda de carreras convencionales, lo que ocasiona saturación en el mercado de trabajo de los egresados; por ello, se hace énfasis en la creación de nuevas licenciaturas con pertinencia social y económica. En San Cristóbal de Las Casas, por ejemplo, existe más de una veintena de IES, entre públicas y privadas. Ello también habla de la creciente demanda de educación superior para los egresados del nivel medio superior, no únicamente de San Cristóbal, sino de la región.

La iniciativa de la CGEIB-SEP de ubicar las UI en localidades rurales o con población mayoritariamente indígena no necesariamente se cumple en la sede central de la UNICH si consideramos que se encuentra en una ciudad de más de doscientos mil habitantes. El argumento a favor de su establecimiento en San Cristóbal se basó en el hecho de que la ciudad es un centro regional importante. Además, en décadas pasadas las expulsiones de indígenas de sus comunidades por conflictos religiosos contribuyeron a la creación de asentamientos irregulares de población desplazada en las orillas de la ciudad, ${ }^{48}$ lo que hoy en día genera también una demanda de servicios educativos.

Quienes ingresan a la UNICH son jóvenes procedentes tanto de los municipios de la región Altos Tsotsil-Tseltal, como de la misma

\footnotetext{
${ }^{48}$ Jan Rus identifica tres olas migratorias quellegaron a San Cristóbal. La primera sucedió en la década de los setenta: "conducida por jóvenes bilingües que querían cambiar de religión y establecerse fuera de sus comunidades de origen, la segunda, se conformó principalmente de refugiados económicos atraídos por las nuevas oportunidades de vivienda y empleo abiertas por la primera ola, y la tercera, consistió cada vez más en refugiados a secas, presionados tanto por condiciones económicas adversas como, después de 1994, por la violencia” (Rus, 2012:225).
} 
ciudad. De acuerdo con los registros existe una presencia considerable de estudiantes de otras regiones del estado -Meseta Comiteca Tojolabal, Selva Lacandona, Maya, Tulijá Tseltal Chol, Valles Zoque, Metropolitana y Sierra Mariscal-, que representan a las principales lenguas indígenas que se hablan en Chiapas (UNICH, 2008b).

La UNICH amplió su proyecto educativo hacia otras regiones, por un lado, al crear mayores oportunidades para que los jóvenes puedan estudiar en su región, y por otro, para responder a las políticas y estrategias impulsadas por la CGEIB-SEP, que principalmente consisten en: a) ampliar la cobertura de educación superior con pertinencia cultural a la población indígena, b) responder a las demandas indígenas, reconociendo los aportes de los pueblos en aspectos culturales y lingüísticos, y c) que la formación ofrecida se oriente a la solución de problemas y al desarrollo integral de su región (Schmelkes, 2008).

Se han creado otras cuatro sedes o Unidades Académicas Multidisciplinarias (UAM) en distintas regiones de Chiapas, tres de las cuales iniciaron labores en 2009 con la misma oferta educativa de San Cristóbal; por ejemplo, en Oxchuc se imparten las licenciaturas en Desarrollo Sustentable y Lengua y Cultura; en Las Margaritas Turismo Alternativo y Lengua y Cultura; en Yajalón Lengua y Cultura y Desarrollo Sustentable, y en Valle de Tulijá (Salto de Agua) Desarrollo Sustentable y Turismo Alternativo. Actualmente también se imparten las licenciaturas de Médico Cirujano, Enfermería Intercultural y Derecho Intercultural. El ingreso a cualquiera de las licenciaturas es anual y preferentemente deben ser cursadas en cuatro años (a excepción de Médico Cirujano, que tiene una duración de seis años). En el Plan Institucional de Desarrollo 2008-2016 se reconoce el rezago educativo de la región Sierra; no obstante, ninguna UAM se ha establecido en dicha región.

La UNICH ha trabajado con la propuesta curricular de la CGEIB, aunque algunos programas educativos y contenidos de asignaturas han cambiado a partir de sugerencias del colectivo de docentes. Las modificaciones curriculares iniciadas en 2009 se realizaron en 
un intento por responder a las especificidades sociales y culturales de la región dando prioridad a las instrucciones de la CGEIB. Así, en 2011 se otorgó mayor peso al modelo curricular por competencias profesionales. A partir de esta actualización, los programas educativos cuentan con tres ejes de formación: Básica, Profesional y Especialización; y cuatro ejes transversales: Disciplinar, Vinculación con la Comunidad, Lenguas y Sociocultural.

La misión de la UNICH es formar profesionistas de calidad, con valores, compromiso social y dominio de lenguas originarias de la entidad a partir de la integración de conocimientos de los pueblos originarios y científicos para contribuir a la construcción de una sociedad con mejor calidad de vida. Con ello se pretende: "mejorar las condiciones de vida de las comunidades a través de sus programas académicos y de vinculación, proveyéndoles de profesionales preparados, capaces de diseñar alternativas propias de desarrollo en los aspectos económicos, sociales y culturales” (UNICH, 2008a:5). Dicha misión tiene una estrecha relación con lo propuesto por Casillas y Santini (2006) sobre la misión de las UI en México.

Hasta mediados de 2020 la UNICH ha contado con siete rectores. El primero fue el antropólogo Andrés Fábregas Puig quien, en un periodo de cinco años, consolidó un proyecto académico y logró posicionar favorablemente la universidad con respecto a las otras UI del país. Sin embargo, en un lapso breve la UNICH ha tenido seis rectores, lo que ha hecho que los proyectos académicos hayan sido azarosos y limitados por la conflictividad interna.

Antes de la creación de la UNICH en Oxchuc, sus pobladores habían hecho gestiones ante diferentes instancias de gobierno, sin éxito alguno, para beneficiarse de una IES; en particular deseaban una sede de la Universidad Pedagógica Nacional o una Escuela Normal Superior con la intención de que sus hijos se formaran como maestros de educación primaria. También en diferentes momentos funcionó, por un corto periodo, una IES privada, pero ante la falta de condiciones para establecerse en la zona y a los altos costos de las colegiaturas dejó de operar. El no reconocimiento oficial de la SEP 
y la negativa de los pobladores a donar un terreno para la construcción de sus instalaciones contribuyeron también a su cierre.

Cuando se instaló la UNICH en Oxchuc los habitantes tenían cierto recelo debido a malas experiencias pasadas; sin embargo, mostraron una mejor aceptación cuando comprobaron que se trataba de una IES con programas de estudios reconocidos por la SEP. En un inicio las autoridades municipales querían que se instalara en terrenos cercanos a la carretera, ${ }^{49}$ pero finalmente los edificios se construyeron en la localidad Piedra Escrita, en un predio donado por las autoridades municipales.

Inicialmente, la UNICH-Oxchuc comenzó sus labores en agosto de 2009 en las instalaciones del Colegio de Estudios Científicos y Tecnológicos del Estado de Chiapas con dos grupos en el turno vespertino, ofreciendo dos licenciaturas: Lengua y Cultura, y Desarrollo Sustentable. Actualmente la unidad cuenta con infraestructura propia que consta de dos edificios idénticos, desde el punto de vista arquitectónico, a los de la sede principal. Uno de ellos está destinado para que el alumnado reciba clases, y el otro para usos administrativos y académicos; en este último se encuentran la oficina del coordinador, una sala de reuniones, los cubículos para el personal docente, el departamento de servicios escolares, la biblioteca, baños y un auditorio. Además de los dos edificios, la universidad cuenta con un invernadero, parcelas demostrativas, un campo de fútbol y cafetería.

Las licenciaturas que se imparten en la actualidad son tres: Lengua y Cultura, Desarrollo Sustentable y Derecho Intercultural, que están dirigidas a los jóvenes de la región que deseen continuar con sus estudios universitarios y que se sientan identificados con la misión de la UNICH. En la primera generación, la difusión se hizo principalmente entre los estudiantes de las preparatorias,

${ }^{49} \mathrm{El}$ pueblo de Oxchuc está dividido por la carretera que comunica el municipio con Ocosingo y Palenque; en ambos lados de la carretera se encuentran diferentes servicios de transporte y comercios. 
pero también entre quienes por alguna situación habían dejado de estudiar. De acuerdo con registros oficiales, la sede de Oxchuc comenzó a funcionar con 68 estudiantes. El 95\% eran bilingües (tseltal y español) y el 5\% restante hablantes pasivos de tseltal, es decir, lo comprendían, pero no lo hablaban (UNICH, 2009).

La primera generación (2009-2013) se caracterizó por contar con estudiantes cuya edad no correspondía necesariamente con el promedio para ingresar a nivel superior, es decir, se matricularon personas que años atrás habían concluido su educación media superior y que por diversas circunstancias interrumpieron su educación. Las generaciones posteriores estuvieron conformadas por estudiantes recién egresados del bachillerato y, de acuerdo con testimonios de los docentes, en ninguna de las generaciones se encontraban jóvenes con experiencia laboral, ni en instituciones gubernamentales ni en organizaciones de la sociedad civil, sino que más bien se trataba de jóvenes que habían contado con el apoyo de sus familias para realizar sus estudios de manera ininterrumpida.

En el perfil de ingreso se toma en cuenta que quien aplica tenga: un interés demostrado por generar propuestas de solución a problemas comunitarios, así como deseos de conocer estrategias para el uso responsable de los recursos, de aprender una lengua originaria y de vincularse con proyectos comunitarios que mejoren las condiciones sociales de los pueblos y organizaciones de las distintas regiones de Chiapas (UNICH, 2013).

Como perfil de egreso se plantea que los estudiantes sean capaces de formular, gestionar y evaluar proyectos que fortalezcan las capacidades organizativas y productivas locales bajo el enfoque del Buen Vivir. Además, se espera que dirijan procesos de investigación participativa para la resolución de problemáticas comunitarias para contribuir al bienestar social desde la participación social y política (UNICH, 2013).

Como se ha señalado anteriormente, los programas educativos cuentan con tres ejes de formación y cuatro ejes transversales. En 
el caso de la licenciatura en Desarrollo Sustentable, esta cuenta con tres líneas de especialización: Productiva, Ambiental y Buen Vivir, con sus respectivas asignaturas optativas.

Hasta el ciclo escolar agosto-diciembre 2014, la licenciatura en Desarrollo Sustentable contaba con 209 estudiantes inscritos, de los cuales el $93.30 \%$ se reconocían como hablantes de lengua tseltal y muchos de ellos eran originarios del municipio de Oxchuc, aunque también había presencia de estudiantes de localidades aledañas como Huixtán, Chanal, Ocosingo, San Juan Cancún e incluso Cintalapa de Figueroa, municipio de la región Centro de Chiapas.

Tabla 3. Licenciatura en Desarrollo Sustentable, UNICH-Oxchuc, 2014-2015

\begin{tabular}{lccrrrr} 
& Hombres & Mujeres & Total & HLI* & \% HLI & \% NO HLI \\
\hline Inscritos en la LDS & 41 & 25 & 66 & 54 & $81.88 \%$ & $18.18 \%$ \\
Hablantes de ch'ol & 2 & 1 & 3 & 3 & $5.55 \%$ & - \\
Hablantes de tseltal & 31 & 18 & 49 & 49 & $90.7 \%$ & - \\
Hablantes de tsotsil & 2 & 0 & 2 & 2 & $3.7 \%$ & - \\
\hline
\end{tabular}

Fuente: Elaboración propia a partir de datos proporcionados por servicios escolares.

${ }^{*}$ HLI: hablantes de una lengua indígena.

Desde que la universidad contó con instalaciones propias, se estableció el horario de clases de 7:00h a 15:00h, de lunes a viernes, y opera bajo un sistema escolarizado. En el periodo en que se realizó la investigación solamente había dos docentes de tiempo completo asignados a la Unidad de Oxchuc, uno para la licenciatura en Desarrollo Sustentable y otro para Lengua y Cultura. Los demás eran contratados por horas y la mayoría viajaba desde San Cristóbal a Oxchuc para cumplir con su horario de trabajo. 



\section{Capítulo 3 \\ Entre la resignificación y la institucionalización de la educación superior intercultural en Chiapas}

\section{Análisis de la interculturalidad}

Para Dietz, en la "educación para descolonizar" aparecen en Latinoamérica "dos innovaciones importantes, el giro poscolonial o decolonial y el diálogo intercultural” (2011:57), como elementos imprescindibles para profundizar en las condiciones sociohistóricas de la colonialidad que prevalecen tanto en el discurso, como en las prácticas educativas, ya que al plantearse la interculturalidad de "arriba hacia abajo" (institucionalizada) no existe la posibilidad de generar transformaciones profundas en las relaciones sociales y, por lo tanto, se reproducen la desigualdad, la subalteridad y la dominación.

Como se ha mencionado, uno de los requisitos para superar la visión folclórica y esencialista de la interculturalidad parte de reconocer que las relaciones entre las culturas están mediadas por el poder. En otros espacios educativos el binomio dominación/sumisión no se retoma como parte de la reflexión y el análisis, lo que limita la consolidación de la "interculturalidad para todos" (López, 2001; Schmelkes, 2003).

En este sentido, las experiencias educativas del CESDER-Moxviquil y de la UNICH-Oxchuc representan un punto de inflexión 
para analizar la educación superior intercultural en Chiapas. En lo sucesivo se estudian ambas IES desde una perspectiva comparativa y complementaria. El análisis no se realiza con la finalidad de evidenciar las ventajas o desventajas de una u otra, sino más bien para encontrar puntos de convergencia que permitan dimensionar los desafíos y las posibilidades de la consolidación de proyectos de educación superior intercultural.

Para profundizar de manera minuciosa sobre la categoría de la interculturalidad es necesario deconstruirla e incorporar elementos precisos a fin de comprenderla ampliamente. Para ello, en este trabajo se retoman cuatro subcategorías: a) cuestionamiento de las relaciones de poder entre las culturas, b) establecimiento de relaciones para el enriquecimiento de la experiencia de vida, c) reafirmación como sujetos ante la vida, y d) re-producción de elementos culturales.

\section{Cuestionamiento de las relaciones de poder entre las culturas}

Las relaciones de dominación/sumisión se introducen de manera inconsciente en la vida cotidiana de las personas y se reproducen a través de diferentes instituciones; el ámbito educativo es uno de los entornos más emblemáticos donde esto ocurre porque en él poco se discute sobre la forma en que las interacciones están mediadas por el poder. Posicionar la discusión de la alteridad en la educación superior contribuye a comprender las diferencias individuales y las diversidades culturales y a la consolidación de la educación intercultural.

De los resultados obtenidos se desprende que la experiencia educativa del CESDER-Moxviquil asume de manera implícita la interculturalidad con la finalidad de que los estudiantes desarrollen una mayor consciencia sobre quiénes son y sobre su papel como sujetos para el desarrollo en su región. Al respecto, uno de ellos apuntó lo siguiente: 
Por ejemplo, lo que se reflexiona es para darnos cuenta cómo nos relacionamos allá afuera. Aquí [en el salón de clases] hemos trabajado las relaciones entre las diferentes culturas, hacemos dinámicas, con eso nos damos cuenta de las formas en que nos relacionamos con una y otra cultura y cómo hay limitaciones para relacionarnos con ellas (entrevista a estudiante del CESDER-Moxviquil).

En el caso del CESDER-Moxviquil, los estudiantes realizan un cuestionamiento sobre las relaciones de poder entre las culturas, aproximándose a lo que Dietz y Mateos denominan "educar para descolonizar", en donde "lo intercultural se discute, resignifica y apropia bajo una mirada poscolonial, [se] recupera la mirada histórica, de larga duración, hacia las relaciones entre colonizadores y colonizados" (2011:57). Algunos estudiantes argumentan que ese cuestionamiento emerge como una posibilidad para analizar la situación desde su contexto comunitario:

Yo creo que hay que reconocer que existe sometimiento de lo exterior, porque de alguna manera las personas no visualizan que están sometidas [...] y lo difícil es primero hacer esa reflexión y aceptar que no debe ser así y que estamos en un sistema de dominación [...] es obligatorio transformar esta relación porque si no vamos a replicar lo mismo que hace el Estado por medio de programas y proyectos; sin embargo, si partimos de que la gente se dé cuenta y ver en qué situación está y a partir de ahí comiencen a proponer en este rollo de autonomía (entrevista a estudiante del CESDER-Moxviquil).

En el CESDER-Moxviquil, a pesar de que los estudiantes no cursan asignaturas con contenido explícito sobre interculturalidad, se encontró que el tema se retoma desde diferentes perspectivas de análisis en los contenidos de cada programa de estudio. Por ejemplo, en una clase se preguntó cuáles eran los aspectos necesarios para 
establecer un modo de vida basado en los principios de la interculturalidad; se reproduce una de las respuestas:

Yo creo que hay dos cosas muy importantes que nos han estado haciendo falta. Yo creo que una es el empoderamiento que, pues, realmente a veces hace falta como fomentarlo, y otra desde uno mismo, por las diferentes culturas que hay y comenzar a cambiar los estereotipos y el dominio que hay en nuestra sociedad (entrevista a estudiante del CESDER-Moxviquil).

Sobresale la idea de empoderamiento que, como se ha visto en páginas anteriores, es una característica de las propuestas educativas alternativas por su cercanía a las perspectivas de análisis construidas desde abajo; por ejemplo, una peculiaridad es formar sujetos con consciencia de su realidad sociohistórica con el propósito de no reproducir los discursos institucionalizados que niegan la diversidad y, por lo tanto, oprimen a los diferentes. Para algunos autores (Dietz y Mateos, 2013) el reto de empoderar a sujetos subalternos parte de no reproducir esquemas asimétricos y neoindigenistas de tipo monológico y monolingüe.

El planteamiento de la interculturalidad desde una perspectiva crítica no únicamente debe revalorizar el pasado sino, como ya se ha dicho, también tiene que evidenciar que el poder obstaculiza la creación de otras formas de relación. De ahí que sea necesario impulsar transformaciones sociales desde abajo que contribuyan gradualmente a socavar las estructuras hegemónicas y a impulsar cambios sistémicos — bajo los principios de igualdad y de justicia social y cultural-.

Una parte fundamental de la interculturalidad consiste en establecer relaciones basadas en el equilibrio, en el respeto por las demás culturas y en propiciar condiciones para el aprendizaje mutuo. Dichas percepciones podrían acercarse a las características del multiculturalismo; sin embargo, en la interculturalidad 
crítica también está presente la idea de equilibrar los elementos culturales, es decir, ya no únicamente se privilegia una cultura sobre otras, sino que se establecen contrapesos que contribuyen a cuestionar y a crear otras maneras de interacción (Mignolo, 2006; Restrepo y Rojas, 2010; Walsh, 2012, 2005). Dichos elementos de análisis de la interculturalidad permean en la propuesta educativa del CESDER-Moxviquil.

Por su parte, en la UNICH-Oxchuc se observa una mayor necesidad de establecer relaciones basadas en el respeto entre las culturas, aspecto más afín al multiculturalismo (Kymlicka, 2012; Meer y Modood, 2011). A pesar de que en la UNICH se implementan contenidos temáticos que gradualmente conducen a los estudiantes a una mayor comprensión de la interculturalidad, se identificó una institucionalización de la interculturalidad que es promovida de "arriba hacia abajo" al conducirse bajo el modelo propuesto por la CGEIB-SEP, lo cual deja poco margen de acción para proponer, crear o cuestionar lo establecido.

En la revisión del programa de estudio de la Licenciatura en Desarrollo Sustentable se encontró que la discusión sobre lo intercultural no es transversal. Por ejemplo, únicamente se identificaron tres asignaturas directamente relacionadas con la interculturalidad; una de ellas se imparte en el primer semestre dentro del eje sociocultural del Área de Formación Básica (Procesos Culturales e Interculturalidad), otra dentro del mismo eje pero en el Área de Formación Profesional (Diálogo Intercultural) y la última (Nuevas Epistemologías para la Interculturalidad) se oferta únicamente para quienes eligen la Línea de Especialización Autogestión y Buen Vivir. Asimismo, dentro del eje de formación sobre Lenguas se ofrece la asignatura Lengua Originaria, desde el primer semestre al sexto, que puede determinar cierta orientación hacia la interculturalidad.

Además, se halló poca relación con las corrientes teóricas actuales de Latinoamérica, como el pensamiento decolonial. No se trataría de adscribirse a dicha perspectiva teórica, pero podría ser 
considerada como otro referente complementario de reflexión y análisis para comprender la realidad desde un marco global y local, más aún cuando se trata de una UI.

Se identificó que entre los docentes y administrativos de la UNICH-Oxchuc hace falta una postura que vaya más allá del modelo educativo intercultural propuesto por la CGEIB-SEP. A pesar de que existe la disposición de discutir, reflexionar y analizar posturas teórico-metodológicas que guíen su práctica docente, se enfrentan a la burocratización de la institución:

No partimos de una teoría conceptual de la interculturalidad, estamos tomando como propuestas las teorías del mismo modelo de la universidad, [la cual] tiene una línea que busca relación interétnica de los alumnos, integración de los conocimientos, equidad de relaciones, compartir conocimientos. Eso es lo ideal, pero en la práctica es tan complicado, que dices ¿en qué momento voy a dar mi clases?, y ¿cómo voy a estar atento a cómo se comporta aquel o aquel? (entrevista a docente de la UNICH-Oxchuc).

Este primer acercamiento permite evidenciar que el proceso educativo de la UNICH-Oxchuc trata de "interculturalizar", es decir, de retomar una versión atenuada de la gestión de la diversidad, principalmente hacia los pueblos indígenas (Dietz, 2008, 2012). En palabras de Walsh (2012) y Tubino (2005), se trata de una interculturalidad desde una "perspectiva funcional", es decir, que no se tocan ni cuestionan las asimetrías ni las desigualdades sociales y culturales presentes en muchos contextos latinoamericanos.

Si bien muchos estudiantes provienen de comunidades cercanas al municipio de Oxchuc, la reflexión en torno a las relaciones entre las culturas aparece de manera escueta al centrarse esencialmente en revalorar la lengua tseltal. El personal docente reconoce que hablar la lengua materna es un elemento que forja la identidad de los sujetos. Considero que este debería ser un punto de par- 
tida para introducir gradualmente en la discusión y el análisis las relaciones de dominación entre las culturas:

La lengua y cultura siempre se está cambiando, lo que valoro es que puedes hablar en tseltal y no te critican y nos intercambiamos ideas con cierto respeto por la pluralidad, la diversidad [...] yo no muy concuerdo con algunas ideas de que hay que portar el traje tradicional, incluso dicen que cuando pierdes la lengua ya no eres tseltal, creo que hay otros elementos como los conocimientos, la forma de ver el mundo, aunque no hable tseltal (entrevista a docente de la UNICH-Oxchuc).

Asumir esa postura ha llegado a fraccionar el colectivo de docentes en dos grupos; por un lado, se encuentran quienes argumen$\tan$ que la interculturalidad debe girar en torno a la lengua y a la vestimenta tradicional, lo cual se acerca al "multiculturalismo liberal” (Díaz-Couder, 1998), teoría según la cual se reconoce la potestad de los grupos lingüística y culturalmente diferenciados de conservar su herencia cultural como parte de sus derechos privados. En ese sentido, existe el riesgo de celebrar las diferencias y no cuestionar las desigualdades sociales existentes (Malik, 1998). Por otro lado, se encuentran aquellos que señalan la necesidad de traspasar la visión folclórica y esencialista de la interculturalidad que desde la institución se transmite. Al respecto un docente apuntó lo siguiente:

[La interculturalidad en la UNICH-Oxchuc] se basa en conceptos que suenan bien y no poco cuestionables, que incluso si te pones radical produce racismo a la inversa; porque no hay una propuesta de relación ni con el Estado, ni con los no indígenas. Hay una reiteración de "eres tú", "tus saberes", "tus localidades" y no existe nada más. Como si una cultura fuera homogénea, y eso por una parte va 
a generar y está generando un espacio para los profesionistas indígenas con un esencialismo y una especie de uso ventajoso de la cuestión étnica (entrevista a docente de la UNICH-Oxchuc).

Lo anterior muestra cómo, en el caso de la UNICH-Oxchuc, el discurso es construido con base en la noción de multiculturalidad, según la cual se aprovechan los espacios de interacción para revalorar y resignificar el uso de la lengua materna, en este caso el tseltal.

Una de las críticas hacia los proyectos educativos interculturales ha sido la falta de un posicionamiento sobre cómo se han construido las formas de dominación entre las culturas. En ese sentido, no es suficiente plantear el respeto y la tolerancia cuando se observan de manera cotidiana en los medios de comunicación y en las acciones institucionales, ni hacer visibles el desprecio por la diversidad y las prácticas de los pueblos originarios, que son vistos como impedimentos para el acceso a la modernidad.

Incorporar el análisis histórico y social de las formas injustas de relación entre las culturas permite cuestionar y redimensionar el modo de interactuar con el resto de la sociedad. Tener presentes las dimensiones de poder y de conflicto es imprescindible en Latinoamérica para establecer relaciones más justas y equitativas que faciliten otras maneras de ser y de estar en el mundo. Por lo presentado, la incorporación de la interculturalidad en el CESDER-Moxviquil se produce desde una perspectiva crítica y experiencial de "abajo hacia arriba”, a diferencia de la UNICH-Oxchuc, que se presenta como un discurso ya dado de "arriba hacia abajo”.

Establecimiento de relaciones para el enriquecimiento de la experiencia de vida

La interculturalidad no puede desligarse del análisis de las relaciones sociales, ni es posible ocultar las estructuras políticas y económicas que la condicionan. Para superar la incomprensión que se 
pueda generar, se debe ir más allá de proponer nuevas formas de interacción entre las culturas y debe reconocerse que las identidades son dinámicas.

Quienes participan de manera consciente en un proceso de formación bajo la perspectiva intercultural contribuyen con su experiencia a reflexionar sobre cómo nos relacionamos y actuamos en la vida cotidiana. En pocos espacios educativos la experiencia se retoma como un recurso para generar aprendizajes significativos y, cuando se hace, se contribuye a trascender de una perspectiva teórica — que tiende a la individualización—, a una que considere el mundo de vida de los participantes como una posibilidad de enriquecer colectivamente el proceso educativo.

De acuerdo con los resultados, los estudiantes del CESDER-Moxviquil reconocen que se ha generado un proceso reflexivo-experiencial —no explícitamente intercultural一, que ha contribuido a generar cambios en su ámbito familiar y organizacional. Así lo señaló un estudiante:

Me identifico con adoptar prácticas ajenas que valoro como positivas y que enriquecen mi vida porque todo lo que aprendo en cualquier materia me ha ayudado bastante sobre la situación social o ambiental. Por social me refiero a los conflictos sobre la tenencia de la tierra; hay que utilizar nuevas cosas o prácticas para la resolución del problema. En cuanto a lo ambiental, me refiero a los cambios que ha habido en las comunidades, como en la utilización o cuidado del suelo, porque la mayoría de las personas utilizan agroquímicos, y lo que hay que hacer son prácticas nuevas para evitar la infertilidad del suelo. Sobre esto solo estoy tomando las prácticas importantes que ayudan a sacar adelante a mi comunidad, porque en la interculturalidad [se] dice que hay que relacionarse con otras culturas y tratar de entenderlas cada uno y compartir lo que cada uno sabe (reflexión grupal con estudiantes del CESDER-Moxviquil). 
En el relato anterior se identifican situaciones de transformación personal que tienen repercusiones a nivel familiar y comunitario. La propuesta de interculturalidad, abordada de manera implícita en el CESDER-Moxviquil, aspira a transformar la realidad del contexto socioambiental de los estudiantes a través de la incidencia que ellos mismos puedan realizar. No significa que se desmarquen totalmente del sistema económico predominante, más bien se busca crear alternativas dentro del mismo sistema. En esta dirección, la propuesta del CESDER-Moxviquil abona a la construcción de nuevas juventudes sensibles a la diversidad cultural para la cimentación de proyectos de vida basadas en el enriquecimiento mutuo.

En el caso de la UNICH-Oxchuc, el énfasis de lo intercultural aparece centrado en el uso de la lengua tseltal como una posibilidad para enriquecer la experiencia de vida del alumnado; esta perspectiva podría alcanzar mayor trascendencia si los estudiantes se encontraran vinculados y articulados a organizaciones o grupos de trabajo a nivel comunitario, a partir de los cuales pudieran participar en un proceso reflexivo-experiencial de más amplia trascendencia.

La mayoría de quienes ingresan a la UNICH-Oxchuc provienen del sistema educativo formal, donde la lengua materna, la vestimenta o los conocimientos locales no juegan un papel predominante en el proceso de enseñanza-aprendizaje; por ello, se hace cierto énfasis en revalorar dichos aspectos y en fortalecer la identidad comunitaria de los estudiantes. Los entrevistados reconocieron que actualmente se produce una relación de reencuentro con su comunidad y su cultura, como se señala en el siguiente relato:

Yo no hablo la lengua al cien como dicen, pero tengo más confianza con las personas de hablar con ellos y he checado la diferencia, que ahorita he tenido cierta ventaja en lo que he estudiado porque ya he aprendido más de ellos que antes no sabía; por ejemplo, cuando estaba en la prepa no sabía cómo era su cultura, y ahorita ya sé por dónde van y 
por qué han perdido todo esto. Yo no porto mi traje tradicional, pero creo que por el simple hecho de hablar mi lengua ya me hace parte de la comunidad (reflexión grupal con estudiantes de la UNICH-Oxchuc).

Lo que se pretende desde la UNICH es fortalecer la lengua y la cultura de los estudiantes, y el acercamiento conceptual a la interculturalidad gira en torno a ello. Además, al estar los estudiantes insertos en una región donde predominan los hablantes de la lengua tseltal, ello hace despertar el interés por aprenderla o reforzarla.

En ambas experiencias educativas los alumnos y alumnas identifican situaciones que les han permitido enriquecer sus experiencias de vida. En el CESDER-Moxviquil, la trascendencia de un plano individual hacia uno colectivo-comunitario es evidente, en parte porque la misma institución lo establece y promueve a través de diferentes estrategias fuera del aula, por ejemplo, en las estancias en organizaciones de la sociedad civil y en el seguimiento de los estudiantes en su comunidad. Caso contrario ocurre en la UNICH-Oxchuc, donde el proceso educativo también tiene repercusiones a nivel individual y comunitario, pero la falta de una política institucional que permita la sistematización de la experiencia dificulta evidenciar lo que sucede en el plano familiar u organizacional. En la Tabla 4 se pueden diferenciar las percepciones de los estudiantes sobre las repercusiones de formarse en una u otra IES. 
Tabla 4. Establecer relaciones en equilibrio

\section{CESDER-Moxviquil}

Yo recibí terapia durante un año, y ahora gracias a eso llevo dos años y medio sin tomar [...] y otra parte, cómo empezar a convivir con la familia, cómo empezar a tomar importancia a la familia, cómo nosotros no podemos ser dueños de nuestra esposa o de nuestros hijos, no podemos ser dueños de los grupos, no podemos decir este es mi grupo, sino decir acompaño este grupo, que es diferente [...] ahora empiezo a hacer dinámicas con mis hijos en vez de "pum" prenderles la tele, empiezo a jugar con ellos con una dinámica y comenzamos a reflexionar sobre la dinámica, creo que eso es lo rico (entrevista a estudiante del CESDER-Moxviquil).

Fuente: Elaboración propia a partir de los resultados.

El hecho de que prevalezca la idea de que la formación universitaria corresponde a un acto individual en la búsqueda de superación personal limita las posibilidades de trascender la formación como una experiencia que articule la importancia de la preparación de sujetos con la necesidad de participar y colaborar en la solución de las problemáticas sociales, ambientales y productivas que actualmente se presentan en los contextos rurales e indígenas. De ahí que establecer relaciones basadas en el equilibrio cultural sea un indicio de que se resignifica el mundo de vida a nivel personal, familiar y comunitario de los estudiantes que participan en los procesos de formación bajo un enfoque intercultural. Por las evidencias descritas, en el CESDER-Moxviquil se observa mayor proyección educativa que en la UNICH-Oxchuc. 
Reafirmación como sujetos ante la vida

En términos generales, los estudiantes - principalmente de origen indígena o campesino- que inician estudios en el nivel superior se enfrentan a situaciones abiertas de racismo y discriminación, lo que ocasiona rupturas con su pasado indígena. De igual forma, las propuestas, tanto alternativas como oficiales, encuentran en el enfoque de la interculturalidad una posibilidad para propiciar procesos de reivindicación cultural.

En el CESDER-Moxviquil y en la UNICH-Oxchuc la "reafirmación como sujetos ante la vida" se encuentra ligada al encuentro con sus raíces, de manera particular con su lengua materna. En los grupos de discusión los estudiantes plantearon diferentes maneras de reafirmarse como sujetos desde una perspectiva intercultural; un primer paso consiste en revalorar los elementos culturales propios. Para Baronnet (2013), tener presentes las características culturales de los estudiantes y los saberes comunitarios permite contrarrestar los efectos del racismo que subsisten en la sociedad. En la experiencia del CESDER-Moxviquil se advierte un énfasis en reivindicar la lengua materna de los jóvenes que provienen de contextos indígenas y campesinos. Un ejemplo de ello se observa en el siguiente relato:

Al pasar el tiempo fui aprendiendo palabras de mis compañeros en lengua tseltal y tsotsil. Le preguntaba a mi abuela si lograba reconocer alguna de ellas, jvaya sorpresa que me llevé cuando me dijo que sí podía acordarse de algunas palabras! En ese momento identifiqué que mis raíces eran de la cultura indígena de los tseltales; en verdad, en ese momento reflexioné y me acordé de todas las veces que yo había discriminado sin motivos, sin razones, sentí una gran vergüenza por mis actos sobre las culturas indígenas, le di un abrazo a mi abuela y le dije que estaba interesado en conocer más 
acerca de su cultura (narración de experiencia de vida, estudiante del CESDER-Moxviquil).

Esta narrativa da cuenta de la potencia de lo experiencial, ya que se construye en la posibilidad de resignificarse en el mundo, no como algo que dictan desde el exterior que se debe hacer sino desde un proceso individual, sobre cómo darse cuenta de algo que no sabía y que aparece en la cotidianidad reflexiva de la existencia misma. En general, los estudiantes muestran interés por revalorar sus orígenes y, al mismo tiempo, reconocen que hay situaciones de dominación/sumisión de una cultura sobre otra, lo que genera pérdida de elementos culturales propios. Esa reflexión y análisis se lleva a cabo en muchos contenidos de las asignaturas; en ese sentido, el aprendizaje de las lenguas maternas se vive como un proceso experiencial que comparten y construyen, principalmente, con sus compañeros de clase, pues no existe una asignatura para su enseñanza; es claro que se aprovecha el capital cultural de los participantes para reconstruirse en su mundo de vida.

[...] siempre discutimos sobre la importancia de la cultura que han dejado los abuelos y de cómo ahora los jóvenes, por ejemplo, ya no quieren hablar tsotsil y se va perdiendo, porque también los mismos maestros [de otros espacios educativos] dicen que no hablen esa lengua. Esa situación la vemos crítica, por ejemplo, en nuestro salón de clases hay tsotsiles, tseltales, mixes y nos comparten su cultura (entrevista a estudiante del CESDER-Moxviquil).

En la discusión grupal con los estudiantes del CESDER-Moxviquil estos señalaron que antes de ingresar a la licenciatura reflexionaban poco sobre lo que sucedía en su vida cotidiana y normalizaban algunos comportamientos sociales como la discriminación. No obstante, participar en un proceso de reivindicación cultural les ha permitido desnaturalizar situaciones cotidianas y resignifi- 
carse como sujetos. Walsh (2005a) plantea que la interculturalidad parte de una base segura sobre uno mismo, es decir, de un claro sentido y conocimiento de quién es uno y cómo se identifica personal y colectivamente. En el CESDER-Moxviquil esa situación ha contribuido a que los estudiantes se reafirmen como sujetos sociohistóricos con un pasado indígena, y en el proceso la diversidad es asumida como un acto de dignidad identitaria.

De igual forma, en la UNICH-Oxchuc se refuerza, aprende y revalora la identidad de los estudiantes, pero a través de la asignatura Lengua Originaria — presenta como limitante que ofrece únicamente el aprendizaje de tseltal—, la cual es de carácter obligatorio durante seis semestres para todos los estudiantes. En pocos casos se experimenta como imposición, pues para muchos estudiantes ha significado un encuentro con sus orígenes. Uno de ellos señaló:

Es una motivación para seguir [estudiando] porque quizás a nivel personal sea como algo aceptable, y quizás sea por venir de una comunidad, me siento orgulloso de mí mismo. Antes de entrar acá tenía la desvalorización de la lengua, y haz de cuenta que no reflexionaba sobre lo que era mi lengua y desconocía mi propia cultura. Yo decía “¿qué onda con eso?” Pero a partir de que me fui involucrando me di cuenta de que quizás sí tiene mucha relación con mi vida personal en el momento en que empiezo a ver que se está perdiendo y yo como persona puedo generar con mi experiencia que sigan adelante y que no se olviden de nuestras raíces (reflexión grupal con estudiantes de la UNICH-Oxchuc).

En ambos casos, CESDER-Moxviquil y UNICH-Oxchuc, la revaloración de la lengua materna entre el estudiantado se genera en el marco de un contexto donde la negación cultural es motivo para sentirse incluido o excluido en una sociedad. Difícilmente las diferencias culturales se valoran como enriquecedoras en la cotidianeidad de 
la sociedad dominante, y mucho menos en los espacios educativos convencionales principalmente por el papel que juegan los medios de comunicación en la construcción de estereotipos y estilos de vida.

Los estudiantes en ambas experiencias educativas mostraron claridad en torno a las relaciones de dominación/sumisión que vivían, lo cual contribuye a posicionarlos ética y políticamente desde la potencia de su cultura, es decir, se van reconociendo en su historia, formas de vida y formas de producción y reproducción cultural — principalmente a través de la lengua materna-, lo que genera un sentido de pertenencia a una comunidad que se resiste y lucha contra procesos socioculturales que van en el sentido de la homogenización sociocultural.

Por los hallazgos encontrados en ambas experiencias educativas, se ha procurado un reencuentro con y una recreación de los orígenes de los estudiantes que coadyuva a que estos se reafirmen y posicionen críticamente como sujetos ante el mundo. Sin embargo, esto se produce en la UNICH-Oxchuc más desde una perspectiva institucionalizada - a partir de asignaturas_-, mientras en el CESDER-Moxviquil se vive como un proceso experiencial.

\section{Re-producción de elementos culturales}

Por elementos culturales se entienden los recursos de una cultura que es necesario poner en juego para formular y realizar un propósito social. Pueden distinguirse, al menos, las siguientes clases de elementos culturales: a) materiales, tanto los naturales como los que han sido trasformados por el trabajo humano; b) de organización, que son las relaciones sociales sistematizadas a través de las cuales se realiza la participación; incluyen la magnitud y las condiciones demográficas; c) de conocimiento, es decir, las experiencias asimiladas y sistematizadas y las capacidades creativas; d) simbólicos: códigos de comunicación y representación, signos y símbolos, y e) emotivos: sentimientos, valores y motivaciones compartidos; la subjetividad como recurso (Bonfil, 1991). 
Las propuestas educativas interculturales presentan el desafío de no asumir elementos culturales de manera acrítica, por el contrario, se debe realizar un análisis riguroso para incorporar estos elementos de manera consciente en los procesos de enseñanza-aprendizaje. Como ya se ha señalado, en ambas experiencias educativas se encontró una tendencia a recuperar los aspectos simbólicos para fortalecer la identidad, por ejemplo, a través de la lengua materna.

De igual forma, se encuentra que la reproducción de formas de organización comunitaria está presente en ambos espacios educativos. Por ejemplo, en el CESDER-Moxviquil se realizan asambleas grupales y generales, las cuales organizan y dirigen los mismos estudiantes a través de un comité sin la intervención directa de profesores, con base en una agenda de trabajo previamente avalada por sus compañeros. Generalmente en ellas tratan asuntos relacionados con su estancia en Moxviquil.

Entre los temas que abordan se encuentran: las normas de convivencia dentro de Moxviquil, la asignación de tareas de los grupos durante su estancia (aseo, preparación de alimentos), cuestiones operativas para mejorar el desarrollo de las clases (fotocopias, materiales, transporte), salidas a prácticas de campo y proyectos de autogestión (caja de ahorro, dotación de semillas criollas, aves de traspatio):

[...] en la asamblea se acordó que en la hora de clases no tienen que llevar tazas ni celulares, y cerrar las laptops, no llevar comida chatarra, eso es un reglamento interno. Porque muchos compañeros a la hora de las clases estaban chateando y llevaban sus tazas y ahí las dejaban, por eso ya no permitimos eso, eso es un reglamento interno [...] Surge de la caja de ahorro porque había compañeros que llegaban a la asamblea, entonces dijimos, ¿qué vamos a hacer con los que no llegan?, porque a algunos no les importaba ir o llegaban tarde y se tuvo que poner una cuota 
[...] Cada año se cambia la mesa directiva. Tenemos nuestra tarjeta de ahorro y manejamos intereses bajos y la asamblea decide si se da el préstamo o no. Hacemos rifas para obtener dinero para nuestra caja y de esa manera capitalizarnos (entrevista a estudiante del CESDER-Moxviquil).

En el CESDER-Moxviquil sobresale también la articulación de conocimientos con otros saberes y formas de pensamiento. Para Saldívar (2006), la interculturalidad no se limita al rescate de saberes y conocimientos culturales locales, sino que parte de los mismos e incorpora nuevos para generar aprendizajes significativos. Por ejemplo, los estudiantes tienen conocimiento sobre las plantas de su localidad para usos medicinales, alimenticios o de construcción, sobre los ciclos de siembra y cosecha, y sobre las actividades que desempeñan sus padres y los conocimientos asociados a ellas. Dichas experiencias se retoman dentro del salón de clases para reflexionar sobre ellas y complementarlas con aspectos teóricos, metodológicos o experienciales.

Como se ha expuesto hasta el momento, en el proceso de formación de los estudiantes del CESDER-Moxviquil están incorporados elementos culturales propios como formas de organización y participación, uso de la lengua materna, conocimiento herbolario de su localidad y mecanismos de intercambio de productos de su región. Ello se articula con la teoría del control cultural propuesta por Bonfil (1991), según la cual este autor señala la capacidad social para usar determinado elemento cultural, pero lo más importante debe ser su reproducción. En el ámbito educativo, Dietz y Mateos (2011) indican que se trata de procesos de apropiación, imposición, enajenación y autonomización, que necesariamente generan divergencias tanto dentro de la comunidad, como en la institución escolar. 
Tabla 5. Lo propio y lo ajeno

\begin{tabular}{|c|c|c|}
\hline \multirow{2}{*}{ Elementos culturales } & \multicolumn{2}{|c|}{ Decisiones } \\
\hline & Propias & Ajenas \\
\hline Propios & Cultura autónoma & Cultura enajenada \\
\hline Ajenos & Cultura apropiada & Cultura impuesta \\
\hline
\end{tabular}

Fuente: Bonfil (1991:50).

Las experiencias educativas que se posicionan como "alternativas”, como las observadas en el caso del CESDER-Moxviquil, se enfrentan al reto de generar procesos de reivindicación cultural promoviendo en todo momento la autonomía, pero también se enfrentan a la necesidad de abrirse a elementos culturales ajenos, siempre realizando un análisis detallado de las implicaciones que determinados elementos culturales tienen en la vida cotidiana.

En una cultura apropiada se necesita no únicamente decidir sobre qué elementos culturales ajenos utiliza o no, sino también se debe valorar si continuar o no con la (re)producción de los elementos culturales propios, con lo que de esa manera se ejerce determinado control cultural. "La identificación étnica con esta 'cultura propia', sin embargo, su instrumentalización reivindicativa, presupone un acto de distanciamiento frente a esta cultura, lo cual desencadena necesariamente un proceso de interculturalidad" (Dietz y Mateos, 2011:148). Lo anterior debe estar acompañado de prácticas educativas que integren con intencionalidad esos aspectos dentro y fuera del aula; por ejemplo, el aprendizaje de una lengua materna no se realiza a través de una asignatura, sino es parte de un proceso experiencial en colectividad.

En cuanto a los estudiantes de la UNICH-Oxchuc, no realizan asambleas para discutir sobre su proceso de formación. Se identificó que cuentan con un Consejo Estudiantil que es avalado por las autoridades de la Unidad Central, destinado a realizar gestiones para infraestructura o eventos culturales, académicos y deportivos. Dicho 
consejo recupera las necesidades de cada grupo para posteriormente discutirlas y presentarlas al coordinador de la UNICH-Oxchuc.

Algunos estudiantes no desconocen que la toma de decisiones y la participación comunitaria se realizan a través de asambleas. Sin embargo, en la UNICH-Oxchuc estas no se encuentran incorporadas como parte de una práctica institucionalizada que contribuya a fortalecer las capacidades de gestión y planeación. Por el contrario, se observaron intenciones aisladas de incorporar saberes locales en los contenidos de las asignaturas, como los conocimientos sobre botánica de los lugares donde los estudiantes realizaban trabajo de campo.

Los hallazgos de la investigación indican que la UNICH-Oxchuc recupera elementos culturales de organización y conocimiento, lo que permite la re-producción de algunos elementos culturales. En el Centro Universitario de Documentación e Información, las vitrinas exhiben maniquíes con vestimenta tradicional de diferentes regiones de Chiapas y, de igual forma, los estudiantes que conducen eventos académicos de importancia portan sus trajes tradicionales y hablan en su lengua materna. Asimismo, se escucha en los pasillos hablar en tseltal, pero no sucede lo mismo con el uso de la vestimenta tradicional, es decir, su utilización no es una práctica cotidiana, lo cual folcloriza la cultura y limita la comprensión de la interculturalidad.

Retomando el mismo ejercicio del CESDER-Moxviquil sobre el modelo de control cultural propuesto por Bonfil (1991), se encontró que en el caso de la UNICH-Oxchuc el uso de la lengua puede ser un elemento enajenado, ya que se omite la importancia que tiene la decisión de los estudiantes en su uso o no dentro del espacio educativo, lo cual resulta en una imposición para los estudiantes tsotsiles y choles. Ello muestra la verticalidad del modelo educativo de la CGEIB-SEP. Para Dietz (2008), en la interculturalización de "arriba hacia abajo" es imprescindible cuestionar si se ha considerado el criterio de los pueblos indígenas sobre la educación que quieren y requieren. 
La importancia de la reproducción de los elementos culturales en los procesos educativos y en la vida cotidiana de las comunidades es fundamental en la medida en que los pueblos originarios continúan teniendo la capacidad para reproducirlos; de no hacerlo, corren el riesgo de convertirse en meros receptores y debilitar así su identidad cultural. De ahí que desde una perspectiva intercultural la (re)producción de elementos culturales propios sea lo conveniente para no desaparecer en un mundo globalizado que enaltece lo ajeno antes que lo propio.

A pesar de que en ambas IES se reconocen y trabajan los elementos culturales de sus estudiantes, las estrategias utilizadas son diferentes en cada una de ellas. En el CESDER-Moxviquil se retoman más elementos porque se recupera la experiencia del alumnado en relación con su comunidad, y a partir de ahí esta se enlaza con los contenidos temáticos de determinadas asignaturas. En la UNICH-Oxchuc la incorporación de los elementos culturales está mediada por la institución misma, como ocurre con la enseñanza exclusiva del tseltal.

De manera particular, en el CESDER-Moxviquil se recuperan de forma sistemática los conocimientos de los estudiantes y de las comunidades, los cuales se incorporan a las actividades cotidianas en el aula o en la institución, pero además se busca que sean compartidos, aplicados o resignificados dentro de su comunidad u organización. Los elementos culturales que se refieren a los procesos organizativos se reproducen a través de la "vida en comunidad" - asambleas o comisiones de trabajo permanentes-. También se generan procesos emotivos, como estimular la motivación para mejorar las situaciones de vida de sus comunidades, y aspectos simbólicos como el uso de la lengua dentro y fuera del aula y de la institución.

La UNICH-Oxchuc reproduce también elementos culturales que se refieren a los conocimientos tanto en el aula, como en la institución. Sin embargo, se observó la falta de recuperación sistemática de los conocimientos comunitarios, que además no se 
incorporan intencionadamente al proceso educativo. Tampoco se observó la adecuación de procesos de organización comunitaria, a excepción del Consejo Estudiantil, y, en cuanto al uso de la lengua — un elemento simbólico de la cultura—, se observó una marcada preferencia institucional por el tseltal.

Como ya se ha señalado, en ambas experiencias se produce una revaloración de la lengua materna; no obstante, en el CESDER-Moxviquil se lleva a cabo a partir de un proceso experiencial no intencionado curricularmente, propiciado y enriquecido por la interacción entre docentes, estudiantes, comunidades y organizaciones.

La situación es similar en la UNICH-Oxchuc, aunque la diferencia reside en que en esta última institución aprender la lengua materna de la región forma parte de un proceso normativo e institucionalizado, establecido obligatoriamente. En consecuencia, se pueden ubicar las estrategias implementadas desde una perspectiva "funcional" de la interculturalidad (Walsh, 2012), porque existe una mayor preocupación por cumplir la norma antes que por generar un proceso reflexivo que permita proyectar en los estudiantes la importancia de mantener, enriquecer y promover el uso de su lengua materna.

\section{Análisis de las prácticas educativas}

\section{El papel del personal docente}

El papel de los docentes se reconoce como de vital importancia para generar procesos significativos de enseñanza-aprendizaje. Como se muestra en la Tabla 6, se observó que el personal docente de ambas IES tiene el propósito de innovar su práctica a través de técnicas y dinámicas para la construcción colectiva y participativa del conocimiento. 
Tabla 6. El papel del personal docente

\begin{tabular}{|c|c|}
\hline \multicolumn{2}{|c|}{ IES } \\
\hline CESDER-Moxviquil & UNICH-Oxchuc \\
\hline Enfoque procesual & Enfoque cognitivo \\
\hline $\begin{array}{l}\text { [...] esa vez les dije, jórale!, vamos a tra- } \\
\text { bajar la representación autobiográfica. } \\
\text { Con objetos y diversos materiales lo- } \\
\text { graron cosas increíbles al representar } \\
\text { sus miedos, sus intereses, momentos } \\
\text { significativos de su pasado. Y yo me } \\
\text { asombré porque pensaba que tenían } \\
\text { dificultades para la abstracción. Hicie- } \\
\text { ron sus autorretratos solo tocándose } \\
\text { sin verse y no juzgaron si era bonito } \\
\text { o feo, entonces muchos de ellos evita- } \\
\text { ron hacer juicios. Yo creo que eso es un } \\
\text { paso significativo que a veces a noso- } \\
\text { tros mismos nos cuesta trabajo evitar. } \\
\text { Creo que es bueno trabajar de mane- } \\
\text { ra individual, en parejas o en equipo } \\
\text { siempre y cuando se persiga un objeti- } \\
\text { vo, un porqué de la actividad (docente } \\
\text { del CESDER-Moxviquil). }\end{array}$ & $\begin{array}{l}\text { He buscado cursos para tener este mo- } \\
\text { delo educativo más colectivo, más de } \\
\text { construir trabajo en equipo y conoci- } \\
\text { miento entre todos [...] generalmente } \\
\text { siempre es hacer equipos y hago di- } \\
\text { námicas para que haya alguien que le } \\
\text { toque específicamente hablar o le toca } \\
\text { hablar a todo el grupo, de esa manera } \\
\text { vas permitiendo que la voz del grupo } \\
\text { no solamente se centre en el chavito } \\
\text { que habla mucho [...] ahí vas viendo } \\
\text { cómo le haces para romper la educa- } \\
\text { ción de la vieja escuela (docente de la } \\
\text { UNICH-Oxchuc). }\end{array}$ \\
\hline
\end{tabular}

Fuente: Elaboración propia a partir de los resultados.

En el caso del CESDER-Moxviquil, el compromiso del personal docente, en general, va más allá del espacio áulico porque prestan especial atención al proceso individual que los estudiantes van desarrollando a lo largo de su formación y a la manera en que sus acciones repercuten en su familia, grupo de trabajo, organización o comunidad. Esto es posible a través del acompañamiento que los docentes realizan a cada estudiante mediante recursos como el diario de campo, terapias individuales o el seguimiento en comunidad.

Una característica del personal docente del CESDER-Moxviquil es su amplia experiencia laboral en procesos comunitarios bajo metodologías participativas, lo cual se presenta como una ventaja institucional para contribuir a la formación de los jóvenes indíge- 
nas y rurales. Desde la coordinación de la licenciatura se promueven espacios para la reflexión y el análisis de la práctica educativa. En general, el colectivo de docentes no busca que la finalidad del proceso de enseñanza-aprendizaje se alcance siempre de forma lúdica o participativa, sino pretende que el estudiantado se sienta interpelado por ese conocimiento al relacionarlo con su experiencia, con la de otros contextos y con la teoría.

Durante algunas clases se observó que el colectivo docente hacía énfasis en cuestionar las condiciones históricas de desigualdad social y económica que padecen principalmente los grupos vulnerables (indígenas, campesinos, migrantes, infancia en situación de calle) en diferentes contextos y regiones (urbanas y rurales). El propósito era recuperar procesos que históricamente han configurado a las sociedades, para posteriormente contrastarlos con los saberes y conocimientos de los estudiantes. La intención subyacente consistía en problematizar sobre la realidad y hacer que el alumnado se posicionara frente a ella. En ese sentido, el docente prioriza el proceso antes que el resultado.

En la UNICH-Oxchuc se lleva a cabo un esfuerzo por atender las necesidades de aprendizaje del estudiantado al promover actividades lúdicas y participativas dentro del aula de clases. Sin embargo, la labor del personal docente se limita a las exigencias institucionales porque se priorizan contenidos curriculares, es decir, se privilegia el logro de los aprendizajes esperados y no los aprendizajes per se como parte de un proceso reflexivo. Por ejemplo, el "proyecto integrador" articula los conocimientos transversales y disciplinares del aula con los conocimientos locales en un trabajo final que los estudiantes realizan durante el semestre; en la valoración de dicho trabajo se privilegia el conocimiento que se recupera de las diferentes asignaturas, y no el proceso mismo de hacer el trabajo en una comunidad. 
Otro aspecto observado es el cambio constante de la plantilla docente, ocasionado por conflictos sindicales, lo que ha propiciado la falta de continuidad de un proyecto educativo intercultural. El papel de los docentes se encuentra condicionado por las disputas de los sindicatos — que luchan por beneficiar a sus agremiados-, por las exigencias y sobrecargas para cumplir los objetivos de cada semestre - docencia, vinculación, tutoría e investigación- y, finalmente, por la falta de respaldo moral y académico para incentivar su labor porque, por ejemplo, no se promueven espacios continuos para la reflexión sobre la práctica docente o para fortalecer su formación desde una perspectiva intercultural.

Los docentes que participan en ambas IES divergen en algunos aspectos que vale la pena señalar para dimensionar los niveles de participación y de compromiso en cada instancia. Los profesores del CESDER-Moxviquil, en su mayoría, forman parte de organizaciones de la sociedad civil o de algún centro de investigación y cuentan con una amplia experiencia de trabajo comunitario $u$ organizacional. Asisten una vez al mes a facilitar su clase y disponen de tiempo suficiente para planear actividades. La institución no les exige realizar vinculación comunitaria porque hay un equipo de docentes que se encarga de manera exclusiva de dar seguimiento a las actividades que los estudiantes realizan en las comunidades. Además, en su mayoría no dependen económicamente de esa actividad.

En la UNICH-Oxchuc la mayor parte de los docentes son jóvenes profesionistas con interés por contribuir a la educación superior intercultural, aunque no cuentan con formación previa en el tema. Sus ingresos económicos derivan principalmente de la actividad que desempeñan en la universidad y generalmente renuevan el contrato cada semestre. En su mayoría tienen estudios de posgrado o se encuentran en proceso de concluirlos. Por lo anterior, tienen la exigencia de cumplir con actividades de docencia, vinculación, tutorías e investigación. Los aspectos señalados de ambas IES, sin duda, marcan una diferencia sobre el papel que desempeñan los docentes en los procesos educativos. 
¿Cómo se enseña y aprende desde la educación intercultural?

La propuesta educativa del CESDER-Moxviquil se ha construido y organizado a partir de la realidad del contexto, junto con la incorporación activa de organizaciones de la región y de diferentes actores sociales, y su propósito es contribuir al desarrollo de las capacidades cognitivas, afectivas y emocionales de los estudiantes.

Por los elementos encontrados en la investigación, el aprendizaje no se centra únicamente en aspectos cognitivos, sino también en el "sentipensar" del estudiantado; de forma constante se aborda en las clases cómo se sienten y qué piensan sobre las situaciones que acontecen en los encuentros. Les incentivan de modo permanente para que investiguen e interactúen con sus familias, organizaciones y comunidades, lo que se complementa con contenidos temáticos basados en las realidades local, regional, nacional y mundial. Se hace énfasis en la utilización de técnicas participativas de aprendizaje, acompañadas del desarrollo de actividades artísticas y lúdicas.

En las reflexiones teóricas que se realizan durante las sesiones de trabajo el colectivo docente retoma de manera permanente elementos del contexto del estudiantado y se procura construir diálogos y debates a través de sus propias experiencias. Esto despierta el interés de algunos por encontrar similitudes en sus comunidades:

En cuanto a la metodología, la mayoría en las primeras concentraciones dicen de entrada que es un modelo nuevo, les rompe el esquema de la típica clase tradicional, el trabajo corporal que se hace con ellos y la distribución del espacio [...] quienes tienen algún referente comparativo lo tienen más claro [...] se sienten escuchados, muy valorados como sujetos de su propio aprendizaje. Desde acá nosotros le llamamos el ciclo experiencial, que es el mismo principio de recuperar no solo de la narrativa oral, sino también corporal, afectiva, teatral, gráfica [...] después nos vamos a la confrontación con propuestas teóricas, con otras expe- 
riencias en video, con experiencias que salen a otros lados, y luego vamos a la parte de la reconfiguración o resignificación de la práctica (entrevista a director del Centro de Formación para la Sustentabilidad Moxviquil, A.C.).

Las estrategias de formación en el CESDER-Moxviquil, en general, parten de un enfoque procesual con el objetivo centrado en cómo se generan las relaciones que contribuyen a construir aprendizajes. Se asume la formación de los estudiantes de manera holística, donde lo psicocorporal, lo lúdico, lo emocional y lo afectivo son una constante. El énfasis está en la práctica-reflexión-teoría.

Así, el aprendizaje se construye desde la experiencia del alumnado, recuperando la emoción del acto educativo, con una actitud atenta, de apertura, disponibilidad y cargada de sensibilidad (Larrosa, 2003). Significa exponer-se a lo espontáneo, mostrar-se tal cual somos, con nuestras alegrías y preocupaciones. Desde lo cotidiano se construye el sujeto, y tomar conciencia de esa cotidianeidad permite empezar a entender su mundo de vida para construirse con consciencia histórica y social, así como reconocer que los conocimientos adquiridos a través de la experiencia también son válidos.

Durante las actividades educativas se realizan narraciones constantes sobre su ser y estar en el mundo de las cuales se derivan escenificaciones, dibujos o canciones. La discusión sobre alguna lectura no se realiza mediante una exposición oral, sino que se trata de hacer una reflexión relacionando directamente la lectura con lo que sucede en el contexto comunitario del alumnado, con su realidad, y es entonces cuando de nuevo se recupera la experiencia: “Aquí me sorprendió la forma de enseñar, aquí no te forman en que aprendas y aprendas de los libros, sino más bien aprendes lo que está pasando en las comunidades, no solamente se van a lo teórico" (entrevista a estudiante del CESDER-Moxviquil).

En experiencias educativas convencionales es altamente valorado lo cognitivo, y el CESDER-Moxviquil no es la excepción; sin 
embargo, el centro cuenta con una alerta epistémica para reconocer las prácticas colonizadoras. Por ejemplo, una docente relató que cuando hizo un examen convencional con preguntas sobre lecturas y autores, un estudiante, hablante de la lengua tseltal, reprobó sin siquiera una respuesta correcta. Cuando habló personalmente con él, supo que no entendía las preguntas. Ante esa situación la docente solicitó el apoyo de un compañero de la clase para que apoyara al estudiante en la traducción del tseltal al español y aplicó un examen oral; ella hacía las preguntas en español y se las traducían al momento.

En el examen [oral] me disculpé con él y le dije: “A ver, yo te estoy aplicando un examen sin que tú tengas la habilidad, entonces, primero disculpa porque esa es mi burrada, porque eso es algo que yo no estoy contemplando y que tendría la responsabilidad de hacer porque yo soy tu acompañante”. [El estudiante] presentó un examen oral de 10. Le hice exactamente las preguntas del examen, le pedía que “M” tradujera el examen, y “M” decía: “¡Pérate “N’” Y de repente "M" se lo quedaba viendo y le decía: "Güey, cuánto sabes" [...] Es como algo constante, el estarles recordando que quien no tiene la habilidad somos nosotros, que ellos están aprendiendo español y que eso es mi burrada, no saber hablar tseltal, entonces terminan dándose cuenta de que hablar su lengua no está mal (entrevista a docente del CESDER-Moxviquil).

La experiencia compartida por la docente es un ejemplo de cómo descolonizar la idea de los exámenes y de la valoración positiva del conocimiento científico; su actitud demuestra que la evaluación puede hacerse no solo en función de los resultados, sino de lo que se pueda construir. En casos muy particulares como el mencionado se busca analizar el problema de una manera multidimensional y se indaga de qué forma el estudiante está participando en su 
comunidad, la relación con sus compañeros de grupo y profesores e incluso su historia familiar y personal. Resignificar la práctica educativa implica un desplazamiento de lo convencional hacia la reflexividad procesual-experiencial.

Por su parte, en la UNICH-Oxchuc regularmente las clases se imparten en salones bajo un modelo convencional, con una preocupación mayor por la cuantificación de los conocimientos. Entre los hallazgos de la investigación se encontró el uso privilegiado del videoproyector para presentaciones en Power Point, lecturas en cada clase y pocas técnicas participativas para la discusión de las temáticas, con un protagonismo del docente en cuanto a guiar el proceso educativo. De igual forma, se identificó la intención de relacionar la discusión teórica con los contextos local y regional, pero sin involucrar los planos personal, familiar y organizacional del estudiante.

Para algunos docentes, entrar a la UNICH-Oxchuc ha significado su primera experiencia laboral y no contaban con formación previa en educación intercultural. En la información recabada se encontró que su práctica educativa se basaba en generar habilidades técnicas y capacidades cognitivas —donde lo memorístico y repetitivo era significativo-, antes que en despertar el interés por el autorreconocimiento e incorporar lo creativo, lo afectivo o lo emocional.

Hay unas materias que no van, solo nos deja lecturas, síntesis [...] al siguiente día o una semana antes, pues leemos las lecturas, y ya la siguiente clase ya comentamos, y a veces exposiciones. Por ejemplo, la semana pasada la maestra nos dejó cuatro lecturas y, de esas, que escogiéramos dos para hacer un mapa mental, pero tuvimos que leer las cuatro para saber qué decía. Para mí, como que no va la metodología de trabajo, yo creo que algunos maestros no implementan una metodología de trabajo diferente, es muy parecida a la metodología de la prepa, nada 
más te deja tu trabajo y ya (entrevista a estudiante de la UNICH-Oxchuc).

Institucionalmente, la práctica educativa de la UNICH se apoya en el modelo por competencias, con lo que se pretende separar de la forma convencional de enseñanza-aprendizaje, haciendo énfasis en relacionar el conocimiento científico con el ancestral. Se basa en el desarrollo de habilidades, conocimientos y actitudes de los estudiantes en cercanía con sus comunidades.

Así, la vinculación comunitaria y el desarrollo de proyectos integradores son actividades fundamentales del modelo. Para lograr estos objetivos se ha necesitado mayor trabajo colegiado y acompañamiento de las actividades realizadas en las comunidades. Sin embargo, algunos docentes demuestran falta de interés y compromiso institucional:

Pienso que aquí nos falla la cuestión didáctica. No sabemos enseñar en un enfoque intercultural, porque la mayoría sí sabe muchas cosas porque sí son buenos académicos, son brillantes como académicos, pero no se quieren ensuciar las botas, no quieren entrar a la comunidad, le tienen pánico (entrevista a docente de la UNICH-Oxchuc).

El proyecto integrador fomenta el trabajo colegiado entre los docentes de las asignaturas y los estudiantes; sin embargo, su operación práctica es limitada debido a la falta de tiempo para la planeación del colectivo de docentes y al desconocimiento del propósito pedagógico del proyecto integrador y del modelo intercultural.

De cierta forma la UNICH fomenta la práctica educativa a través de la vinculación comunitaria; sin embargo, se queda muy limitada en cuanto a los profesores, porque normalmente el aprendizaje que ellos obtienen a través de la vinculación no lo ponen en práctica, porque si fuera 
así, todo lo que se ha aprendido de vinculación se vendría implementando aquí en la UNICH, por ejemplo, prácticas agrícolas, formas de cultivo. Falta esa incorporación de los conocimientos de las comunidades para fortalecer la práctica educativa (reflexión grupal con estudiantes de la UNICH-Oxchuc).

Durante la presentación de los proyectos integradores a cargo de un grupo de tercer semestre de la licenciatura en Desarrollo Sustentable, se realizó un resumen de los temas abordados en cada asignatura, pero sin relacionarlos en algún momento con la vinculación comunitaria o con su experiencia. También hubo espacios de discusión entre los docentes para demostrar sus conocimientos sobre las asignaturas, y estos recibían aplausos cuando los estudiantes expresaban aprobación o el silencio cuando deseaban mostrar desaprobación.

Los estudiantes dirigían sus exposiciones a los docentes excluyendo al resto de sus compañeros. Antes de comenzar con la presentación, cada equipo repartía únicamente a los docentes agua, fruta, tamales, pozol o cualquier otro alimento, con lo que inconscientemente reproducían prácticas segregacionistas que la educación intercultural busca erradicar. Esta situación pasó desapercibida, y a pesar de que se hicieron cometarios escuetos sobre la situación, los estudiantes continuaron dando algún obsequio; se desaprovechó ese escenario para reflexionar de manera crítica sobre esa situación particular. A pesar de ello, los trabajos mostraban un esfuerzo por acercarse a la comunidad, pero la pregunta continúa abierta: ¿cómo se pueden generar otras formas de interacción entre la comunidad, el estudiantado y el personal docente?

Por los hechos hallados, en la UNICH-Oxchuc hace falta una mayor discusión, reflexión y apropiación del modelo intercultural. Existe una continuidad del modelo convencional de enseñanza-aprendizaje, donde la metáfora de la "pedagogía del bonsái" encuentra lugar, al limitar la potencialidad del sujeto de realizar 
una ruptura epistémica y de construir una pedagogía crítica con pertinencia cultural.

Para descolonizar los procesos de enseñanza-aprendizaje es imprescindible construir un proceso de reflexividad que trascienda hacia formas no convencionales de educación; no debe partir simplemente de relacionar distintas formas de conocimiento, sino más bien de contribuciones críticas que emanen de él para coadyuvar a generar otros procesos de construcción y apropiación creativa del conocimiento.

\section{¿Qué se enseña y para qué se enseña en la educación intercultural?}

En el CESDER-Moxviquil, como se ha tratado, se pretende que el estudiante se reconozca como un actor fundamental de su propio proceso de enseñanza-aprendizaje y que al mismo tiempo desarrolle habilidades, conocimientos y actitudes a través de un mayor contacto con su realidad comunitaria, pero también con otros contextos socioculturales. De ahí que la intencionalidad de la enseñanza esté orientada hacia las conexiones entre lo social, lo político y lo económico: "[...] los y las docentes tenemos una intencionalidad de transformación social” (entrevista a docente del CESDER-Moxviquil).

Por lo expuesto hasta el momento se observa que existe el deseo de construir una propuesta pedagógica procesual-experiencial desde y para la interculturalidad, con el reto de incentivar en los estudiantes procesos de transformación desde su vida cotidiana y para su comunidad. Es una orientación hacia la "interculturalidad crítica”, la cual se enfoca en iniciar procesos de abajo hacia arriba. Sin embargo, difícilmente esta puede ser una estrategia contrahegemónica porque los estudiantes no se vinculan directamente a los movimientos sociales de su región ni luchan abiertamente contra la globalización hegemónica, sino que su aspiración está centrada en su entorno familiar y comunitario. 
[...] en el seminario de sustentabilidad me he dado cuenta de cómo está el mundo, porque antes pensaba que solo mi comunidad está mal [...] me he dado cuenta que mi lugar es ser campesino y desde mi lugar de ser campesino yo quiero aportar algo al mundo (entrevista a estudiante del CESDER-Moxviquil).

Las reflexiones contribuyen a que los estudiantes gradualmente manifiesten un interés por los problemas globales, y eso les genera cierta capacidad crítica para analizar lo que sucede también en sus comunidades. Para Mignolo se trata de "desnaturalizar la matriz colonial del poder que posibilite además tener un posicionamiento crítico ante la ideología hegemónica dominante” (2006:15).

Aunque no es una exigencia que los estudiantes regresen a sus comunidades, se construyen mecanismos para facilitar que su preparación en la licenciatura contribuya a mejorar la situación de vida de su entorno comunitario. En los grupos de discusión, los estudiantes coincidieron en que la forma de entender su comunidad ha cambiado desde que ingresaron a la licenciatura:

[...] primero hay que reconocer el valor de vida que tiene una comunidad, porque antes de llegar aquí la vida la veíamos de una manera muy diferente, más bien la veíamos con los ojos del capitalismo, de ir con eso de tener carro, casas de lujo, y que estando en el campo uno no vale y es uno pobre y jodido. Ya vimos que ser campesino no es sinónimo de pobre y jodido, así nos lo hacen ver el capitalismo, y con las prácticas y reflexiones ya nos dimos cuenta de eso (reflexión grupal con estudiantes del CESDER-Moxviquil).

En el relato anterior se encuentra reflejado un cuestionamiento a la imposición simbólica de formas de vida que a través de diferentes dispositivos de poder se ha introyectado en los anhelos de muchas personas. De igual forma, se observa que, al ser partícipes de 
una educación no convencional, los estudiantes generan procesos de concientización sobre la estructura económica actual y sobre las implicaciones en la cotidianeidad de los campesinos e indígenas en contextos rurales. Es alentador porque dichas reflexiones contribuyen a visibilizar otras formas de ser y estar en el mundo que no necesariamente tienen que ser las hegemónicas.

Implícitamente se espera que los estudiantes regresen algo de lo aprendido a las comunidades y, de cierta forma, profesionalicen su práctica en las organizaciones sociales en las que participan. Para ello se requiere de un proceso gradual de interacción dentro y fuera de su contexto. Por la formación que reciben, se anhela que los estudiantes tengan la posibilidad de aportar elementos de reflexión y análisis que contribuyan a transformar las relaciones históricas de injusticia que prevalecen en los contextos comunitarios:

[...] me he involucrado dando talleres en la comunidad y hasta ahorita a ellos [personas de la comunidad] les gusta esta nueva perspectiva de dar los talleres. Desde que entré a la licenciatura la confianza se ha incrementado con mi comunidad, ya hay gente que me busca y me pide mi opinión para algunos temas (entrevista a estudiante del CESDER-Moxviquil).

A partir del tercer año los estudiantes cuentan con herramientas teóricas y metodológicas para realizar diagnósticos participativos, con lo cual pueden priorizar problemas (cuarto año), para posteriormente desarrollar un proyecto comunitario (quinto año). A los estudiantes de la primera generación se les pidió realizar un trabajo de investigación como requisito de titulación. Los temas surgieron desde sus intereses personales ligados a sus vidas cotidianas, políticas, productivas y sociales; por ejemplo, trataron temas como los sistemas jurídicos tradicionales, la producción de café, las memorias históricas de la comunidad, la vestimenta tradicional, el alcoholismo o la violencia de género. 
El reto para la licenciatura será pensar otras maneras posibles de titulación. Si bien muchos de los temas surgen de las historias personales del estudiantado, se les pide realizar un análisis a nivel comunitario del problema, con lo cual se conjuga un tercer requisito, la devolución de los resultados obtenidos a la comunidad a través de una propuesta didáctica.

En la licenciatura se promueve una reunión con los padres, madres, parejas, hijos, tíos y amigos con la intención de involucrarlos en el proceso formativo de los estudiantes. En la educación intercultural, la articulación con el mundo de vida de los participantes posibilita incorporar otros ámbitos de aprendizaje y enseñanza, y la comunidad forma parte de ese mundo. En una de estas reuniones documenté que los familiares reconocen cambios significativos en los estudiantes, ya que los han visto participar de manera activa en su comunidad e involucrarse en la identificación de problemas. Indicaron que trabajan lo aprendido a través de talleres con pequeños grupos de la comunidad, por ejemplo, haciendo compostas, hortalizas, reforestación o cuidado del ambiente, entre otras actividades.

Pues en mi caso, yo llevo ocho años de casada y he visto cambios positivos en mi esposo, porque tenemos una hija y a veces como papás traemos esa de idea de "haz tu tarea, a, e, i, o, u”. Y ya con él es diferente, se pone a cantar, a jugar y pues eso es bonito. Y en cuestión del cuidado del medio también nos ha dicho que no debemos desperdiciar agua, no contaminar; a mí me encanta usar cloro con tal de desinfectar cosas y dice él que no, y que hay otras cosas opcionales para limpiar la casa. Tiene otra forma de ver la vida; siempre ha sido así, pero aquí le han ayudado a desarrollar esas habilidades [...] él no solo ve lo superficial, sino que busca la raíz (reflexión grupal, esposa de estudiante del CESDER-Moxviquil). 
Por los hallazgos encontrados, en el CESDER-Moxviquil la intención de la propuesta educativa se construye con el respaldo de la familia, la comunidad y la organización de los estudiantes. Sin embargo, es difícil asegurar que estos puedan lograr transformaciones inmediatas en el entorno comunitario, porque sin duda esto se alcanzará como parte de un proceso que se enriquecerá con la participación desinteresada de los miembros de su localidad y de sus organizaciones e instituciones.

Por su parte, en la UNICH-Oxchuc se identificó que los docentes están atrapados en la lógica de la interculturalidad funcional, es decir, cumplen con los contenidos curriculares de cada programa de estudio, de forma segmentada y con énfasis en la enseñanza dentro del aula. Esa situación genera poca capacidad para que estudiantes y docentes se reconozcan como actores fundamentales del proceso educativo. Por ello, el desarrollo de sus habilidades, conocimientos y actitudes queda supeditado al ámbito institucional, más aún cuando no se exige una relación directa entre el estudiante y su comunidad.

Los docentes reconocen como limitante la priorización del aula como espacio para el aprendizaje. A través de su práctica, los estudiantes tienen aprecio por la diversidad cultural y por su identidad vinculada al uso de su lengua materna. El reto se encuentra en propiciar el interés del alumnado por vincularse con las comunidades y en desencadenar un acompañamiento sistemático del trabajo que desempeñan en ellas.

En algunos casos se crea en los estudiantes cierta capacidad crítica para analizar el contexto donde se encuentran, lo que les ayuda a identificar sus expectativas a favor del mejoramiento de las condiciones de vida de su contexto. Sin embargo, se enfrentarán a la complejidad de iniciar un proceso participativo dentro de su propia comunidad debido a que durante su formación la cercanía con ella ha sido nula o poco sistemática.

La idea de los padres es que nos están mandando a la escuela para que después nos vean en la oficina con traje y 
corbata, ese es el deseo de un padre, de ver a sus hijos así, pero rompemos esos paradigmas de los padres porque no precisamente tenemos que trabajar así, en una oficina. $\mathrm{Mi}$ propósito es terminar mi carrera y luego volver a mi comunidad para trabajar con padres de familia en proyectos de agroecología y trabajar con mi misma familia (entrevista a estudiante de la UNICH-Oxchuc).

Con los estudiantes se discutió en qué medida la formación recibida les había permitido generar un sentido de arraigo en su comunidad, y sobre este punto coincidieron en que la visión sobre su comunidad había cambiado a partir de que ingresaron a la licenciatura en Desarrollo Sustentable, porque tras el aprendizaje veían amplias posibilidades para regresar. Señalaron que era una opción laboral acompañar los procesos comunitarios, pero desde afuera como: "promotor de proyectos para la comunidad para tener un sustento económico que sea de beneficio para el pueblo y para mí también” (reflexión grupal con estudiantes de la UNICH-Oxchuc). Sin embargo, estarán en desventaja debido a su falta de participación sistemática en las comunidades, por eso una opción recurrente es colaborar como agentes externos:

[...] en cuarto semestre me visualizaba en una oficina de gobierno, pero ahora me visualizo como una persona independiente para bajar proyectos para las comunidades. A mí me gustaría ser independiente, trabajar en la comunidad con aves de corral, y ya como los maestros dicen, no dependes de nadie, no tienes patrón. O también me gustaría crear proyectos comunitarios, pero dentro de las comunidades, no de los que baja el gobierno. Aunque no tengo experiencia en ese trabajo comunitario, sí tengo noción de cómo llevarlo en la práctica (entrevista a estudiante de la UNICH-Oxchuc). 
Habría que insistir en que desde los proyectos integradores se pide al alumnado un acercamiento a la comunidad para permitir la generación de aprendizajes significativos; no obstante, en dichos proyectos se prioriza la incorporación de contenidos temáticos de las asignaturas, más que la reflexión sobre la práctica de los conocimientos y las experiencias adquiridos. Al preguntar al personal docente sobre el proceso de enseñanza-aprendizaje, consideraron que atiende a las necesidades más apremiantes del entorno comunitario, y algunos coincidieron con el siguiente argumento:

[...] se atiende a las necesidades para que el chico salga de su pueblo [...] si se quedan es para generar nuevamente relaciones de poder. Ellos quieren tener dinero, un puesto político y lo que quieren es reproducir las relaciones asimétricas en las que han vivido (entrevista a docente de la UNICH-Oxchuc).

Lo anterior se puede sostener cuando en el contexto de la cabecera municipal de Oxchuc existen profesionistas que, en su mayoría, participan en la educación de nivel básico y medio superior. El testimonio anterior no se puede generalizar porque también hay estudiantes que pretenden vincularse a organizaciones sociales, con lo que esperan contribuir a mejorar las condiciones de vida de la población con la que interactúan.

A pesar a ello, esa situación no se encuentra intencionada en el proceso de formación de los estudiantes de la UNICH-Oxchuc porque no existen mecanismos o estrategias que los vinculen con sus propias comunidades, con sus grupos de trabajo o con las organizaciones de la región. Los conocimientos teóricos y prácticos que adquieren poco se articulan con procesos organizacionales, productivos, ambientales o sociales que permitan evidenciar la formación de sujetos críticos con capacidad de hacer propuestas en su contexto comunitario. El formar sujetos implica despertar interés, en ellos y en la misma universidad, de impulsar proyectos de sociedad desligados de la lógica de acumulación de capital. 
Desde que ingresan a la UNICH-Oxchuc se pide a los alumnos y alumnas que gradualmente se incorporen a su comunidad mediante mecanismos de vinculación con la intención de que después puedan intervenir directamente sobre alguna problemática identificada o bien puedan retomar esa experiencia para diseñar un proyecto de investigación para su titulación. En cuanto a los proyectos de investigación para titulación de los estudiantes de octavo semestre de la licenciatura en Desarrollo Sustentable, nueve se presentaron bajo la modalidad de "tesis" ${ }^{50}$ y uno presentó un "diseño de proyecto de desarrollo" para crear un centro cultural en la cabecera municipal de Oxchuc con el objetivo de:

[...] ayudar a la difusión, valorización y rescate de las prácticas tradicionales, con objetivo de que lleguen personas de diferentes lugares. También estará vinculada con pequeños productores para apoyar a la economía local. Ya se ha pensado que los proveedores sean San Juan, la comunidad de vinculación, y el café-restaurante será también para rescatar los platillos tradicionales, pero también los platillos gourmet. Pretendemos buscar financiamiento con CDI, INALI y otras instituciones, pero también buscar lazos con otros centros culturales como Kinoki en San Cristóbal. Queremos hacer talleres con temáticas culturales y ambientales con los jóvenes para buscar los talentos que hay en el municipio (entrevista a estudiante de la UNICH-Oxchuc).

El ejemplo anterior es claro para mostrar cómo se encuentra incorporada en algunos estudiantes la idea del "promotor del desarrollo”; aunque tienen la intención de beneficiar a los productores,

\footnotetext{
${ }^{50}$ Entre los temas de proyecto de tesis se encontraron los siguientes: huertos escolares y educación ambiental, la problemática de la falta de agua, los cambios en la forma de alimentación, el uso de agroquímicos y las plantas medicinales.
} 
implícitamente construyen una idea del desarrollo de "arriba hacia abajo" con una marcada folclorización de la cultura. En otras palabras, se observa una orientación introyectada de la "interculturalidad funcional".

A partir de lo anterior se pueden identificar diferencias entre una y otra institución, lo cual tiene mucho que ver con la articulación que se ha tejido con las organizaciones de la sociedad civil de la región. De igual forma, se puede argumentar que desde el CESDER-Moxviquil lo que se enseña está estrechamente relacionado con el contexto social, familiar, cultural y productivo de los estudiantes, lo que contribuye a que estos se posicionen desde un pensamiento crítico de su realidad bajo la utopía de construir un mundo más justo. De esta forma, se pretende que el estudiantado inicie procesos participativos y pueda asumir un papel protagónico en su comunidad. La apuesta consiste en reconocerlos como actores fundamentales de su propio proceso educativo.

En definitiva, el lugar para generar aprendizajes desde una perspectiva intercultural no se limita al aula, sino que está abierto hacia otros espacios que propicien aprendizajes significativos. Para lograrlo se necesita establecer alianzas de cooperación con miras a contribuir desde diferentes ángulos — pero con un objetivo común - a propiciar la transformación de la realidad.

Con respecto a la UNICH-Oxchuc, como ya se ha señalado, el proceso de enseñanza-aprendizaje tiene el propósito de generar en los estudiantes aprecio por la vida comunitaria e interés por transformar sus condiciones de vida; no obstante, hay una centralidad en el aula, la cual es reconocida como el espacio donde se generan pequeñas transformaciones. Una limitante de lo anterior es que no se genera un proceso continuo de participación en las comunidades, por lo que esto repercute en el estudiante, en la mayoría de los casos, en un desarraigo de su comunidad. 


\section{Construcción de capacidades para la vinculación comunitaria}

Estrategias de acercamiento: universidad-comunidadorganizaciones

El CESDER es una propuesta educativa que cuestiona el aislamiento de las universidades de su entorno inmediato, particularmente de los contextos donde se reproducen y profundizan las condiciones de desigualdad y negación cultural al propiciarse la migración hacia los centros urbanos de mayor dinamismo económico. Por ello se plantea el reto de generar capacidades humanas para que los estudiantes reivindiquen su identidad y construyan posibilidades de reinsertarse en sus comunidades desde diferentes actividades sociales y productivas.

La propuesta del CESDER-Moxviquil se erige como un esfuerzo para rearticular el proceso educativo con su contexto, pero también a los sujetos con su historia, desde la reivindicación de sus raíces como base para la proyección de los pueblos hacia el futuro, un futuro en el que tengan cabida sus formas particulares de vivir.

La vinculación comunitaria se convierte por tanto en uno de los ejes centrales del proyecto educativo que ha permitido desarrollar distintos mecanismos, estrategias y prácticas sociales que superan las formas convencionales de vinculación social o de extensión universitaria establecidas en la educación superior (prácticas de campo, servicio social, prácticas profesionales, estancias técnicas en empresas, etcétera), que responden más a la visión mercantilista, que redefine la función de la escuela como respuesta al mercado laboral y reduce el objetivo de la misma a la formación profesional para la inserción laboral de los egresados (Saldívar, 2012).

Desde su fundación, el CESDER ha desarrollado un planteamiento metodológico educativo situado, comprometido políticamente con los grupos sociales excluidos. Su propuesta se centra en la idea de construir comunidades de aprendizaje que antepongan 
el reconocimiento de los problemas de los estudiantes y los contextos socioculturales donde viven, como base para construir estrategias que permitan reflexionar sobre ellos y atenderlos de alguna manera. En las comunidades de aprendizaje, aprender y compartir son parte cotidiana de la forma de interactuar con las personas, y se asume la responsabilidad social de la formación de los sujetos que habitan en un espacio y un territorio compartido. En ese sentido, supera las formas tradicionales de la educación superior, en las que se determina a priori lo que se debe enseñar a los sujetos, que son despojados de su mundo de vida al asignarles contenidos desde fuera de su realidad cotidiana y se les "empuja" a aprender para el mercado laboral, más que a aprender para la vida.

Durante los primeros tres años de la licenciatura el estudiante desarrolla capacidades, definidas "como el complejo de conocimientos (saber), habilidades y destrezas (poder hacer), y actitudes y valores (ser)" (Domínguez, s/f), para aplicar en su comunidad principalmente. En ese sentido, existe una primera vinculación entre escuela-comunidad propiciada por el estudiante.

Todo es en función de su realidad [...] aquí en la primera clase que yo acompaño, lo que es Comunidad de Aprendizaje, les pedimos que ellos nos platiquen cómo es su comunidad, que ellos hagan un mapa de su comunidad, que nos digan cómo es, qué lengua hablan, cuál es la historia de su comunidad. La mayoría de los chavos no sabían nada y empezar a conocer eso les comienza a dar identidad [...] por ejemplo, he leído que dicen: "es que no sabía que mi abuelo fue fundador de la comunidad, que fue quien la registró” [...] Con eso se dan cuenta de que pertenecen a esa comunidad y les genera un cambio de identidad de arraigo (entrevista a docente del CESDER-Moxviquil).

Cuando los estudiantes acceden a la educación superior, en la mayoría de los casos se produce una ruptura con su entorno comuni- 
tario, lo que imposibilita generar lazos estrechos de colaboración. En contraste, una educación contextualizada en la que se promueve un reencuentro comunitario - como una de las principales fuentes para generar situaciones de aprendizaje- hace que los estudiantes comiencen a tejer vínculos con su comunidad a partir de la recuperación de su historia y de su identidad, lo que les permite comenzar a apreciar y revalorar los saberes y las prácticas locales, como lo ilustra el siguiente testimonio:

Después de trabajar un tiempo en Tijuana regresé a mi comunidad y participé en las asambleas católicas interregionales. Después de un tiempo me dijeron si quería aceptar un cargo y no lo dudé, porque se dan cuenta de quiénes participábamos más y de quiénes hablábamos un poquito más de español. También participo con una asociación que se llama Centro de Apoyo Educativo para la Comunidad y tiene mucha relación con la Iglesia católica. Hay muchas cosas diferentes que veo en mi comunidad con lo que me llevo de aquí [CESDER-Moxviquil], aunque no lo pongo en práctica, entonces ya veo un ambiente diferente, veo las formas de organización, cómo se organizan para los cargos, cosa que antes no hacía [...] me ha permitido ver cosas más allá de como estaba antes (entrevista a estudiante del CESDER-Moxviquil).

En la mayoría de los estudiantes destaca su amplia experiencia en organizaciones de la sociedad civil de la región. De acuerdo con los datos de registro en la licenciatura, del total de estudiantes inscritos (53) el 81.11\% (43) estaban ligados a organizaciones sociales, grupos de trabajo o cargos comunitarios, lo que facilitaba su labor dentro de la comunidad:

En la actualidad coordino un área de salud [en Kinal Antsetik, A.C.] porque cuando yo salí de la prepa era una ne- 
cesidad de las mujeres que pedían eso y que ellas veían en su comunidad. Bajo esa demanda creamos esa área de salud, aunque es más alternativo, de herbolaria. Con algunas prácticas que hacemos en la licenciatura he empezado a hacer trabajo con mi familia y otras [familias], pero también con otra compañera hemos empezado a trabajar con un grupo de artesanas de nuestra comunidad. Lo que hacemos con ellas es hacer huertos familiares [...] y ahora también nos solicitaron otro grupo de mujeres hacer lo mismo con ellas y se han involucrado dos o tres de sus maridos, así hemos hecho un huerto colectivo. Es mejor cuando te lo piden porque hay más compromiso de trabajo (entrevista a estudiante del CESDER-Moxviquil).

Algunos estudiantes señalan que antes de ingresar a la licenciatura ya habían colaborado en distintas actividades en su comunidad. Ese vínculo se refuerza cuando desde la licenciatura se involucran en apoyar de manera paulatina los procesos comunitarios, ya sea a través de talleres como parte de su formación o por su trabajo en alguna organización. De esa manera, sus prácticas están orientadas hacia la generación de capacidades para el aprendizaje autónomo y permanente en pleno contacto con su contexto, con su realidad comunitaria:

Siempre es importante [ir a su comunidad], a veces me visitan en la asociación que trabajo [Hagamos el Camino para una Vida Mejor, A.C.], las mujeres para que les ayude a gestionar un proyecto [...] Lo más importante para mí es que he bajado proyectos y por eso lo vinculo mucho con la licenciatura y con mi comunidad. Lo que yo les digo es que ellas tienen derecho a organizarse, a ocupar un cargo sin que yo o alguien más las esté organizando (entrevista a estudiante del CESDER-Moxviquil). 
Los docentes buscan establecer espacios y actividades para estrechar relaciones cercanas con las autoridades comunitarias con el fin de saber cómo ven la participación de los estudiantes en la comunidad. En general, la opinión de las autoridades sobre ellos es favorable en el momento de interactuar, pero el alumnado también se encuentra con obstáculos que no le permite llevar a cabo sus actividades como quisieran:

Anteriormente no me importaba lo que pasaba en mi comunidad. Con los chavos ya hay como un poco más de respeto y con los señores más grandes también, no sé cómo explicarlo, pero ha cambiado. La forma de relacionarme ha sido igual, solo que con la visión que uno tiene aquí en la licenciatura, que vemos los temas del medio ambiente y otros temas, puedo dar puntos de vista. Como soy de la misma comunidad se puede decir que hay cuestiones sociales, se puede decir que roces familiares y hay conflictos de intereses que no me dejan trabajar bien con el grupo, y si hago un trabajo siempre pido que se revise lo que yo hago para que vean que hago algo (entrevista a estudiante del CESDER-Moxviquil).

Cada estudiante vive un proceso de liderazgo y participación diferente en su comunidad, lo cual depende de las características sociales, económicas y culturales de su contexto. Compartir su experiencia y recibir retroalimentación, tanto de sus compañeros como de los docentes, favorece que gradualmente identifiquen problemas e intereses para futuras acciones.

La vinculación comunitaria no solamente es el proceso mediante el cual los estudiantes pueden participar en su comunidad, sino también consiste en interaccionar con otros elementos del contexto comunitario y urbano:

La vinculación con la comunidad implica que conozcan otras formas de vida urbanas. Los últimos años hemos in- 
tencionado más que puedan acceder a experiencias que sabemos que en su comunidad no van a tener esa oportunidad. Nos ha tocado llevarlos a un concierto de música clásica de la sinfónica de Chiapas, muestras teatrales de la ciudad, foros de discusión o incluso una vez organizamos una ida al cine porque muchos no lo conocían [...] eso es para que conozcan otros referentes [...] han hecho performance en la plaza de la ciudad, en la calle, son cosas diferentes para ellos. Para nosotros eso es la vinculación no solo con su comunidad, sino con el mundo [...] previamente se prepara un guion de preguntas a hacer o de observación, y una vez que regresan se reflexiona sobre esa experiencia (entrevista al director del Centro de Formación para la Sustentabilidad Moxviquil, A.C.).

Las expectativas de los estudiantes están puestas principalmente en trabajar para, en y desde su comunidad, ya sea de manera independiente o a través de una organización. De acuerdo con la encuesta aplicada, al terminar su licenciatura los estudiantes muestran deseos como los siguientes:

- Me gustaría participar en formación educativa, realizar un proceso integral con alguna comunidad con visión a largo plazo, conformar un centro educativo en cuestiones alternativas y vivir en y de ese espacio.

- Trabajar como promotor forestal en mi comunidad.

- Al terminar la licenciatura mis expectativas son crear una asociación civil y trabajar con grupos en temas como el buen vivir, el capitalismo y la autonomía.

- Poner en práctica lo aprendido y trabajar con mi comunidad y, por supuesto, vivir allí.

- Seguir implementando la soberanía alimentaria para tener ni poco ni mucho, para satisfacer las necesidades o crear un área de agroecología para convivir con todo, 
pero ir construyendo mi trayectoria de vida. Sé que me llevará varios años alcanzar mi sueño. Estoy en la construcción de una planeación en mi propia comunidad, pero lo básico es con mi familia, como primer paso.

- Impulsar un proceso de trabajo colectivo donde se tomen en cuenta los diferentes valores sociales, culturales, espirituales, ambientales.

- Trabajar en el CONALEP en un área de educación ambiental, y trabajar con niños para empezar a concientizarlos.

- Trabajar con grupos en diferentes comunidades, tener mi propio rancho donde pueda producir aves de traspatio, hortalizas, etcétera.

- Generar empleos sin afectar el ambiente y no entrar en el sistema capitalista; generar conciencia para que las personas valoren los productos locales.

- Ser empleado de mi misma comunidad para contribuir al desarrollo social, ambiental y económico.

- Por un lado, trabajar como docente en nivel preparatoria implementando una educación diferente, pero también, y a más largo plazo, consolidar una especie de consultoría para gestión de proyectos.

- En principio para poder llevar a cabo el plan que tenía junto con mi familia antes de empezar la licenciatura, es importante que mi esposa pueda terminar sus estudios al igual que mis hijas. Después o al mismo tiempo, crear una granja agroecológica que sirva como ejemplo para otras personas y cuidar que todo se haga con lo que aquí he aprendido.

Como puede observarse, hay una intencionalidad clara en la formación de los estudiantes que de una u otra manera se ha proyectado en ellos. Aunque no podrán generar cambios estructurales, sí estarán en la capacidad de hacer pequeñas modificaciones en su vida cotidiana, por ejemplo: trabajar para ser autosuficientes, establecer 
relaciones más justas de mercado para y con los productores locales, y contribuir hasta cierto punto a construir otras maneras de relacionarse con la naturaleza y la sociedad. Lo anterior cobra mayor sentido cuando ellos desean empezar (o empiezan) a nivel familiar.

Las expectativas de los estudiantes están puestas en generar procesos de autogestión con su comunidad, en servir en ella a través de un cargo comunitario o en dedicarse a la docencia. En este sentido, por las condiciones actuales de desempleo trabajar para su comunidad es una alternativa viable no solo por la formación que han recibido, sino también porque se necesitan factores como: establecer circuitos de comercialización y relaciones de comercio más justas, construir procesos de formación informales con campesinos e indígenas de la región o promover la soberanía alimentaria en su contexto. Lo interesante es que muchas de esas acciones ya están siendo implementadas, por lo menos a nivel familiar.

Por su parte, los estudiantes de la UNICH-Oxchuc comienzan a vincularse con las comunidades a través de grupos de trabajo formados por alguna otra institución gubernamental; por ejemplo, con las mujeres del Programa Prospera (antes llamado Oportunidades) o con el alumnado de alguna escuela primaria. En ocasiones trabajan pocos hombres y mujeres ante la falta de interés del resto de la comunidad.

La aprobación para iniciar el trabajo de campo se encuentra bajo la responsabilidad del docente encargado del eje de vinculación comunitaria, quienes consideran los siguientes criterios: a) que el estudiante tenga como lengua materna la que se hable en la comunidad para generar confianza y facilitar el trabajo, b) considerar la situación económica para hacer sus prácticas, pensando que se tendrá que ir constantemente a las comunidades, y c) los hallazgos que encuentre serán parte del proyecto integrador que se presenta al final de cada semestre.

Dichos aspectos son considerados durante los primeros semestres; sin embargo, si los estudiantes deciden cambiar de comunidad dejan a la deriva el proceso construido en semestres anteriores. En 
esos casos se limita la continuidad del proceso iniciado, además de que se produce descontento entre los pobladores y rechazo hacia otros estudiantes cuando llegan a la misma comunidad a realizar las prácticas de vinculación.

La propuesta educativa de la UNICH pretende coadyuvar a solucionar problemáticas dentro de las comunidades, aunque es una tarea que no parece generar el suficiente interés en las comunidades mismas; es decir, los estudiantes podrían incentivar otras formas de relación y participación si estuvieran más acompañados por instituciones gubernamentales de la región, organizaciones de la sociedad civil y actores comunitarios. Los hallazgos indican que se llevan a cabo acciones aisladas y desarticuladas unas de otras, lo que genera una inversión de tiempo, dinero y esfuerzo constantes en las comunidades e impide establecer un proceso de acompañamiento, más aún cuando la cooperación entre la universidad y las comunidades de la región no ha sido sistemática. Al respecto un docente señaló lo siguiente:

Hasta ahorita no se han establecido redes con la comunidad porque no tenemos impacto todavía, no hay ese acercamiento de la universidad con la comunidad y de la comunidad con la universidad, solamente es a través de los alumnos, todavía no hemos aterrizado la relación con las autoridades [...] incluso la universidad está ubicada en una comunidad que se llama Piedra Escrita, que hasta ahorita no hemos tenido un acercamiento con ellos por el proceso administrativo, que no se logra romper. Lo intercultural es una etiqueta política nada más (entrevista a docente de la UNICH-Oxchuc).

Los docentes sugieren a los estudiantes que cuando trabajen en las comunidades no promuevan actitudes paternalistas, por ejemplo, que no ofrezcan insumos a cambio de información, como ocurre bajo las políticas implementadas desde la idea del Estado bene- 
factor. En estos casos las comunidades reciben "ayuda de los de fuera" -láminas, tinacos, pisos firmes, proyectos productivos, etcétera-, lo que ocasiona que la participación esté condicionada a recibir algo a cambio. Sin embargo, las políticas y las prácticas institucionales contradicen el discurso, como se observa en el siguiente testimonio:

Se supone que con el asunto de la vinculación comunitaria debe crearse el empoderamiento, pero la UNICH hizo un convenio con CDI [...] la mayoría de nosotros no supimos en qué momento se hizo una consulta con las comunidades para entregarles instrumentos [musicales], nos dijeron nada más: "compañeros, tal día nos vemos en Oxchuc para entregar los instrumentos a las comunidades" [...] después se enteraron otras comunidades y nos dieron la solicitud para que les entreguemos instrumentos también [...] al final la UNICH está fomentando el paternalismo (entrevista a docente de la UNICH-Oxchuc).

Esta situación se reproduce al interior de las aulas; por ejemplo, en la presentación de los proyectos integradores un equipo de estudiantes señaló que por su propia voluntad "[le] nació de ir a darle algo [al entrevistado] a cambio de información”. En este sentido, aunque los estudiantes demuestren las mejores intenciones por implementar mecanismos participativos de manera consciente, se ven envueltos en un sistema de dar y recibir a cambio de establecer algún tipo de colaboración u obtener información.

Durante muchas décadas el Estado ha promovido programas asistenciales en las comunidades, lo que ha ocasionado situaciones de apatía y desinterés por solucionar sus problemas. Los programas de ese tipo promueven que la solución venga desde afuera y no se retoman las capacidades que desde adentro se pueden potenciar para iniciar procesos que favorezcan a las comunidades. Debido a ello, muchas veces los estudiantes de 
la UNICH-Oxchuc no pueden hacer trabajo comunitario; se encuentran con situaciones como la mencionada en el siguiente testimonio: "si no me vas a dar nada, mejor no participo contigo, además es tu tarea de la escuela” (reflexión grupal con estudiantes de la UNICH-Oxchuc).

En ese sentido, los estudiantes de la UNICH-Oxchuc han llegado a tener desencuentros con otras sedes que realizan vinculación en las mismas comunidades, lo cual también repercute en la práctica docente:

Un grupo que estaba en quinto semestre muy bien en una comunidad, después llegaron unos de San Cristóbal a la misma comunidad con una caja de refrescos, con eso después la comunidad ya les pedía refrescos [a los estudiantes de Oxchuc] para que pudieran seguir trabajando [...] nosotros siempre en el salón de clases tratamos de romper esos patrones del paternalismo [...] pero otros estudiantes y las mismas autoridades de la UNICH lo fomentan (entrevista a docente de la UNICH-Oxchuc).

Los estudiantes que no encuentran una respuesta favorable para trabajar con pobladores de la comunidad deciden realizar la vinculación comunitaria en escuelas de educación básica involucrando a niñas y niños, por ejemplo, en temas ambientales y productivos. En algunos casos se incentivó la participación de familiares en la instalación de huertos escolares. Esta, a pesar de ser una estrategia que permitía fomentar la participación comunitaria, no logró continuidad semestre tras semestre.

Con base en los hallazgos de esta investigación se puede argumentar que la mayoría de los estudiantes esperan colaborar con las comunidades de diferentes formas, como las siguientes:

- Trabajar como promotor comunitario haciendo proyectos que salgan desde la comunidad. 
- Promover en comunidades locales las nuevas alternativas y estrategias de producción; experimentar y aplicar lo aprendido.

- Gestionar, desarrollar y evaluar proyectos para las comunidades de manera independiente; no estar arraigado a una institución.

- Trabajar con comunidades rurales en proyectos e instituciones como la Secretaría de Agricultura, Ganadería, Desarrollo Rural y Pesca o la Secretaría del Medio Ambiente y Recursos Naturales.

- Desarrollar proyectos sustentables en las comunidades, por ejemplo, la preparación de una parcela adecuada con usos y técnicas agroecológicas.

Entre las expectativas de los estudiantes se observa una enajenación y desvinculación del lugar de origen, es decir, no se puede negar que les interesa colaborar con su comunidad, pero sus inquietudes se dirigen hacia construir una colaboración de afuera hacia adentro, por lo que se orientan más a la promoción del desarrollo en la región sin considerar que forman parte de un pueblo con características particulares, lo que contribuiría a implementar acciones de mayor trascendencia.

En cuanto a las expectativas institucionales, no encuentran mucha correspondencia con las planteadas desde el modelo educativo intercultural (Casillas y Santini, 2006), es decir, las esperanzas de transformación social promovidas por el estudiantado tendrán que esperar un poco mientras no se asuma una política institucional de vinculación como un proceso creativo, sistemático, dinámico y reflexivo con los actores regionales, las organizaciones de la sociedad civil y las autoridades comunitarias y municipales, que haga viables el impulso y el sostenimiento de los proyectos desde una perspectiva intercultural, y que tome realmente en cuenta las marcadas desigualdades históricas y las necesidades de implementar otras formas de relación entre los sujetos. 
En términos generales, el acercamiento entre universidad, comunidad y organizaciones es un mecanismo que incentiva la diversificación de espacios de aprendizaje con distintos contextos y actores sociales. Como se ha mostrado, existen diferentes procesos de acercamiento. Por ejemplo, los estudiantes del CESDER-Moxviquil acceden al centro con el respaldo de una organización, con lo que se gesta una triangulación de compromisos entre el estudiante, la organización y la comunidad; en este sentido, los procesos de aprendizaje y práctica se orientan de abajo hacia arriba. En la UNICH-Oxchuc la situación es diferente porque los estudiantes no ingresan con el respaldo formal de su comunidad o de una organización; más bien se espera que en el transcurso de su formación estrechen relaciones, pero bajo una normativa institucional que burocratiza la práctica educativa. En este sentido, los procesos son de arriba hacia abajo.

En síntesis, el CESDER-Moxviquil parte de una actitud crítica para la transformación de la realidad e impulsa un proceso educativo en el que las organizaciones y las comunidades, en su mayoría, se involucran de manera desinteresada porque reconocen el compromiso de los jóvenes con el bienestar local y comunitario.

Por su parte, en la UNICH-Oxchuc se prioriza una relación de carácter funcional con las comunidades y las instituciones gubernamentales, más que con las organizaciones de la sociedad civil de la región. Se encuentra también en esta institución una falta de mecanismos de cooperación desde la universidad hacia las comunidades y los actores locales. En ambas instituciones educativas los estudiantes se topan con dificultades para involucrar a los pobladores en los procesos.

\section{Alternancia educación/producción}

La alternancia educación/producción se plantea como un mecanismo para establecer una comunicación directa con los diversos actores que se encuentran en la comunidad y al mismo tiempo en la organización o institución en donde los estudiantes, que se en- 
cuentran comprometidos a desarrollar su proceso de formación en estrecha relación con sus comunidades y organizaciones sociales o pequeños grupos locales, ponen en práctica sus aprendizajes (Navarro et al., 2014).

En el CESDER-Moxviquil, una vez que los estudiantes ingresan a la licenciatura se les solicita que trabajen de manera vinculada con un grupo de su comunidad, que generalmente es su propia familia. Con ella realizan prácticas de lo aprendido en las sesiones de la licenciatura; por ejemplo, llevan a cabo actividades agroecológicas como el impulso y mantenimiento de huertos familiares, la elaboración de abono orgánico u otras acciones dirigidas al cuidado del ambiente.

Esa búsqueda de coherencia entre lo que se plantea en la licenciatura y lo que se hace en la comunidad y familia se ve reforzada por el seguimiento en campo de sus actividades, en las que buscan la participación colectiva de todos los involucrados en su proceso de formación profesional. En los años segundo y tercero un equipo de docentes se encarga de acompañar sistemáticamente las actividades realizadas en comunidad por los estudiantes con la finalidad de reflexionar, retroalimentar y resignificar el papel que estos desempeñan en su comunidad u organización, con lo que se busca conocer cómo comparten y aplican sus aprendizajes:

La idea era solo hacer una visita, pero después cambió porque necesitábamos saber si habían hecho cambios a partir de las sugerencias que les habíamos hecho, porque necesitaban foguearse para hacer talleres [...] pensamos también realizar intercambios de experiencias entre ellos para que se sumaran a lo que sus compañeros estaban haciendo en su comunidad. Eso fue muy enriquecedor [...] fue sorprendente ver a un estudiante haciendo un taller sobre soberanía alimentaria en su comunidad a partir de un taller que se hizo en clases [...] otros hacen trabajos más a nivel familiar, [...a un estudiante] la asamblea lo corrió porque 
se oponía a la instalación de un proyecto de una empresa extranjera (entrevista a docente del CESDER-Moxviquil).

En el seguimiento en campo que el equipo de docentes de CESDER-Moxviquil realiza con cada uno de los estudiantes se percibe el interés de la población en participar y colaborar en la formación profesional de los jóvenes, con lo que se reanima la idea de que el aula no es el único espacio para el aprendizaje, sino también la comunidad. Se observó que los docentes retroalimentaban las prácticas de los estudiantes con el propósito de mejorar las futuras participaciones de estos últimos.

El trato que los estudiantes reciben en su comunidad a través de prácticas específicas es también un proceso de aprendizaje, tanto para ellos como para la comunidad y los docentes, situación que enriquece la práctica educativa que se realiza en el CESDER-Moxviquil. Además, el hecho de que los estudiantes reciban un acompañamiento en campo marca también una diferencia significativa en el proceso de enseñanza-aprendizaje. En el trabajo con los grupos de discusión, los estudiantes reconocieron que enfrentaban distintas condiciones adversas para acompañar y participar en los procesos de mejoramiento de las condiciones de vida de su comunidad:

Esta carrera, con los trabajos que estamos haciendo, aún no logramos estar totalmente en la comunidad, como por ejemplo cuando yo intento hacer otras cosas, pues hay una cerrazón completa de lo que yo pueda compartir porque soy mujer. Es una situación muy difícil que podamos incidir ahí y porque además no podemos trabajar con toda la comunidad como quisiéramos. Si no te permiten estar en la comunidad, no puedes incidir en la solución de los problemas de la comunidad (reflexión grupal con estudiantes del CESDER-Moxviquil). 
Un aspecto central en los estudiantes del CESDER-Moxviquil es que continúan ligados a su comunidad, organización o familia durante sus estudios de licenciatura, lo cual les permite implementar acciones de producción agroecológica a pequeña escala, o bien construir espacios de reflexión y análisis sobre las situaciones sociales o productivas de su comunidad, aunque eso dependerá del grado de aceptación y participación que tengan. Lo que es invaluable es la recuperación de su experiencia como insumo en la práctica educativa.

En el caso de la UNICH-Oxchuc existe una falta de estrategias sistemáticas para el acompañamiento en las comunidades a los estudiantes. Esto se identificó que se debe, por un lado, a la burocratización en la institución, que imposibilita que algunos docentes se comprometan con el proyecto educativo intercultural y, por otro, a la falta de reconocimiento institucional a los docentes que realizan vinculación comunitaria. A pesar de ello, se han llevado a cabo esfuerzos para una mejor interacción entre los estudiantes, los docentes y la comunidad.

Por ejemplo, desde la llegada de la UNICH al municipio de Oxchuc algunos docentes han implementado una agenda para realizar actividades en la comunidad; sin embargo, a pesar de que en su trabajo acompañaban a los estudiantes en las prácticas de vinculación comunitaria, eran sancionados administrativamente por no acudir al salón de clases. De igual forma, muchos docentes optaban por ir a las comunidades los fines de semana con la finalidad de encontrar a personas con las que pudieran iniciar un proceso participativo:

A veces hemos trabajado más por voluntad, porque nosotros somos maestros de asignatura y no tenemos apoyos de la institución. Lo que hemos hecho es establecer un calendario con los grupos, se juntan las horas que son de vinculación comunitaria y así nos vamos todo el grupo a la comunidad, pero eso implica ir todo el santo día y recursos económicos [...] la universidad no considera el tiempo que tú inviertes. Decían: "lo hiciste porque quisiste, porque 
tú quisiste ir”. Así, se pagan las horas que estás frente a grupo, pero no fuera de [...] pero la vinculación es práctica (entrevista a docente de la UNICH-Oxchuc).

La mayoría del personal docente de la UNICH-Oxchuc es de asignatura, lo cual implica que en su carga horaria no estén claramente contempladas la investigación, las tutorías y la vinculación comunitaria, por lo que en la práctica realizan estas actividades por voluntad propia. Regularmente, quienes ingresan a laborar como docentes a esta universidad lo hacen con un gran ánimo y con el compromiso de "hacer bien la vinculación comunitaria", pero en el transcurso de los semestres se percibe una clara desmotivación y se van ajustando a las normas institucionales.

El proceso administrativo no fortalece los procesos de vinculación comunitaria puesto que los recursos para poder visitar a las comunidades llegan a mitad de semestre o a finales de semestre, cuando ya hiciste las dos vinculaciones comunitarias. Eso es dinero para pasaje y alimentación de maestros y estudiantes, pero muchos maestros no lo usan para los estudiantes, solo para ellos. Regularmente los jóvenes cuentan que nada más el docente dice que: "son sus viáticos” y ya. Eso reduce un poco la ida a comunidad porque son jóvenes que no tienen los suficientes recursos para darle la continuidad necesaria (entrevista a docente de la UNICH-Oxchuc).

La manera en que se realiza la vinculación con la comunidad restringe el óptimo acompañamiento y un mejor aprovechamiento del proceso de enseñanza-aprendizaje. En los grupos de discusión con los estudiantes se encontró que, a pesar de que conocen la problemática de las comunidades, difícilmente pueden contribuir a generar procesos de desarrollo local; en este sentido, consideran que la interacción en la comunidad es limitada, al igual que el acompañamiento de los docentes. 
Establecer mecanismos en la UNICH-Oxchuc que permitan dar seguimiento al papel de los estudiantes y docentes en campo implicaría una política institucional que respalde dichas acciones, en la que la comunidad universitaria se sienta acompañada e identificada con un posicionamiento ético-político. Lo anterior, nuevamente, abre la posibilidad de reflexionar sobre el compromiso asignado a los estudiantes para ser "promotores" de cambio en sus comunidades. La alternancia educación/producción se enfrenta con la dificultad de generar procesos de participación con los actores locales, organizaciones e instituciones de la región.

En ambas instituciones, CESDER-Moxviquil y UNICH-Oxchuc, se encuentran diferentes formas de alternar educación/producción; de igual forma, algunos estudiantes logran establecer procesos de reflexión y análisis sobre aspectos productivos y sociales con los pobladores de la región, aunque se enfrentan a la falta de participación y de apropiación de sus propuestas estudiantiles.

El logro de la alternancia educación/producción se determina a partir de la articulación entre la institución y los procesos comunitarios que se desarrollan de manera colaborativa y sin imposiciones. En cierta medida, en el CESDER-Moxviquil se logra con el acompañamiento sistemático y articulado a las organizaciones, comunidades y grupos de trabajo que los estudiantes promueven en sus localidades; esa situación difiere de la que se presenta en la UNICH-Oxchuc, donde no existen mecanismos que permitan una articulación con los procesos comunitarios que se desarrollan en la región, además de que no cuenta con espacios de reflexión y sistematización de la experiencia de vinculación comunitaria para poder determinar el éxito o el fracaso de las acciones.

Estancias en organizaciones sociales de la región

En el CESDER-Moxviquil, otra de las estrategias relevantes utilizadas para establecer vinculación comunitaria (bajo tres ejes: comunidad, estudiantes y organizaciones) es la promoción de estancias 
de colaboración de los estudiantes fuera de su comunidad de origen con el objetivo de conocer otras experiencias y enriquecer las propias a partir de una mirada comparada con lo que sucede en su realidad. Estas estancias se realizan a partir del tercer año de la licenciatura, durante sus prácticas profesionales, e incentivan procesos de vinculación diferentes a los establecidos con su comunidad.

La gestión de estancias para poner en práctica sus conocimientos se realiza con varias semanas de anticipación, y para llevarlas a cabo se eligen preferentemente organizaciones de la sociedad civil. La propuesta parte por lo común de la coordinación de la licenciatura, principalmente a través del área de acompañamiento en campo. También ha sucedido que las organizaciones soliciten becarios o voluntarios a fin de trabajar en sus áreas de incidencia para realizar actividades muy puntuales (Navarro et al., 2014).

Los lineamientos a tomar en cuenta para elegir la organización o institución con la que habrán de vincularse son: que exista compatibilidad entre sus actividades y el interés del estudiante, y que se programen actividades afines al perfil de este. ${ }^{51}$

Se ha pedido que realicen una estancia en una organización [...], hicimos un plan de trabajo para la organización de quince días para que realmente estuvieran ocupados, no sacando copias o estar sentados [...], preparamos previamente a los estudiantes con lecturas de acuerdo con los objetivos de cada organización, los mandamos en pareja con su despensa, la mayoría se quedaba con las familias. Fue un aprendizaje muy rico para ellos [...], hubo muchos que sufrieron mucho, les tocó familias muy pobres que comían hojas de rábano porque no tenían nada más. Se die-

\footnotetext{
${ }^{51}$ Entre las organizaciones que han participado se encuentran: la Fundación León XIII, el Grupo de Investigación, Asesoría y Acciones para el Desarrollo Comunitario (GIAADEC), Voces Mesoamericanas, Palucheen, la Preparatoria Bivalente Bartolomé de Las Casas, el Centro de Derechos Indígenas, A.C.-Misión Bachajón, Kinal Antzetik, Enlace Comitán, Cupa Sijminu, S.C. y el Centro de Derechos de la Mujer, entre otras.
} 
ron cuenta de cómo trabaja la familia y a algunos hicimos que les cayera el veinte del trabajo comunitario (entrevista a docente del CESDER-Moxviquil).

La evaluación de las estancias, proceso al que pueden sumarse los docentes, coordinadores y administrativos, se realiza de manera conjunta a través de una reunión entre estudiantes y el equipo de seguimiento en campo. Es un espacio pensado para compartir la experiencia y visualizar las mejoras que se pueden hacer sobre la actividad realizada. En la evaluación que se llevó a cabo para este trabajo, los estudiantes señalaron que su participación a través de las estancias les había permitido poner en práctica conocimientos adquiridos en la licenciatura, lo que facilitó que generaran mecanismos para alcanzar una mayor organización y participación de las familias con las que interactuaron, aunque también reconocieron la importancia de mejorar sus estrategias. Al respecto señalaron lo siguiente:

Bueno, a mí me tocó estar con Voces Mesoamericanas [...] llegamos el domingo y nos recibieron bien, el lunes empezamos a hacer visitas a las comunidades para conocer los grupos con los que se están implementando proyectos en las comunidades [...] aunque ahorita ese grupo está en la gestión de un proyecto de apicultura, nuestra propuesta era también que nosotros pudiéramos dar un taller. Presentamos un video de apicultura para reflexionar un poco porque es un grupo que no tiene experiencia en eso, y el video les ayudó a ver si están en condiciones de tener ese proyecto o mejor cambiaban. Reflexionaron un poco y resultó que sí, que sí tienen las condiciones para hacerlo. Dimos un taller de reciclaje de basura, sobre todo de "pet”, y más tarde un taller práctico de manejo de lombricomposta, y aunque no llevamos lombrices les enseñamos el proceso de cómo trabajar con ellas. Ya ahora le quedó el compromiso a Vo- 
ces Mesoamericanas de llevar lombrices californianas. Por la noche presentamos la película La jaula de oro y después se reflexionó sobre ella. Al día siguiente partimos a otra comunidad a evaluar un proyecto de vivero, y ahí sí no había nada que hacer porque la coordinadora del proyecto no hizo el seguimiento, porque el año pasado hicieron injertos, pero como vieron que no pegó levantaron las mallas y todo. Visitamos muchas comunidades, dimos talleres de aves de traspatio, hicimos diagnósticos comunitarios, análisis FODA con grupos consolidados (entrevista a estudiante del CESDER-Moxviquil).

De igual forma, otro estudiante relató la experiencia de su estancia en una organización desde otra perspectiva:

Mi presentación fue en la iglesia el domingo y ese día la gente tenía otra información. Yo tenía información de que iba a hacer hortalizas y me comenzaron a preguntar si ya tenía un plan de trabajo y les dije que no, les digo que tengo que construir con ustedes, tengo que ver cómo están organizados. La gente como que está acostumbrada a que siempre les llevan el plan, y no están acostumbrados a que hay otras formas de trabajar más conjuntamente, más participativo; y en ese momento comenzamos a planear conjuntamente con las mujeres las actividades para visitar sus huertas [...] A las que se involucraron en los talleres les enseñé cómo aprovechar las verduras, cómo aprovechar las frutas de otra manera, hice postres de plátano con azúcar y harina y ese taller fue el que tuvo más éxito porque llegaron quince mujeres (narración de estudiante del CESDER-Moxviquil).

A pesar de que desde el CESDER-Moxviquil se busca que los estudiantes tengan una participación directa en las organizaciones para propiciar procesos de transformación social, esa decisión es 
ajena a ellos y a la misma licenciatura, es decir, depende del ritmo y las acciones que en ese momento cada organización esté emprendiendo. Las estancias son una oportunidad para evidenciar el crecimiento personal del estudiantado, para poner en práctica los conocimientos adquiridos y también para ubicar posibles acciones a realizar a partir de la participación con la comunidad.

En contraparte, la UNICH-Oxchuc no cuenta con mecanismos de cooperación con organizaciones que permitan a los estudiantes hacer estancias en ellas e implementar en experiencias de trabajo comunitario los conocimientos y capacidades adquiridos. En su lugar, se continúa con la manera convencional de vincular a los estudiantes preferentemente con instituciones gubernamentales.

El servicio social de la UNICH está orientado hacia tres sectores, a) el gobierno, con sus programas contra la pobreza dirigidos a la población marginada, b) las organizaciones de la sociedad civil, con programas como equidad de género, producción sustentable o mercado justo, y c) el sector empresarial, con algunas actividades de servicio en el marco de la denominada responsabilidad social de las empresas o para promover pequeñas empresas familiares. En el trabajo de campo se encontró que los estudiantes realizaban su servicio social en instituciones gubernamentales y académicas, y en una cantidad menor en comunidades. ${ }^{52}$

Para realizar el servicio social, los estudiantes cuentan con el apoyo de un docente que es el encargado de asesorar, guiar y revisar la documentación y los reportes del servicio social. Para Pe-

\footnotetext{
${ }^{52}$ En el caso particular de los estudiantes de Oxchuc, se cuenta con registros de que los estudiantes han realizado su servicio social en las escuelas primarias, el centro de salud, el Centro de Desarrollo Comunitario Porfirio Encino Hernández, La Albarrada, el Centro Estatal de Lenguas, Arte y Literatura Indígenas (CELALI), la Comisión Nacional Forestal (CONAFOR), la Comisión Nacional para el Desarrollo de los Pueblos Indígenas (CDI), el Consejo Nacional de Fomento Educativo (CONAFE), el Parque Nacional Lagunas de Montebello, la Comisión Nacional de Áreas Naturales Protegidas (CONANP), la Secretaría de Agricultura, Ganadería, Desarrollo Rural, Pesca y Alimentación (SAGARPA), la Casa de la Cultura de Oxchuc, el Sistema para el Desarrollo Integral de la Familia (DIF), la Sociedad Cooperativa Productores Agropecuarios Casa Ecológica Dos Arbolitos, y en las localidades de Crusilja, Ejido La Arena y La Palma.
} 
ña-Cuanda, Marín y Camacho, el servicio social, busca no solo contribuir a la formación académica y profesional de los jóvenes, sino fundamentalmente que sus resultados produzcan beneficios a la comunidad y a la sociedad en general. Señalan que ese trabajo se logra al integrar la participación de docentes y directivos: "a través del llenado de formatos enviados electrónicamente” (Peña-Cuanda, Marín y Camacho, 2015:11).

Algunos estudiantes, por el mismo proceso de participación que han llevado a cabo en cierta comunidad, deciden continuar en ella bajo la modalidad de servicio social; su contribución parte de la identificación de una problemática concreta, y asumen un compromiso con las autoridades de la localidad a través de la implementación de un plan de trabajo. Sus reportes bimestrales se entregan con el sello y firma de la autoridad en turno con la finalidad de transparentar el proceso del servicio social:

Nosotros motivamos a los estudiantes para que sigan en su misma comunidad haciendo el servicio social; entonces, por ejemplo, básicamente ellos identificaron que la gente necesita un abono orgánico porque tienen una plaga en su papa, y como ya saben esas cuestiones lo hacen en la comunidad [...] hay una parte donde no te da tiempo, pero es importante hacerlo, es esto de inspección, inspección sorpresa, donde ya va alguien de servicio social a ver si está en el horario y con tal señor. Es aleatoria y de manera sorpresiva, al menos con eso de cierta manera se amortigua un poco el fraude (entrevista a docente de la UNICH).

En el caso de los estudiantes de la UNICH-Oxchuc, tienen la posibilidad de hacer su servicio social en la localidad durante todo un semestre; quienes no lo desean, pueden cumplir con sus 480 horas de temporada vacacional fuera de Oxchuc. El estudiante cuya experiencia se muestra a continuación optó por esta modalidad: 
Pues, al empezar, la verdad no sabía dónde podía hacer mi servicio social. La escuela solo nos dio una explicación de qué documentación debíamos tener para hacer el servicio social y cómo hacer todos nuestros trámites para llevarlo a cabo. Ya en clases una maestra nos informó que tenía contacto con algunas instituciones en donde podíamos hacer nuestro servicio social y nos comentó que había espacio en Montebello y en La Albarrada. El contacto fue directamente con ella, ella fue nuestra asesora de servicio social (entrevista a estudiante de la UNICH-Oxchuc).

No hay duda de que en su servicio social los estudiantes desarrollan nuevas capacidades relacionadas con la licenciatura, pero no se hace una evaluación sistemática sobre los alcances, aprendizajes o capacidades que desarrollan; regularmente este servicio se asume como un trámite administrativo, como un requisito a cumplir para la titulación, y la experiencia que se genera queda solamente entre el estudiante y el docente. No se ha considerado que sea un proceso participativo de reflexión y de acompañamiento a los estudiantes en las comunidades en el que se involucre a las organizaciones de la sociedad civil, a instituciones gubernamentales y académicas y a actores sociales en el proceso de reflexión de su práctica.

Entre las divergencias entre el CESDER-Moxviquil y la UNICH-Oxchuc sobresale que, la primera, mantiene vínculos cercanos con las organizaciones de la sociedad civil a través de sus estudiantes y de la participación directa del colectivo docente que forma parte de ellas. En ese sentido, su política institucional se dirige al trabajo comunitario en la región. Por su parte, la UNICH-Oxchuc aplica la modalidad de servicio social como se hace convencionalmente en la mayoría de las universidades, es decir, los estudiantes se involucran en el servicio social a partir de la misma oferta que promueve la universidad. De igual forma, el seguimiento es casi nulo pues no hay docentes asignados para llevarlo a cabo. 


\section{Desafios de la vinculación comunitaria}

Como se ha señalado, los estudiantes del CESDER-Moxviquil participan en diferentes actividades de su comunidad, principalmente con las familias cercanas a ellos para iniciar procesos que requieren mayor organización. Como es de esperarse, en los primeros años su participación es menor, a diferencia de en los últimos, aunque hay que recordar que el proceso de cada estudiante es diferente: algunos lo llevan a cabo a través de su organización, y otros, por ejemplo, durante el proceso comienzan a interesarse sobre lo que sucede en su comunidad y empiezan a asistir a las asambleas, como se ejemplifica en el siguiente testimonio:

Al principio no tienen participación directa en comunidad. Durante su participación en asambleas se van dando cuenta de que es algo que ellos pueden hacer, porque al principio ni mencionan las asambleas de su pueblo. Después, a mí me tocó ver que en sus diarios [de campo] decían: "pues es que le pedí a mi papá acompañarlo a la asamblea, y me di cuenta que se tardan mucho discutiendo y que ya están aburridos y que votan nomás por votar". Así van dándose cuenta de cómo pueden participar (entrevista a docente del CESDER-Moxviquil).

El objetivo es que tengan participación en la asamblea de su comunidad para tratar de incidir en las decisiones que se toman. Por lo que expresaron los estudiantes a partir de las entrevistas, la mayoría de ellos cuenta con el respaldo de su comunidad y ha llegado a participar favorablemente en las tomas de decisiones durante las asambleas. Por ejemplo, algunos señalaron que habían acordado hacer limpieza y reforestación de la comunidad, iniciar procesos de huertos familiares o implementar cursos o talleres con niños y niñas sobre temas relacionados con el cuidado del ambiente. De 
igual forma, enfrentaron algunos obstáculos que limitaban su participación, como se señala en el siguiente testimonio:

No es tan fácil el decir que la gente "le entre", yo creo que es un reto tan grande que nos va a llevar un proceso, porque la gente está acostumbrada con lo que ha vivido, con lo que es más fácil, en cambio, si dices "nos sentemos acá y vamos a empezar a hacer una hortaliza sin usar químico y hacemos nuestros biocidas", hay gente que dice "está padre", pero hay quienes dicen "yo no le entro", yo creo que ése es el reto (entrevista a estudiante del CESDER-Moxviquil).

Hay quienes señalan que no cuentan con el apoyo suficiente de su comunidad y se les ha negado el acceso por ser arrendatarios no ejidatarios o porque considerar que son "unos chamaquitos y que no pueden enseñar nada" (entrevista a docente del CESDER-Moxviquil). Incluso no les han permitido acceder por oponerse a proyectos que afectaban a la comunidad; por ejemplo, un estudiante señaló que se opuso a un proyecto de energía eólica por los daños que podría causar a la salud y al ambiente. Relató que muy pocos lo escucharon y que la asamblea ya había tomado la decisión de aceptar el proyecto durante varios años a cambio de un pago mínimo anual por la renta de las tierras. A partir de entonces, él no podía participar en la asamblea comunitaria y el trabajo de concientización lo hacía de otra manera:

Por ejemplo, en mi comunidad están discutiendo eso de lo del parque eólico y yo, como pertenezco a la parte de los pobladores, hice una intervención de cómo analizar los impactos que pueden provocar en el ambiente y en la salud [...] también hay actores que te quieren atacar, entonces fue algo duro. Porque hay varios que "se me vinieron encima”, incluso el comisariado ejidal, y entonces yo ya no busqué otra forma para incidir más allá [...] ahorita la em- 
presa acaba de hacer un pago del segundo año como renta del terreno y cada ejidatario recibió $\$ 300.00$ por año. Cada terreno está vendido, pues, porque es para 50 años. Ese día quise llegar a dar mi punto de vista y me cerraron la puerta, no me dejaron entrar [...] entonces, lo que estoy haciendo es un video para compartir los daños y así ganarme la confianza de la gente (reflexión grupal con estudiantes del CESDER-Moxviquil).

Otro estudiante señaló los factores que le limitaron su participación en la comunidad:

Allá, por ejemplo, en mi comunidad, que a un joven lo vean hablando dicen: “¿Este qué va a saber?, es un chamaco, yo ya hacía las cosas cuando él todavía estaba en pañales”. Entonces esa es la cuestión, no solo por ser mujer, sino también por ser joven y, bueno, yo creo que esa parte de solucionar los problemas todavía se está construyendo, yo creo que es un proceso y todavía nos falta terminar la licenciatura porque, se crea o no, la cédula te abre muchas posibilidades (reflexión grupal con estudiantes del CESDER-Moxviquil).

Cuando se han propuesto intervenir en la solución de los problemas de su comunidad tienen que enfrentarse a otros actores que ejercen influencia sobre el resto de la población. A pesar de lo anterior, los estudiantes tienen capacidades (herramientas metodológicas, actitudes y conocimientos) para intervenir en la comunidad. Reconocen al mismo tiempo que las situaciones de conflicto y las relaciones de poder pueden ser oportunidades para tratar de incidir en las problemáticas. Es importante insistir en que a partir de las prácticas que realizan, se observan mayores logros de los estudiantes a nivel familiar y grupal, y menos en el ámbito comunitario, a pesar de lo cual en muchos casos cuentan con el respaldo de sus organizaciones. 
En el caso de la UNICH-Oxchuc, la institución se enfrenta al desafío de asumir el compromiso de acompañar los procesos que los estudiantes realizan en las comunidades; es decir, no basta con enviarlos, sino se requiere buscar mecanismos que permitan develar que la vinculación comunitaria puede llegar a ser beneficiosa tanto para la población receptora como para la misma institución, porque a partir de ella se contribuye a formar estudiantes que en un futuro pueden regresar a sus comunidades desde una situación diferente. Al respecto, un estudiante señaló lo siguiente:

En mi experiencia, pues, que casi no íbamos a comunidad a hacer trabajo directo, llegábamos esporádicamente, era un trabajo para cumplir con las materias. Lo podíamos hacer nosotros sin necesidad de ir a la comunidad, inventábamos cifras y talleres. En nuestro cuarto hacíamos los dibujos en el paleógrafo, y ya, le tomábamos fotos y eso lo presentábamos a los maestros. Cuando la maestra nos decía: "la próxima semana vamos a ir a la comunidad y vamos a hablar con los agentes de la comunidad para ver si lo que ustedes hicieron realmente es un problema”, y ya todos comenzamos a ir a la comunidad y hacer contactos, y eso fue bueno para conectarnos para empezar realmente a hacer los talleres en la comunidad (entrevista a estudiante de la UNICH-Oxchuc).

Las experiencias narradas muestran cómo desde la UNICH-Oxchuc se asume la intervención en las comunidades como una oportunidad de aprendizaje; no obstante, algunos de los estudiantes no visualizaban esta opción como una posibilidad de laborar ahí, sino más bien se veían trabajando en instituciones gubernamentales para promover el desarrollo en sus comunidades "de afuera hacia adentro":

A los alumnos no les gusta hacer vinculación, o sea, esa es una de las cosas más contundentes que yo he visto; no es una práctica que les parezca de lo más adecuada por- 
que en una lógica rural, por ejemplo, ni siquiera vamos a lo indígena, eres universitario para no llenarte de lodo los zapatos, y entonces ¿por qué vas a regresar a la comunidad? Eso es lo que dicen los chavos cuando les hablas; y la otra es que tampoco hay receptividad de la comunidad, siempre les exigen que les den un refresco, dinero, etcétera (entrevista a docente de la UNICH-Oxchuc).

Asimismo, uno de los directivos mencionó:

Hemos llegado a idealizar a los estudiantes. En la realidad muchos no se están arraigando a su comunidad, ya no quieren regresar a su comunidad, quieren trabajar en una institución, en una oficina y a partir de ahí hacer vinculación con su comunidad [...] nuestro ideal es que vayan los estudiantes a la comunidad, alguno que otro sí, y no se va a poder aunque estemos ahí duro y duro, yo creo que es mejor cambiar el perfil porque no se va a lograr (entrevista a directivo de la UNICH).

Considero que antes de adecuar el perfil de egreso se debería reflexionar sobre la formación de estudiantes en una universidad intercultural, es decir, habría que cuestionarse qué sucede durante su proceso educativo para que la mayoría no considere necesario colaborar en y para su comunidad. Una de las razones se puede encontrar en la falta de compromiso institucional por promover la vinculación comunitaria más allá de una actividad académica centrada en el aula a través de proyectos integradores. No menos importante es la necesidad de contar con docentes que tengan experiencia de trabajo comunitario, además de un perfil profesional adecuado.

Particularmente, en la UNICH-Oxchuc tanto los docentes como los estudiantes se enfrentan al reto de iniciar procesos de reflexión con miras a mejorar las condiciones de vida de las personas con quienes interactúan. Al respecto, un docente señaló: 
[...] al ver que no hay beneficios van restringiendo la participación, por ejemplo, hay jóvenes que están en quinto semestre y que dos años y medio estuvieron trabajando en la comunidad, pero que ahora decidieron ya no seguir participando con este grupo porque la misma comunidad no ha visto ningún beneficio; pero más allá de eso no se cumplieron los objetivos ante la asamblea y, al no encontrar resultados inmediatos, la comunidad decidió no continuar con la participación de los estudiantes [...] ven que para ellos es nada más sacar información, llenar los documentos, firmarlos y sellarlos, entonces llegan a ya no legitimar más el proceso (entrevista a docente de la UNICH-Oxchuc).

Sin lugar a dudas ambas instituciones presentan retos y obstáculos particulares que no son comparables por las diferencias entre ellas. En el caso del CESDER-Moxviquil, aunque los estudiantes inician con procesos de participación a nivel familiar u organizacional, enfrentan el desafío de ser reconocidos por su propia comunidad como actores fundamentales para incidir en el mejoramiento de su situación de vida. En algunos casos sucede que, a pesar de que les dan la apertura para realizar talleres participativos, analizar planes y proyectos comunitarios o realizar prácticas agroecológicas con grupos de trabajo, los estudiantes difícilmente son reconocidos como interlocutores confiables para la solución de problemas porque consideran que son jóvenes y que tienen muy poca experiencia. De esta manera, el reto para el CESDER-Moxviquil es incidir en los procesos comunitarios.

Para la UNICH-Oxchuc el desafío consiste en involucrar en el análisis de la realidad, de manera participativa y desinteresa$\mathrm{da}$, tanto a actores comunitarios como a las instituciones y organizaciones sociales, para encontrar intereses compartidos que enriquezcan la germinación de procesos de vinculación comunitaria. Es decir, en la medida en que los estudiantes se involucren de manera gradual en los procesos comunitarios y se fortalezcan 
sus capacidades teóricas y metodológicas, la vinculación dejará de considerarse como una obligación académica.

En definitiva, ambas experiencias educativas enfrentan el reto de involucrarse, desinteresada y participativamente, en el curso natural de los procesos comunitarios. Es difícil saber qué repercusiones tendrán con el transcurso del tiempo; por ahora, ambas experiencias son pequeñas esporas diseminadas en contextos comunitarios con la firme aspiración de generar transformaciones en un futuro inmediato para la educación superior intercultural en Chiapas.

\section{Análisis integral de las experiencias de formación}

\section{CESDER-Moxviquil}

La propuesta de formación del CESDER-Moxviquil pone el énfasis en la construcción de aprendizajes centrados en el proceso y la experiencia; se privilegia la reflexión sobre la práctica más que el resultado, y con ello se abre la posibilidad permanente de resignificar el proceso de enseñanza-aprendizaje. Este aspecto es fundamental debido a que en la mayoría de las universidades convencionales la experiencia y la reflexión pocas veces son incorporadas a los planes y programas de estudio, lo cual representa un distanciamiento entre la realidad sociocultural de los estudiantes y lo que sucede, teórica y metodológicamente, en el aula.

En el CESDER-Moxviquil se privilegia la interacción que se establece con las organizaciones de la sociedad civil, grupos de trabajo, familias y actores sociales; son ellos mismos quienes retroalimentan los procesos de aprendizaje de los estudiantes en el ámbito comunitario. Lo anterior se ha logrado por el acompañamiento sistemático de un equipo de docentes de la licenciatura con el propósito de fortalecer los vínculos entre estudiantes, comunidad, universidad y organizaciones. 
Sobresale que las organizaciones de la sociedad civil se han involucrado de manera colaborativa en dos sentidos: el primero, al respaldar económica o moralmente a los integrantes que buscan profesionalizar su práctica y, el segundo, al contar con algunos docentes que forman parte de ellas. De esa manera, se crea un compromiso entre las comunidades de los estudiantes, las organizaciones de la sociedad civil y el CESDER-Moxviquil. Contar con la participación de los actores sociales y comunitarios ha contribuido a construir una propuesta educativa acorde al contexto sociocultural y a la realidad de los participantes.

Las características mencionadas difícilmente se encuentran en la mayoría de las universidades convencionales debido a que estas últimas privilegian los sectores empresarial y gubernamental, y generalmente, cuando establecen relaciones con las comunidades, lo hacen para intervenir en acciones puntuales privilegiando el resultado antes que el proceso, por lo que no se garantiza la participación continua de los estudiantes ni de otros sectores sociales en el proceso educativo, de tal manera que aspiran a la capacitación para un mercado laboral que responda al interés del capital económico.

El proceso de enseñanza-aprendizaje ha permitido un posicionamiento crítico de los estudiantes sobre las relaciones de poder que prevalecen en muchos contextos comunitarios y, de igual forma, ha contribuido a recuperar y resignificar la identidad de los alumnos al promover en ellos un acercamiento gustoso a sus orígenes culturales. No obstante, a pesar de que los estudiantes revaloran su lengua y su cultura, hace falta mayor proyección institucional para fortalecer la enseñanza de las lenguas maternas, es decir, para profundizar en la lectura, la escritura y la enseñanza de la gramática.

Una debilidad manifiesta es la falta de participación de algunos docentes en las reuniones periódicas de coordinación de la licenciatura, lo que dificulta establecer un plan de trabajo consensuado colectivamente. Su ausencia se justifica porque deben atender otros compromisos laborales. De igual forma, hace falta incorporar las múltiples voces de las personas que participan directa o in- 
directamente en el proceso de formación y, por ejemplo, fortalecer el intercambio de experiencias entre docentes, directivos, padres, madres, familiares y amigos de los estudiantes. Lo anterior, aunque representa una acción aislada y en construcción, permite la reflexión creativa y crítica sobre el propio proceso de formación, particularmente sobre la práctica educativa, la vinculación comunitaria y la interculturalidad. A partir de los elementos mencionados es posible identificar en el CESDER-Moxviquil un acercamiento a la perspectiva de la interculturalidad crítica.

\section{UNICH-Oxchuc}

Una de las fortalezas de la UNICH-Oxchuc es que se trata de una de las UI oficiales de México que, además, está ubicada en una región con una significativa presencia de la diversidad étnica, cultural y linguística del país. La práctica pedagógica de esta universidad se orienta a retomar elementos socioculturales del contexto; curricularmente ofrece asignaturas destinadas explícitamente a aprender la lectoescritura de las lenguas maternas de la región, lo cual contribuye a que los estudiantes revaloren y resignifiquen su identidad.

El aporte fundamental de la UNICH-Oxchuc sobre las demás universidades parte de valorar la formación de jóvenes de contextos rurales e indígenas que ante la desigualdad socioeconómica difícilmente podrían acceder a otra opción educativa; en ese sentido, se espera que durante y después de su formación los estudiantes se comprometan a implementar proyectos (productivos, culturales, económicos, ecológicos) con sus comunidades.

De igual forma, en la UNICH-Oxchuc la vinculación comunitaria se considera como una actividad sustantiva del quehacer universitario, a través de la cual se busca estrechar lazos de cooperación con las comunidades de la región. En este sentido, cada semestre se realiza un proyecto integrador con la finalidad de articular los contenidos temáticos de cada asignatura a través de las acciones implementadas en la comunidad por los estudiantes. 
No obstante, existe desinterés por parte de algunos docentes, estudiantes y pobladores de las comunidades. Se observó que la práctica educativa se encontraba acotada por la burocratización institucional, por una planta docente fragmentada debido a las disputas sindicales y, en consecuencia, por cambios constantes del personal. No es de menor importancia mencionar que los conflictos sociales y políticos de la región también han contribuido a mermar la vinculación comunitaria.

A pesar de que la UNICH-Oxchuc tiene una destacada presencia en la región, necesita construir mecanismos institucionales para articularse con los actores sociales, comunidades y organizaciones que inciden en el contexto. Asimismo, una tarea pendiente es establecer procesos de vinculación comunitaria en los cuales se promueva un acompañamiento y una sistematización de la práctica, antes que valorar únicamente el resultado del proyecto integrador.

Como se ha expuesto, el desafío para la UNICH-Oxchuc consiste en generar estrategias que permitan la participación de los actores comunitarios de manera desinteresada. Aunque se encontraron aspectos significativos sobre la construcción de la interculturalidad (lectoescritura en tseltal e incorporación del contexto sociocultural de los estudiantes), es necesario traspasar la identificación de lo intercultural con lo indígena, en otras palabras, se trata de superar una perspectiva funcional de la interculturalidad para tender hacia una perspectiva crítica en la que se incorpore un cuestionamiento a las condiciones históricas de dominación entre las culturas para proponer otras formas de vida y de interacción entre los sujetos.

La UNICH-Oxchuc, en general, aporta elementos para la resignificación de la práctica educativa; sin embargo, es primordial considerar que las transformaciones más importantes deben hacerse de abajo hacia arriba. 


\section{Conclusiones}

La presente investigación tiene como punto de llegada la reflexión sobre la formación de jóvenes rurales e indígenas que participan en IES con enfoque intercultural. Esta inquietud encontró respaldo teórico en el pensamiento decolonial, principalmente construido desde la perspectiva de la interculturalidad crítica propuesta por Walsh (2005b, 2012) y Tubino (2005).

La interculturalidad, ya sea abordada de manera implícita (CESDER-Moxviquil) o explícita (UNICH-Oxchuc), debe asumir un enfoque crítico sobre las relaciones de poder que históricamente han prevalecido, a través de la colonialidad del poder, del saber y del ser (Mignolo, 2006). Dicho análisis debe estar ligado a la realidad del contexto o región, pero con una actitud modesta y abierta hacia las propuestas educativas sostenidas "desde abajo", como ocurre con varias experiencias de México o del sur del continente, porque es en esta región donde actualmente se está forjando "otra" educación con perspectiva intercultural desde y para los pueblos originarios, y donde además se ha demostrado que los proyectos educativos no pueden sostenerse sin la cooperación y el acompañamiento de las organizaciones y movimientos indígenas o afrodescendientes.

Así, la educación superior en México se enfrenta al reto de resignificar el hecho educativo y, en consecuencia, incorporar las distintas maneras de entender y ver el mundo para alejarse cada vez más de la visión mercantilista (impuesta por organismos internacionales, universidades convencionales, instituciones gubernamentales o centros de investigación, entre otros), y responder más a las demandas de los actores y al contexto social donde interac- 
cionan (y desde donde parece definirse otra idea de destino común que no es la del horizonte capitalista predominante).

Por los hallazgos alcanzados, se puede concluir que el reto es generar una pedagogía intercultural en la cual se recuperen las experiencias locales, se creen capacidades y condiciones para hacer una reflexión crítica sobre el sistema económico actual y se logre una posición frente a las formas hegemónicas de construcción del conocimiento. Se trata de impulsar una pedagogía abierta al diálogo para crear situaciones de aprendizaje con intencionalidad dirigida hacia la acción y la transformación.

Se encontró que, tanto el CESDER-Moxviquil como la UNICH-Oxchuc, soportan en la interculturalidad una alternativa para atender las manifestaciones de la diversidad étnica y lingüística de los estudiantes; no obstante, en la UNICH-Oxchuc se trata de una perspectiva "institucionalizada" (Dietz y Mateos, 2011), es decir ya hecha, que responde a las mismas exigencias que la CGEIB-SEP marca para las UI; en consecuencia, la preocupación está centrada en responder y atender al marco normativo. Si bien tiene aspectos positivos como propiciar la revaloración de la cultura y la identidad de los estudiantes, no se evidencia un cuestionamiento claro hacia las relaciones de dominación/sumisión que prevalecen en los contextos comunitarios.

En ese sentido, el significado otorgado a la interculturalidad en la UNICH-Oxchuc se sostiene en relaciones basadas en la tolerancia, el respeto, el intercambio de conocimientos y, fundamentalmente, en el uso de la lengua tseltal, lo que remite a una interculturalidad restringida y funcional. Si bien estos son elementos necesarios para propiciar un encuentro intercultural, en el fondo corresponden a una perspectiva multiculturalista (Meer y Modood, 2011). En ese sentido, se encontró que la UNICH-Oxchuc debe asumir no únicamente la transversalidad de la interculturalidad en sus programas educativos, sino también una perspectiva crítica que se encamine hacia la acción y la transformación. 
Por su parte, en el CESDER-Moxviquil la perspectiva intercultural —a pesar de que no se explicita institucionalmente- se orienta a retomar el uso de las lenguas originarias, las relaciones basadas en el respeto y el intercambio de conocimientos. En esta propuesta educativa aparece de manera sistemática un cuestionamiento hacia las relaciones de poder, principalmente sobre las situaciones que los estudiantes enfrentan cuando interactúan en sus contextos comunitarios; el hecho de que aparezca dicha interrogante permite un acercamiento a la perspectiva crítica de la interculturalidad. Con ello se contribuye a que en su vida cotidiana los estudiantes profundicen, redefinan y propongan otras formas de relación con sus familias o grupos de trabajo.

Conviene resaltar que se encontró que la interculturalidad aparece como medio y como fin en ambas IES, pero con diferencias significativas que se exponen a continuación.

En el CESDER-Moxviquil la interculturalidad aparece como un medio porque se construye como parte de un proceso en el que la interacción y la experiencia son materia prima para posibilitar otras formas de relación, coadyuvando así a que los estudiantes adquieran gradualmente mayor consciencia sobre sus orígenes y su papel como sujetos social y políticamente comprometidos con el bienestar local y comunitario. En consecuencia, el interés por transformar la realidad se convierte en un fin cuando así se asume, es decir, cuando se persigue la utopía de lograr relaciones más justas y equitativas dentro de la comunidad, la organización o la familia. De esta manera, la interculturalidad se alcanza cuando se trasgrede la normatividad de las discusiones reflexivas y teóricas que se dan en el aula y se enfrenta la realidad de los contextos comunitarios a través de la participación de los estudiantes.

Por su parte, en la UNICH-Oxchuc se revela que la interculturalidad es un medio cuando se recupera la consciencia crítica a través de la revaloración de la lengua materna (tseltal) y se incorporan los conocimientos previos de los estudiantes para resignificarlos con la teoría. Sin embargo, la interculturalidad se desvanece 
como fin al no encontrar un objetivo claramente definido sobre su papel dentro de la comunidad o región que permita a los estudiantes generar sentido de arraigo y la necesidad de incidir en las problemáticas que ahí se presentan. En consecuencia, se aborda la interculturalidad con una preocupación mayor por administrar la diversidad que por contribuir a transformar o cuestionar las condiciones adversas de las comunidades de origen de los estudiantes.

En síntesis, los resultados obtenidos sobre la categoría de interculturalidad permiten identificar los alcances teóricos y metodológicos de ambas IES. También permite reconocer la necesidad de incentivar mayor reflexión y análisis en ellas para entender los remanentes de la colonialidad instaurados de manera subjetiva en las relaciones cotidianas. Conviene subrayar que, a pesar de presentar avances significativos para la reivindicación cultural de los estudiantes, aún falta incidir directamente en los contextos donde están inmersos, ya que es ahí donde la interculturalidad no logra superar las relaciones de poder presentes. El reto para las IES consiste en asumir el bagaje cultural de los pueblos originarios, pero despojado de la mirada multiculturalista y a partir de ello construir un encuentro intercultural que desde una perspectiva crítica enriquezca la práctica educativa a través de la experiencia, el diálogo y la praxis en los contextos socioculturales.

Sobre las prácticas educativas se concluye que en el CESDER-Moxviquil, más allá de propiciar un ambiente facilitador para el proceso de enseñanza aprendizaje (a través de actividades lúdicas y participativas) y de promover la construcción de conocimientos a partir de la experiencia, el diálogo y la reflexión, se busca generar procesos de vinculación, de acompañamiento, de problematización de la realidad y de revaloración cultural, antes que enfocarse únicamente en los resultados.

Institucionalmente, lo anterior deriva de la ventaja de que la mayoría de los docentes de este proyecto educativo están vinculados a organizaciones sociales, universidades y centros de investigación de la región. Además, la práctica educativa se fortalece al 
articularse con padres de familia, actores sociales, mujeres, productores, campesinos, etcétera, como una contribución más a la formación de los estudiantes. En ese sentido, el fin de la práctica educativa es lograr que los estudiantes obtengan mayor consciencia sobre su entorno para incidir desde y para su comunidad.

Lo anterior es diferente en la UNICH-Oxchuc debido a que su práctica educativa está más dirigida a los resultados (principalmente a atender los contenidos temáticos, centrados en el proyecto integrador cada semestre), antes que a generar procesos. En consecuencia, la práctica educativa es ajena a la experiencia y a los procesos de vinculación que los estudiantes construyen en su comunidad porque no se promueven institucionalmente espacios de reflexión, análisis o acompañamiento para ello.

Así, la práctica educativa se encuentra desarticulada de las organizaciones sociales, los actores comunitarios, los productores, los campesinos o los padres de familia porque estos no encuentran un "para qué" o una finalidad clara de las acciones emprendidas desde la universidad. También se demostró la evidente necesidad de fortalecer curricularmente la transversalidad de una práctica educativa con mayor apego a los criterios teóricos y metodológicos de la interculturalidad. Aún con esas limitantes, se halló que los docentes y estudiantes de la UNICH tienen voluntad para cambiar el proceso educativo, situación que debe aprovecharse para incidir no solo en las relaciones institucionales, sino también en la educación que se requiere para ese contexto particular.

En conclusión, la práctica educativa desde la interculturalidad crítica debe estar cargada de una intencionalidad que despierte en el estudiante la necesidad de hacer algo por sí mismo y por su entorno familiar y comunitario de cara a transformar las formas injustas de relación que prevalecen entre las culturas para convertirse en un sujeto activo en la construcción de su propio proceso educativo. Se trata de facilitar encuentros en los se reivindiquen la identidad y la investigación sobre el contexto social y cultural, y que, de igual manera, se incorporen la expe- 
riencia y el diálogo para establecer relaciones más horizontales entre los sujetos.

Las dos categorías antes mencionadas -interculturalidad y práctica educativa - se cristalizan en la construcción de capacidades sociales para la vinculación comunitaria. Como se ha mostrado, en el caso del CESDER-Moxviquil resalta el respaldo que los estudiantes reciben de las organizaciones sociales, lo que facilita procesos de reflexión y análisis al interior de sus comunidades. En consecuencia, la generación de capacidades para la vinculación comunitaria se construye en estrecha relación con sus comunidades, organizaciones y familias, lo que contribuye a generar vínculos de largo alcance.

En contraste, los estudiantes de la UNICH-Oxchuc, en su mayoría, no encuentran en sus comunidades una posibilidad para regresar e iniciar en ellas procesos de transformación; esto puede deberse a que institucionalmente no se fomenta el arraigo en ellas, es decir, no se generan capacidades para la vinculación o son de corto alcance. En el caso de esta universidad, se encontró que la falta de articulación con organizaciones y actores sociales de la región coloca a los estudiantes como actores secundarios, con poca influencia en su comunidad o región. Aunque eso no significa que no se generen posicionamientos críticos, la diferencia es que no reciben retroalimentación de los actores sociales, las organizaciones sociales, los grupos de trabajo comunitarios o sus familias.

Los hallazgos encontrados permiten concluir que los estudiantes del CESDER-Moxviquil se visualizan trabajando en y para su comunidad "desde adentro", en colaboración, principalmente, con organizaciones sociales, asociaciones civiles o a título personal, mientras que los estudiantes de la UNICH-Oxchuc se ubican como agentes externos "desde afuera" en colaboración, principalmente, con instituciones gubernamentales. Ello demuestra una sutil, pero determinante, diferencia en su quehacer como futuros profesionistas.

Es necesario reconocer la importancia de abordar la vinculación comunitaria articulada a los diferentes actores sociales que 
intervienen en la formación de los estudiantes justamente para enriquecer y acompañar el proceso educativo. Por consiguiente, el desafío consiste en forjar sentido y significado en la formación de los estudiantes, un sentido en el que se reconozcan los diferentes contextos para generar un aprendizaje que contribuya a formar sujetos desde una práctica reflexiva, donde además la diversidad se vea como una oportunidad de enriquecer la vida diaria.

Como se ha presentado, el aporte fundamental de este trabajo se centra en comprender cuáles son los alcances de la educación intercultural y las repercusiones de esta en las comunidades donde se vinculan. Abre también un espacio para reflexionar sobre el compromiso de que las instituciones, directivos, docentes, estudiantes, actores sociales, comunidades, familias y organizaciones sociales tienen en los espacios de formación comunitaria.

En síntesis, lo expuesto en cuanto a ambas experiencias ofrece elementos para argumentar la necesidad de resignificar la educación superior intercultural. En ese sentido, la interculturalidad, la práctica educativa y la generación de capacidades para la vinculación comunitaria no deben ser asuntos exclusivos de los estudiantes de contextos rurales e indígenas formados bajo enfoques educativos interculturales, sino más bien habría que insistir en la transversalización de la educación intercultural.

A partir de los resultados de esta investigación se sugiere que es necesario considerar que la interculturalidad no solamente es un asunto que atañe a los pueblos originarios, sino también a otros grupos subalternos que históricamente han sido menospreciados (migrantes y afrodescendientes, por ejemplo), pero principalmente a quienes han estado en una posición de dominación cultural. Por consiguiente, el reto es lograr una apropiación teórica e implementar mecanismos prácticos desde la crítica y la reflexión que ayuden a que las acciones educativas tengan mayor coherencia.

Por los hallazgos mostrados, se sugiere llevar a cabo la revisión misma del modelo de la CGEIB-SEP para evitar, en la medida de lo posible, la homogeneización de un "modelo educativo" para la 
totalidad de las UI del país, en primer lugar porque las características históricas, ambientales, productivas, sociales y culturales son diferentes en cada región o estado, en segundo lugar porque sería valioso hacer pequeñas adecuaciones curriculares o flexibilizar la currícula de acuerdo con la realidad del lugar donde se encuentra ubicada cada UI —es necesario ir más allá de incorporar la lengua originaria de la región-y, en tercer lugar, porque la discusión crítica de la interculturalidad debe incluirse de una manera más intencionada en la currícula, y esta discusión debe enriquecerse además de su propio contexto y de otros actores sociales, aunque este último aspecto no debe tomarse en cuenta únicamente en las UI, sino en todas las IES.

En el CESDER-Moxviquil, aunque se efectúa un seguimiento de los procesos a nivel individual y colectivo de los estudiantes, se debe prestar mayor atención a fortalecer algunos aspectos, como el desarrollo de competencias para el bilingüismo coordinado, no con la finalidad de castellanizar a los estudiantes, sino de crear contrapesos que posibiliten una mejor interacción con los contextos en los que se vinculan, pero sobre todo que les permita empoderarse, reivindicar su identidad indígena y, al mismo tiempo, apropiarse de elementos culturales que enriquezcan su desempeño académico y profesional. 


\section{Referencias}

Abellán, Rogelio, Remedios de Haro y Andrés Frutos (2010). "Una aproximación a la educación inclusiva en España”. En Revista de Educación Inclusiva, vol. 3, núm. 1, pp. 149-164.

Acuerdos de San Andrés (1996). Acuerdos sobre derechos y cultura indígenas.

Alvarado, Aida (2009). "Vinculación universidad-empresa y su contribución al desarrollo regional". En Ra Ximhai, septiembrediciembre, vol. 5, núm. 3, pp. 407-414.

Asociación Nacional de Universidades e Instituciones de Educación Superior (ANUIES) (2012). Plan de desarrollo al 2016. Hacia la proyección de la vinculación de las IES para la innovación orientada al desarrollo sustentable de las regiones en México. México: Red Nacional de Vinculación-ANUIES.

Báez-Jorge, Félix (2009). "Prólogo”. En Gonzalo Aguirre Beltrán, Regiones de refugio. El desarrollo de la comunidad y el proceso dominical en Mestizoamérica. México: Fondo de Cultura Económica, Universidad Veracruzana, pp. 9-14.

Bárcena, Fernando (2005). La experiencia reflexiva en educación. Barcelona: Paidós.

Bárcena, Fernando, Jorge Larrosa y Joan Mèlich (2006). "Pensar la educación desdela experiencia”. En Revista Portuguesa de Pedagogía, núm. 40-1, pp. 233-259.

Baronnet, Bruno (2012). Autonomía y educación indígena. Las escuelas zapatistas de la Selva Lacandona de Chiapas, México. Quito: Abya Yala. Baronnet, Bruno (2013). "La autonomía como condición para la educación intercultural”. En Sergio Hernández, María Ramírez, 
Yunuen Manjarrez y Aarón Flores (coords.), Educación intercultural a nivel superior: reflexiones desde diversas realidades latinoamericanas. México: UIEP, UCIRED, UPEL.

Baronnet, Bruno (2015). "El movimiento zapatista y la educación para la autonomía”. En Patricia Medina Melgarejo (coord.), Pedagogías insumisas. Movimientos político-pedagógicos y memorias colectivas de educaciones otras en América Latina. México: Universidad de Ciencias y Artes de Chiapas-Centro de Estudios Superiores de México y Centroamérica, Educación para las Ciencias en Chiapas, A.C., Juan Pablos Editor.

Baronnet, Bruno y Medardo Tapia (coords.) (2013). Educación e interculturalidad. Política y políticas. Cuernavaca, México: UNAM-CRIM.

Barry, Brian (2001). Culture and equality: an egalitarian critique of equality. Londres: Polity Press.

Baumann, Gerd (2001). El enigma multicultural. Un replanteamiento de las identidades nacionales, étnicas y religiosas. Barcelona: Paidós Ibérica.

Berlanga, Benjamín (2005). "Introducción a la ponencia de Hugo Zemelman”. En Hugo Zemelman, Hacia la construcción conceptual y metodológica de un enfoque político de comunidades de aprendizaje $y$ trabajo en red en organizaciones de la sociedad civil (ponencia). Puebla: UCI-RED.

Berlanga, Benjamín (2007). El grito como proyecto educativo (el enfoque ético-político de la propuesta pedagógica de comunidades de aprendizaje). A partir de la presentación realizada en el Centro de Estudios Ecuménicos. Puebla: UCI-RED. Recuperado de: http://www.ucired.org.mx/ publicaciones/desde-el-pensamiento-de/hugo-zemelman/item/20el-grito-como-proyecto-educativo

Berlanga, Benjamín (2014). El giro intercultural: una tarea pendiente en las Universidades Interculturales en México. México: UCIRED. Recuperado de: http://www.ucired.org.mx/memorias/item/109-elgiro-intercultural

Berlanga, Benjamín y Ulises Márquez (1995). Las escuelas rurales de formación para el trabajo: una opción educativa para la agricultura de 
pobreza. En Educación y pobreza: de la desigualdad social a la equidad. México: UNICEF, El Colegio Mexiquense.

Bermúdez Urbina, Flor Marina (2015). "Interculturalidad, etnicidad e intermediación cultural en la formación de profesionales indígenas. Concepciones y prácticas en la Universidad Intercultural de Chiapas”. En Patricia Medina (coord.), Sujetos y conocimientos situados, políticas del lugar en educación. Trayectos y experiencias pedagógicas de investigación en la construcción de interculturalidades activas. Oaxaca: 1450 Ediciones, UNACH, UABJO, UNICH, UPN.

Bertely, María (1998) "Educación Indígena del siglo XX en México". En Pablo Latapí (coord.), Un siglo de educación en México. México: CONACULTA, FCE.

Bertely, María, Gunther Dietz y María Guadalupe Díaz (coords.) (2013). Multiculturalismo y educación 2002-2011. México: ANUIES, COMIE. Besalú, Xavier (s/f). Aspectos generales de la diversidad cultural y Educación intercultural. Recuperado de: https://fdocuments.ec/amp/ document/xavier-besalu-costa-puesta-en-practica-de-la-educacionintercultural-en-los.html

Besalú, Xavier, José García y Raúl García (coords.) (2014). "Estado de la cuestión y principales progresos en las políticas que regulan los derechos de los inmigrantes extranjeros: Acceso a los servicios sociales y a la educación”. En Xavier Besalú et al. (coords.), Aproximación al estado de la interculturalidad. Red de escuelas interculturales. Madrid: Liga Española de la Educación y la Cultura Popular, Wolters Kluwer España, S.A.

Bolaños, Graciela, Libia Tattay y Avelina Pancho (2008). "Universidad Autónoma, Indígena e Intercultural: un espacio para el posicionamiento de epistemologías diversas”. En Daniel Mato (coord.), Diversidad cultural e interculturalidad en educación superior. Experiencias en América Latina. Caracas: Instituto Internacional para la Educación Superior en América Latina y el Caribe (IESALC)-UNESCO.

Bonfil Batalla, Guillermo (1982). "De culturas populares y política cultural”. En Guillermo Bonfil Batalla, José Joaquín Blanco et al., 
Culturas populares y política cultural. México: Museo de Culturas Populares, SEP, pp. 9-22.

Bonfil Batalla, Guillermo (1991). Pensar nuestra cultura. México: Alianza Editorial.

Campos, Guillermo y Germán Sánchez (2005). "La vinculación universitaria: ese oscuro objeto del deseo”. En Revista Electrónica de Investigación Educativa, vol. 7, núm. 2. Recuperado de: http://redie. uabc.mx/vol7no2/contenido-campos.html

Casillas, Lourdes y Laura Santini (2006). Universidad intercultural: modelo educativo. México: CGEIB-SEP.

Castillo, Elizabeth y José Caicedo (2015). "Las batallas contra el racismo epistémico de la escuela colombiana. Un acontecimiento de pedagogías insumisas”. En Patricia Medina Melgarejo (coord.), Pedagogías insumisas. Movimientos político-pedagógicos y memorias colectivasdeeducacionesotrasen América Latina. México:Universidad de Ciencias y Artes de Chiapas-Centro de Estudios Superiores de México y Centroamérica, Educación para las Ciencias en Chiapas, A.C., Juan Pablos Editor.

Ceceña, Ana Esther (2008). De los saberes de la emancipación y de la dominación. Buenos Aires: CLACSO.

Cerruto, Leonel (2009). "La experiencia de la Universidad Indígena Intercultural Kawsay (UNIK)”. En Daniel Mato (coord.), Instituciones interculturales de educación superior en América Latina. Procesos de construcción, logros, innovaciones y desafios. Caracas: Instituto Internacional de la UNESCO para la Educación Superior en América Latina y el Caribe (IESALC)-UNESCO.

Citarella, Luca (1990). “Capítulo 1 México”. En Francesco Chiodi (comp.), La educación indígena en América Latina: México, Guatemala, Ecuador, Perú, Bolivia, t. 1. Santiago, Chile: UNESCO-OREALC.

Comité Clandestino Revolucionario Indígena-Comandancia General del Ejército Zapatista de Liberación Nacional (1996). "Cuarta Declaración de la Selva Lacandona”. Recuperado de: http://palabra. ezln.org.mx/comunicados/1996/1996_01_01_a.htm 
Consejo de Europa (2008). Libro blanco sobre el diálogo intercultural. Vivir juntos con igual dignidad. Estrasburgo: Gobierno de EspañaMinisterio de Cultura.

Diario Oficial de la Federación (2002). Constitución Política de los Estados Unidos Mexicanos.

Díaz, María (2001). Técnica y tradición. Etnografía de la escuela rural mexicana y de su contexto familiar comunitario. México: El Colegio de Puebla, Plaza y Valdés.

Díaz-Couder, Ernesto (1998). "Diversidad cultural y educación en Iberoamérica”. En Revista Iberoamericana de Educación, núm. 17, mayo-agosto.

Díaz-Polanco, Héctor (2006a). “Caracoles: La autonomía regional zapatista”. En El Cotidiano, vol. 21, núm. 137, mayo-junio, pp.44-45.

Díaz-Polanco, Héctor (2006b). Elogio de la diversidad: globalización, multiculturalismo y etnofagia. México: Siglo XXI.

Dietz, Gunther (2008). “La experiencia de la Universidad Veracruzana Intercultural”. En Daniel Mato (coord.), Diversidad cultural $e$ interculturalidad en educación superior. Experiencias en América Latina. Caracas: Instituto Internacional para la Educación Superior en América Latina y el Caribe (IESALC)-UNESCO.

Dietz, Gunther (2012). Multiculturalismo, interculturalidad y diversidad en educación: una aproximación antropológica. México: Fondo de Cultura Económica.

Dietz, Gunther y Laura Mateos (2008). "El discurso intercultural ante el paradigma de la diversidad: estructuraciones subyacentes y migraciones discursivas del multiculturalismo contemporáneo". En Santiago Bastos (comp.), Multiculturalismo y futuro en Guatemala. Guatemala: FLACSO, OXFAM, pp. 23-54.

Dietz, Gunther y Laura Mateos (2011). Interculturalidad y educación intercultural en México: un análisis de los discursos nacionales $e$ internacionales en su impacto en los modelos educativos mexicanos. México: CGEIB-SEP.

Dietz, Gunther y Laura Mateos (2013). “Una década de educación intercultural en México: Debate “entre empoderamiento indígena 
y transversalización de la diversidad”. En Sergio Hernández, María Ramírez, Yunuen Manjarrez y Aarón Flores (coords.), Educación intercultural a nivel superior: reflexiones desde diversas realidades latinoamericanas. México: UIEP, UCIRED, UPEL.

Dobbernack, Jan (2010). "Things Fall Apart: Social Imaginaries and the Politics of Cohesion”. En Critical Policy Studies, vol. 4, núm. 2, pp. 146-163.

Documento base de la licenciatura en Planeación del Desarrollo Rural (2008). México: CESDER-PRODES, A.C.

Domínguez, Silvia (s/f). "Centro de Estudios para el Desarrollo Rural, CESDER, A.C: Licenciatura en Planeación del Desarrollo Rural”. México: CESDER-PRODES, A.C.

Dussel, Enrique (2005). Transmodernidad e interculturalidad. México: Universidad Autónoma de México.

Fábregas, Andrés (2005). "La interculturalidad en el mundo contemporáneo”. En Gaceta de la Universidad Intercultural de Chiapas, núm. 1, pp. 3-5.

Flores, José y Alfredo Méndez (2012). “UNISUR: Una universidad de los pueblos paralos pueblos”. En La Jornada del Campo, núm. 62. Recuperado de: http://www.jornada.unam.mx/2012/11/17/cam-unisur.html

Flores, Lucio (2008). "Formação Indígena na Amazônia Brasileira”.

En Daniel Mato (coord.), Diversidad cultural e interculturalidad en educación superior. Experiencias en América Latina. Caracas: Instituto Internacional para la Educación Superior en América Latina y el Caribe (IESALC)-UNESCO.

Fornet-Betancourt, Raúl (2002). "Lo intercultural: el problema de su definición”. En Yolanda Onghena (ed.) Interculturael. Balance y perspectivas. Barcelona: Fundación CIDOB.

Fornet-Betancourt, Raúl (2009). Intersubjetividad en el proceso de subjetivización. México: CGEIB-SEP.

Franco, Jean (2004). "La máquina de guerra subalterna: mujeres, guerra y derechos”. En Metapolítica, núm. 36, vol. 9, julio-agosto, pp. 75-82.

Freire, Paulo (1973). ¿Extensión o comunicación? La concientización en el medio rural. México: Siglo XXI. 
Freire, Paulo (2002). Pedagogía del oprimido. México: Siglo XXI.

Galán, Felipe y Sergio Navarro (2015). “Indigenismo y educación intercultural: una discusión necesaria. La experiencia en la Universidad Intercultural del Estado de Tabasco”. En Desacatos, núm. 52, pp. 144-159.

Gamboa, Jonatan (2007). "Las misiones culturales entre 1922 y 1927". Ponencia presentada en el IX Congreso Nacional de Investigación Educativa, Mérida, Yucatán, Consejo Mexicano de Investigación Educativa.

Gasché, Jorge (2008). "La motivación política de la educación intercultural indígena y sus exigencias pedagógicas. ¿Hasta dónde abarca la interculturalidad?”. En María Bertely, Jorge Gasché y Rossana Podestá (coords.), Educando en la diversidad. Investigaciones y experiencias educativas interculturales y bilingües. Quito: Abya Yala. Gasché, Jorge (2010). "De hablar de la educación intercultural a hacerla”. En Mundo Amazónico, núm. 1.

Gazzola, Ana (2008). "Prefacio”. En Daniel Mato (coord.), Diversidad cultural $e$ interculturalidad en educación superior: experiencias en América Latina. S/l: Organización de las Naciones Unidas para la Educación, la Ciencia y la Cultura-Instituto Internacional para la Educación Superior en América Latina y el Caribe (IESALC)UNESCO, pp. 11-15.

Giménez, Gilberto (1997). “Materiales para una teoría de las identidades sociales”. En Frontera Norte, vol. 9, núm. 18, julio-diciembre, pp. 9-28.

Gobierno del Estado de Chiapas (2003). Los Acuerdos de San Andrés. Tuxtla Gutiérrez, Chiapas: Consejo Estatal para la Cultura y las Artes de Chiapas.

Godenzzi, Juan (2005). "Situación de los pueblos indígenas en América Latina”. En Juan Godenzzi y Marcela Tovar, Creación de ambientes interculturales en contextos educativos multiculturales. Curso piloto dirigido a formadores de educadores indígenas. Red Interamericana de Formación de Formadores en Educación Indígena, COLAM-UPN. 
González Casanova, Pablo (1965). La democracia en México. México: ERA. González Casanova, Pablo (2001). "Los zapatistas del siglo XXI”. En Temas para el Debate, núm. 79, pp. 48-50.

Gould, Giacomo (1997). Vinculación universidad-sector productivo. Una reflexión sobre la planeación y operación de programas de vinculación. México: ANUIES, Universidad Autónoma de Baja California.

Gualdieri, Beatriz, María Vázquez y Marta Tomé (2008). “Educación y multiculturalidad: una experiencia de integración dialéctica entre extensión, docencia e investigación desde la Universidad Nacional de Luján”. En Daniel Mato (coord.), Diversidad cultural $e$ interculturalidad en educación superior. Experiencias en América Latina. Caracas: Instituto Internacional para la Educación Superior en América Latina y el Caribe (IESALC)-UNESCO.

Guerra, Ernesto y María Meza (2009). "El corto y sinuoso camino de la Universidad Autónoma Indígena de México (UAIM)”. En Daniel Mato (coord.), Instituciones interculturales de educación superior en América Latina. Procesos de construcción, logros, innovaciones y desafios. Caracas: Instituto Internacional para la Educación Superior en América Latina y el Caribe (IESALC)-UNESCO.

Guerra, Ernesto, María Meza y Eduardo Sandoval (2011). "La interculturalidad adjetivada”. Ponencia presentada en el Segundo Foro Internacional de Multiculturalidad, 21, 22 y 23 de septiembre, Celaya, Guanajuato: Universidad de Guanajuato Campus CelayaSalvatierra.

Hansen, Randall (2006). "The Danish cartoon controversy: a defence of liberal freedom.” En International Migration, vol. 44, núm. 5, pp. 7-16. Hobsbawm, Eric (1992). Naciones y nacionalismo desde 1780. Barcelona: Crítica.

Huerta, María, Ignacia Serrano y Marco Comunidad (2008). Zautla de la A a la Z. Un ejemplo de autogestión del desarrollo social. México: CESDER-PRODES, A.C

Iablonska, Aleksandra (2015). "La Universidad Comunal Intercultural de Cempoaltépetl: un proyecto político, cultural y pedagógico”. En Patricia Medina Melgarejo (coord.), Pedagogías 
insumisas. Movimientos político-pedagógicos y memorias colectivas de educaciones otras en América Latina. México: Universidad de Ciencias y Artes de Chiapas-Centro de Estudios Superiores de México y Centroamérica, Educación para las Ciencias en Chiapas. A.C., Juan Pablos Editor.

Kymlicka, Will (1996). Ciudadanía multicultural. Barcelona: Paidós. Kymlicka, Will (2012). “Comment on Meer and Modood”. En Journal of Intercultural Studies, vol. 33, núm. 2, pp. 211-216.

Lara, Ana (2013). "Educación compensatoria en contextos educativos interculturales. Escuela de familia”. En José López Belmonte (coord.), Diversidad cultural y educación intercultural. Melilla: GEEPP Ediciones.

Larrosa, Jorge (2003). Entre las lenguas. Lenguaje y educación después de Babel. Barcelona: Laertes.

Lehmann, David (2015). “Convergencias y divergencias en la educación superior intercultural en México”. En Revista Mexicana de Ciencias Políticas y Sociales, vol. LX, núm. 223, enero-abril, pp. 133-170.

Levey, Geoffrey (2012). "Interculturalism vs. Multiculturalism: A Distinction without a Difference?” En Journal of Intercultural Studies, vol. 33, núm. 2, pp. 217-224.

López Belmonte, José (coord.) (2013). Diversidad cultural y educación intercultural. Melilla: GEEPP Ediciones.

López, Francisco (2013). "Interculturalidad e inmigración en el ámbito educativo”. En José López Belmonte (coord.), Diversidad cultural y educación intercultural. Melilla: GEEPP Ediciones.

López, Luis Enrique (2009). "Interculturalidad, educación y política en América Latina: perspectivas desde el Sur pistas para una investigación comprometida y dialogal”. En Luis Enrique López (coord.), Interculturalidad, educación y ciudadanía perspectivas latinoamericanas. Bolivia: FUNPROEIB, Plural editores.

López, Luis Enrique (2001). La cuestión de la interculturalidad y la educación latinoamericana. Documento de apoyo de la Séptima Reunión del Comité Regional Intergubernamental del Proyecto Principal de Educación en América Latina y el Caribe. UNESCO. 
López, Luis Enrique y Wolfgang Küper (1999). "La educación intercultural bilingüe en América Latina: balance y perspectivas”. En Revista Iberoamericana de Educación, núm. 20, mayo-agosto, pp. 17-85.

López, Nicols y Damián Poveda (2015). "Poner a andar la palabra. Experiencia educativa para el fortalecimiento de la identidad política y cultural Nasa en Tierradentro (Colombia)”. En Patricia Medina Melgarejo (coord.), Pedagogías insumisas. Movimientos político-pedagógicos y memorias colectivas de educaciones otras en América Latina. México:Universidad deCienciasy Artes deChiapas, Centro de Estudios Superiores de México y Centroamérica, Educación para las Ciencias en Chiapas, Juan Pablos Editor.

Malagón, Luis (2006). "La vinculación universidad-sociedad desde una perspectiva social”. En Revista Educación y Educadores, vol. 9, núm. 2, pp. 79-93.

Malik, Kenan (1997). “Los peligros del pluralismo”. En Atril, núm. 0.

Malik, Maleiha (2007). "Modernising Discrimination Law: Proposals for a Single Equality Act for Great Britain”. En International Journal of Discrimination and the Law, vol. 9, núm. 2, pp. 73-94.

Mallea, Julio (2008). "El Programa de Técnicos Superiores en Justicia Comunitaria de la Facultad de Derecho y Ciencias Políticas de la Universidad Mayor de San Andrés”. En Daniel Mato (coord.), Diversidad cultural e interculturalidad en educación superior. Experiencias en América Latina. Caracas: Instituto Internacional para la Educación Superior en América Latina y el Caribe (IESALC)-UNESCO.

Martínez, María, Rubén Muñoz, Raúl Gutiérrez y Sandra Ramos (2015). "Procesos de acompañamiento por medio de la investigaciónacción participativa en una escuela autónoma de Zinacantán, Chiapas”. En Desacatos, núm. 48, pp. 14-31.

Mateos, Laura (2011). La migración transnacional del discurso intercultural. Su incorporación, apropiación y resignificación por actores educativos en Veracruz. Quito: Abya Yala.

Mateos, Laura y Gunther Dietz (2013). “Universidades Interculturales en México”. En María Bertely, Gunther Dietz y María Guadalupe 
Díaz (coords.), Multiculturalismo y educación 2002-2011. México: Consejo Mexicano de Investigación Educativa, A.C., Asociación Nacional de Universidades e Instituciones de Educación Superior. Mateos, Laura, Rosa Mendoza y Gunther Dietz (2013). "Diversidad e interculturalidad en la educación superior convencional”. En María Bertely, Gunther Dietz y María Guadalupe Díaz (coords.), Multiculturalismo y educación 2002-2011. México: Consejo Mexicano de Investigación Educativa, A.C., Asociación Nacional de Universidades e Instituciones de Educación Superior, pp. 307-347. Mato, Daniel (2008). Diversidad cultural e interculturalidad en educación superior: experiencias en América Latina. S/l: Organización de las Naciones Unidas para la Educación, la Ciencia y la Cultura, Instituto Internacional para la Educación Superior en América Latina y el Caribe (IESALC)-UNESCO.

Mato, Daniel (coord.) (2009a). Instituciones Interculturales de Educación Superior en América Latina. Procesos de construcción, logros, innovaciones y desafios. Caracas: Instituto Internacional para la Educación Superior en América Latina y el Caribe (IESALC)-UNESCO.

Mato, Daniel (coord.) (2009b). Educación superior, colaboración intercultural y desarrollo sostenible/buen vivir. Experiencias en América. Caracas: Instituto Internacional para la Educación Superior en América Latina y el Caribe (IESALC)-UNESCO.

Mato, Daniel (2010a). "Diversidad cultural e interculturalidad en educación superior. Tendencias y experiencias en América Latina”. En Boletín IESALC Informa de Educación Superior. núm. 212, diciembre. Recuperado de: http://www.iesalc.unesco.org.ve/ index.php?option=com_content\&view=article\&id=2488: convoca toria-participe-en-el-nuevo-observatorio-de-diversidad-cultural-einterculturalidad-del-enlaces\&catid=6\&Itemid=729\&lang=es

Mato, Daniel (2010b). "Las iniciativas de los movimientos indígenas en educación superior: un aporte para la profundización de la democracia”. En Revista Nueva Sociedad, núm. 227, mayo-junio, pp. 102-119. 
Mattiace, Shannan (2002). "Una nueva idea de nación: autonomía indígena en México”. En Shannan Mattiace, Rosalva Aída Hernández y Jan Rus (eds.), Tierra, libertad y autonomía: impactos regionales del zapatismo en Chiapas. México: Centro de Investigaciones y Estudios Superiores en Antropología Social, International Work Group for Indigenous Affairs.

McDowell, Linda (2000). Género, identidad y lugar. Un estudio de las geografías. Barcelona: Cátedra.

Meer, Nasar y Tariq Modood (2011). "How does interculturalism contrast with multiculturalism?” En Journal of Intercultural Studies, vol. 33, núm. 2, pp. 2-23.

Mignolo, Walter (2003). Historias locales/diseños globales: colonialidad, conocimientos subalternos y pensamiento fronterizo. Madrid: Akal.

Mignolo, Walter (2006). "Postcolonialidad y de-colonialidad. Entrevista a Walter Mignolo”. En Sigma. Revista de Estudiantes de Sociología, núm. 8, II semestre.

Mignolo, Walter (2014). "Retos decoloniales, hoy”. En María Borsani y Pablo Quintero (comps.), Los desafíos decoloniales de nuestros dias: pensar en colectivo. Neuquén: EDUCO, Universidad Nacional del Comahue.

Moll, Luis (1997). “Vygotski, la educación y la cultura en acción”. En Amelia Álvarez (ed.), Hacia un curriculum cultural. La vigencia de Vygotski en la educación. Madrid: Fundación Infancia y Aprendizaje, pp. 39-53.

Moreno, Maricruz y Rolando Maggi (2011). Estrategias de vinculación de las universidades mexicanas con las empresas. Ponencia presentada en el México: COMIE XI Congreso Nacional de Investigación Educativa. Recuperado de: http://www.comie.org. $\mathrm{mx} /$ congreso/memoriaelectronica/v11/docs/area_13/1236.pdf

Navarro, Sergio y Flor Marina Bermúdez (2019). “Consideraciones críticas y conflicto político en la Educación Superior Intercultural en México, el caso de la Universidad Intercultural de Chiapas”. En Reencuentro. Análisis de Problemas Universitarios, vol. 30, núm. 75, pp. 61-88. 
Navarro, Sergio y Victoria Rojas (2015). “Reflexión teórica-práctica del quehacer de la investigación en la Universidad Intercultural del Estado de Tabasco”. En Revista Ruta Antropológica, año 1, núm. 2, pp. 19-28.

Navarro, Sergio y Antonio Saldívar (2011). "Construcción y significado de la intercultural en la Escuela Normal Indígena Intercultural Bilingüe “Jacinto Canek”. En Revista Pueblos y Fronteras Digital, vol. 6, núm. 12, pp. 67-104.

Navarro,Sergio,JudithEnríquez,Patricia VelazcoyCésarEstrada(2014). "La vinculación comunitaria: estrategias para su fortalecimiento desde la educación superior: el caso del CESDER sede San Cristóbal de Las Casas, Chiapas, México”. Ponencia presentada en el III Foro Investigación Vinculada en las Universidades Interculturales de México. Veracruz, México, 8 al 10 de octubre.

Orgad, Liav (2009). “Cultural Defence'of Nations: Cultural Citizenship in France, Germany and the Netherlands”. En European Law Journal, vol. 15, núm. 6, pp. 719-737.

Peña-Cuanda, María, Carmen Marín y Angélica Camacho (2015). "Género, lenguas originarias y vinculación comunitaria: una apuesta de transversalidad en las currículas a nivel superior para apuntalar la educación intercultural”. Ponencia presentada en el Congreso Latinoamericano de Americanistas Conflicto Paz e Identidades, El Salvador, 12 al 17 de julio.

Phillips, Anne (1999). "La política de la presencia: la reforma de la representación política”. En Soledad García y Steven Lukes (comps.), Ciudadanía: justicia social, identidad y participación. Madrid: Siglo XXI, pp. 253-256.

Poder Ejecutivo Federal (2013). Plan Nacional de desarrollo 2012-2018. México: Secretaría de Gobernación.

Policy Exchange (2007). Living apart together: British Muslims and the paradox of multiculturalism. Londres: Policy Exchange.

Pries, Karin (1991). Más allá de las grandes vías: aprender en situaciones educativas. Hacia una didáctica de los temas generadores ejemplificado en el CESDER de Zautla. México: CESDER-PRODES, A.C. 
Quijano, Aníbal (1992). "Colonialidad y modernidad/racionalidad”. En Heraclio Bonilla (comp.). Los conquistados. 1492 y la población indígena de las Américas. Quito: Tercer Mundo, Libri Mundi Editores.

Rauber, Isabel (2011). Revoluciones desde abajo. Gobiernos populares y cambio social en Latinoamérica. La Paz: Fundación Boliviana para la Democracia Multipartidaria.

Restrepo, Eduardo y Axel Rojas (2010). Inflexión decolonial: fuentes, conceptos y cuestionamientos. Colombia: Instituto de Estudios Sociales y Culturales Pensar-Universidad Javeriana.

Rivas, Jorge (2005). "Pedagogía de la dignidad del estar siendo. Entrevista con Hugo Zemelman y Estela Quintar”. En Revista Interamericana de Educación de Adultos, vol. 2, núm. 1, pp.113-140.

Rivera Cusicanqui, Silvia (2010). Ch’ixinakax utxiwa: una reflexión sobre prácticas y discursos descolonizadores. Buenos Aires: Tinta Limón.

Robles, Martha (1977). Educación y sociedad en la historia de México. México: Siglo XXI.

Rockwell, Elsie (2009). La experiencia etnográfica: historia y cultura en los procesos educativos. Buenos Aires: Paidós.

Rojas-Cortés, Angélica y Erica González-Apodaca (2016). “El carácter interactoral en la educación superior con enfoque intercultural en México”. En LiminaR. Estudios Sociales y Humanísticos, vol. 14, núm. 1, pp. 73-91.

Rus, Jan (2012). El ocaso de las fincas y la transformación de la sociedad indígena de los Altos de Chiapas 1974-2009. México: CESMECAUNICACH.

Saavedra, José (2008). "Universidad Intercultural Indígena Originaria Kawsay”. En Daniel Mato (coord.), Diversidad cultural e interculturalidad en educación superior. Experiencias en América Latina. Caracas: Instituto Internacional para la Educación Superior en América Latina y el Caribe (IESALC)-UNESCO.

Saldívar, Antonio (2006). "Principios fundamentales de la educación intercultural”. En Ecofronteras, núm. 29, pp. 22-26. 
Saldívar, Antonio (2012). Educación superior, desarrollo y vinculación sociocultural. Análisis de experiencias educativas universitarias en contextos rurales e indígenas. Tesis doctoral, Getafe, España: Universidad Carlos III de Madrid.

Sánchez, Sebastián (2013). "Las manifestaciones de la diversidad cultural y su utilización educativa”. En José López Belmonte (coord.), Diversidad cultural y educación intercultural. Melilla: GEEPP Ediciones.

Sandoval, Eduardo y Eduardo Guerra (2007). "La interculturalidad en la educación superior en México”. En Ra Ximhai, mayo-agosto, año/vol. 3, núm. 2, pp. 273-288.

Sandoval,Ernesto(2002).“Universidadesindígenas:otromodelodesaberes”. Recuperado de: https:/www.insumisos.com/lecturasinsumisas/ UNIV\%20INDIGENA\%20MEXICO.pdf

Santos, Boaventura de y César Rodríguez Garavito (eds.) (2007). El derecho y la globalización desde abajo. Hacia una legalidad cosmopolita. México: UAM, Anthropos.

Santos, Miguel (2013). "El valor de la convivencia y el reto de la interculturalidad”. En José López Belmonte (coord.), Diversidad cultural y educación intercultural. Melilla: GEEPP Ediciones.

Sarango, Luis (2008). "La experiencia de la Universidad Intercultural de las Nacionalidades y Pueblos Indígenas Amawtay Wasi”. En Daniel Mato (coord.), Diversidad cultural $e$ interculturalidad en educación superior. Experiencias en América Latina. Caracas: Instituto Internacional para la Educación Superior en América Latina y el Caribe (IESALC)-UNESCO.

Sarango, Luis (2009). "Universidad Intercultural de las Nacionalidades y Pueblos Indígenas 'Amawtay Wasi'. Ecuador/Chinchaysuyu”. En Daniel Mato (coord.), Instituciones interculturales de educación superior en América Latina. Procesos de construcción, logros, innovaciones y desafios. Caracas: Instituto Internacional para la Educación Superior en América Latina y el Caribe (IESALC)-UNESCO.

Sartori, Giovanni (2001). La sociedad multiétnica. Madrid: Taurus 
Schmelkes, Sylvia (2003). "Educación superior intercultural: el caso de México”. Conferencia dictada en el Encuentro Internacional Intercambio de Experiencias Educativas, "Vincular los Caminos a la Educación Superior”, organizado por la Ford Foundation, la Unidad de Apoyo a las Comunidades Indígenas de la Universidad de Guadalajara y la ANUIES, 17 a 19 de noviembre de 2003. Recuperado de: http://www.ses.unam.mx/curso2015/pdf/11sep-Schmelke-02.pdf Schmelkes, Sylvia (2008). "Las universidades interculturales en México: ¿Una contribución a la equidad en educación superior?” Ponencia presentada en el First Conference on Ethnicity, Race, and Indigenous Peoples in Latin America and the Caribbean, San Diego, California, Universidad de California, 22 al 24 de mayo.

Sleeter, Christine (2004). "El contexto político de la educación multicultural en los Estados Unidos”. En Cuadernos Interculturales, vol. 2, núm. 3, julio-diciembre, pp. 9-22, Chile: Universidad de Valparaíso.

Stavenhagen, Rodolfo (2013). "La política indigenista del Estado mexicano y los pueblos indígenas en el siglo XX”. En Bruno Baronnet y Medardo Tapia (coords.). Educación e interculturalidad. Política y políticas. Cuernavaca, México: CRIM-UNAM.

Suárez, Martín (2007). "Cultura de la modernidad/posmodernidad, implicaciones en la educación venezolana. Una mirada desde el ámbito universitario para la formación docente”. En Universitas Tarraconensis. Revista de Ciències de L'Educació, núm. 1, pp. 177-191.

Subcomandante Insurgente Marcos (2003). "Chiapas, la treceava estela (quinta parte): una historia”. En La Jornada, 28 de julio. Recuperado de: http://www.jornada.unam.mx/2003/07/28/005n1pol. php?printver $=1 \&$ fly $=1$

Taylor, Charles (1993). El multiculturalismo y la política del reconocimiento. México: FCE.

Tejerina, Benjamín (1999). "El poder de los símbolos: Identidad colectiva y movimiento etnolingüístico en el País Vasco”. En REIS. Revista Española de Investigaciones Sociológicas, núm. 88, pp. 75-105. 
Terry, Robert (1993). “A Parable: The Ups and Downs”. En J. Andrzejewski (ed.), Oppression and Social Justice: Critical Frameworks. Nueva Jersey: Ginn Press, Needham Heights, pp. 61-63.

Tinajero, Jorge (1993). Misiones culturales mexicanas. 70 años de historia. México: Centro de Cooperación Regional para la Educación de Adultos en América Latina y el Caribe. Recuperado de: http:// tumbi.crefal.edu.mx/rieda/images/rieda-1993-2/historia1.pdf

Tubino, Fidel (2005). "La interculturalidad crítica como proyecto éticopolítico”. Ponencia presentada en el Encuentro Continental de Educadores Agustinos, Lima, 24-28 de enero de 2005. Recuperado de: http://www.oalagustinos.org/edudoc/LAINTERCULTURALIDA DCR\%C3\%8DTICACOMOPROYECTO\%C3\%89TICO.pdf

Tubino, Fidel (2009). "Los desafíos de las políticas y las culturas: ¿interculturalismo o multiculturalismo?” En Memoria Revista sobre Cultura, Democracia y Derechos Humanos, núm. 6. Perú: Instituto de Democracia y Derechos Humanos de la Pontificia Universidad Católica del Perú.

UNESCO (2001). Declaración Universal de la UNESCO sobre la diversidad cultural.

UNICH (2008a). Informe de la administración 2005-2008. La experiencia de la Universidad Intercultural de Chiapas a cuatro años de su fundación. Chiapas. México: UNICH, Gobierno del Estado de Chiapas. Recuperado de: http://www.unich.edu.mx/wp-content/ uploads/2012/03/Informe_Rector_2008.pdf

UNICH (2008b). Plan Institucional de Desarrollo 2008-2016. Chiapas: UNICH.

UNICH (2009). Informe institucional 2009. Chiapas: UNICH. Recuperado de: http:/www.unich.edu.mx/wp-ontent/uploads/2012/03/Informe_ Rector_2009.pdf

UNICH (2013). Informe institucional 2013. Chiapas: UNICH.

Valenzuela, Estela (2008). "Formación docente en contexto de diversidad linguística y cultural desarrollada en el Centro de Investigación y Formación para la Modalidad Aborigen”. En Daniel Mato (coord.), Diversidad cultural e interculturalidad en 
educación superior. Experiencias en América Latina. Caracas: Instituto Internacional para la Educación Superior en América Latina y el Caribe (IESALC)-UNESCO.

Vallaeys, François (1999). "El desafío de enseñar ética en la universidad”. En Papeles de Ética, Economía y Dirección, núm. 4.

Vasconcelos, José ([1937]2011). La creación de la Secretaría de Educación Pública. México: Instituto Nacional de Estudios Históricos de las Revoluciones de México.

Velasco, Honorio y Ángel Díaz de Rada (1997). La lógica de la investigación etnográfica. Madrid: Trotta.

Velasco, Saúl(2010)."Políticas (y propuestas) de educación intercultural en contraste”. En Saúl Velasco y Aleksandra Jablonska (coords.), Construcción de políticas educativas interculturales en México. México: Universidad Pedagógica Nacional.

Velasco, Saúl (2015). "Movimiento indígena en México y educación alternativa”. En Patricia Medina Melgarejo (coord.). Pedagogías insumisas. Movimientos político-pedagógicos y memorias colectivas de educaciones otras en América Latina. México: Universidad de Ciencias y Artes de Chiapas-Centro de Estudios Superiores de México y Centroamérica, Educación para las Ciencias en Chiapas, A.C., Juan Pablos Editor.

Velasco, Juan (2000). ¿El multiculturalismo una nueva ideología? Alcances y límites de la lucha por las identidades culturales. Madrid: Akal.

Villafuerte, Daniel (2004). La frontera sur de México. Del TLC México al Plan Puebla Panamá. México: Instituto de Investigaciones Económicas-UNAM, Plaza y Valdés.

Walsh, Catherine (2002). “(De) construir la interculturalidad. Consideraciones críticas desde la política, la colonialidad y los movimientos indígenas y negros en el Ecuador”. En Norma Fuller (ed.), Interculturalidad y política. Desafios y posibilidades. Lima: Red para el Desarrollo de las Ciencias Sociales en el Perú. 
Walsh, Catherine (2004). "Geopolíticas del conocimiento, interculturalidad y descolonialización”. En Boletín ICCI-ARY Rimay, año 6, núm. 60, marzo.

Walsh, Catherine (2005a). La interculturalidad en la educación. Perú: Ministerio de Educación de Perú-DINEBI, UNICEF.

Walsh, Catherine (2005b). "Introducción”. En Catherine Walsh (ed.), (Re)pensamiento crítico y matriz (de)colonial. Quito: UASB, Abya Yala. Walsh, Catherine (2007). "Interculturalidad y colonialidad del poder. Un pensamiento y posicionamiento 'otro' desde la diferencia colonial”.EnSantiago Castro-Gómezy Ramón Grosfoguel(comp.).El giro decolonial: reflexiones para una diversidad epistémica más allá del capitalismo global. Bogotá: Siglo del Hombre Editores, Universidad Central-Instituto de Estudios Sociales Contemporáneos, Pontificia Universidad Javeriana-Instituto Pensar.

Walsh, Catherine (2012). Interculturalidad crítica y (de)colonialidad. Ensayos desde Abya Yala. Quito: Abya Yala.

Warnholtz, Margarita (2013). "Universidades indígenas sin reconocimiento del Estado (primera parte)”. En Animal Político, 5 de abril Recuperado de: https:/www.animalpolitico.com/ codices-geek/universidades-indigenas-sin-reconocimiento-delestado-primera-parte/

Zemelman, Hugo (1990). "Introducción". En Hugo Zemelman (ed.), Cultura y política en América Latina. México: Siglo XXI.

Zemelman, Hugo (2005a). "Hacia la construcción conceptual y metodológica de un enfoque político de comunidades de aprendizaje y trabajo en red en organizaciones de la sociedad civil”. Puebla, México: UCI-RED.

Zemelman, Hugo (2005b). 'Pedagogía de La dignidad del estar siendo'. En Jorge Díaz Pedagogía de La dignidad del estar siendo. Entrevista con Hugo Zemelman y Estela Quintar”. En Revista Interamericana de Educación de Adultos, vol. 27, núm. 1.

Zemelman, Hugo (2012). Los horizontes de la razón. I. Dialéctica y apropiación del presente. Barcelona: Anthropos Editorial. 
Discursos y prácticas de la educación superior intercultural.

La experiencia de Chiapas,

de Sergio Iván Navarro Martínez, terminó de imprimirse en

Editorial Fray Bartolomé de Las Casas, A. C. Av. Pedro Moreno \#7, Barrio de Santa Lucía, 29250. San Cristóbal de Las Casas,

Chiapas, México, en noviembre de 2020.

Se tiraron 200 ejemplares.

Cuidado de la edición a cargo de María Isabel Rodríguez Ramos

Diagramación y formación a cargo

de Irma Cecilia Medina Villafuerte 


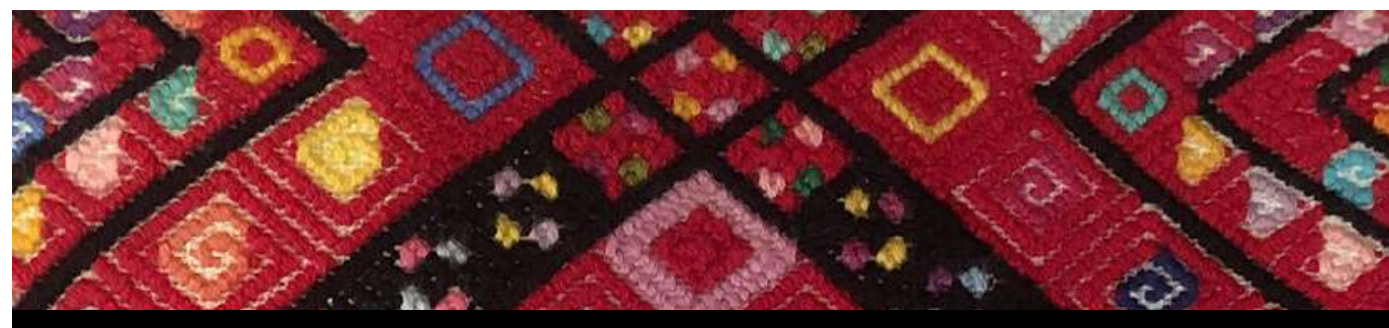

"En toda América Latina -advierte Gunther Dietz- los sistemas educativos nacionales vienen arrastrando una importante deuda histórica con los pueblos originarios y con sus juventudes". Un rápido balance de las respuestas a las demandas de una educación específica redunda en una educación de baja calidad, descontextualizada, y cultural y lingüisticamente impertinente y enajenante, especialmente en la educación superior. En México, donde este problema se agudiza, el subsecretario de Educación Superior Luciano Concheiro calificó la situación como "brutal desigualdad": solo un 1.2\% de las y los jóvenes hablantes de alguna lengua originaria de México logran ingresar a la educación superior.

Sergio Navarro Martínez irrumpe en este trabajo con una mirada que -lejos de documentar el pesimismo- aborda, desde un enfoque sustentado en un diálogo entre la interculturalidad crítica, la etnografía y la perspectiva decolonial, los siguientes interrogantes: ¿de qué manera se presenta y trabaja la interculturalidad? ¿cómo se retoman los fundamentos de la educación intercultural?, ¿cómo se generan las capacidades para la vinculación comunitaria?, ¿qué tipo de desarrollo se piensa para las comunidades? y ¿de qué manera se establecen los vínculos con la comunidad?

Este nuevo libro, resultado del trabajo editorial entre CLACSO y el CESMECA, vuelve sobre uno de los temas centrales de la educación superior en México. Haciendo foco en Chiapas, Navarro Martínez pone en discusión la situación política en la que emergieron las experiencias del CESDER-Moxviquil y la UNICH-Oxchuc, así como la vinculación que establecen con los diferentes actores sociales para su funcionamiento.

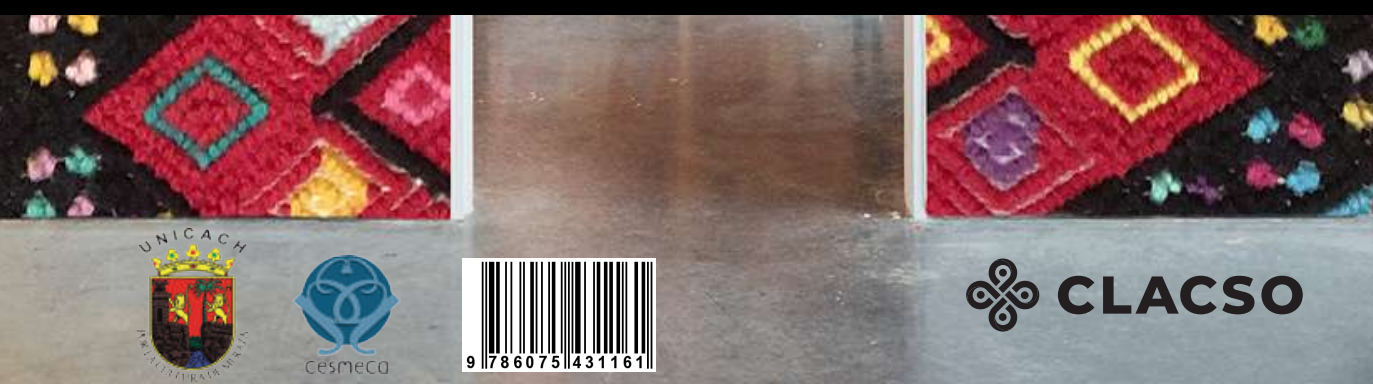

